\title{
ReCONNAISSANCE RePORT ON DAMAge to ENGINEERED STRUCTURES DURING THE MAY 1999 OKLAHOMA CITY TORNADO
}

Michael A. Riley

Building and Fire Research Laboratory

Gaithersburg, MD 20899-8611

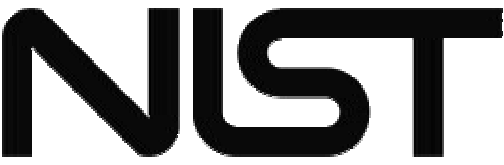

United States Department of Commerce Technology Administration National Institute of Standards and Technology 



\section{ReCONNAISSANCE RePORT ON DAMAge to ENGINEERED STRUCTURES DURING THE MAY 1999 OKLAHOMA CITY TORNADO}

Michael A. Riley

August 2002

Building and Fire Research Laboratory

National Institute of Standards and Technology

Gaithersburg, MD 20899-8611

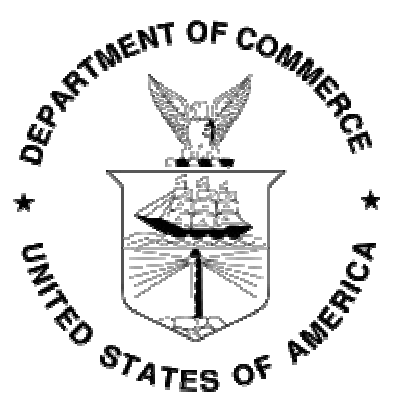

United States Department of Commerce

Donald L. Evans, Secretary

Technology Administration

Phillip J. Bond, Under Secretary for Technology

National Institute of Standards and Technology

Arden L. Bement, Jr., Director 


\section{ABSTRACT}

On 3 May 1999, a major storm passed through the mid-west, spawning at least 76 tornadoes, and killing more than 50 people. The Oklahoma City, Oklahoma, metropolitan area was the hardest hit, with 43 fatalities, and 10000 homes destroyed or severely damaged. The losses due to damage caused by the storm exceeded $\$ 1.1$ billion. The National Weather Service rated the tornado that struck Oklahoma City as a F5 on the Fujita tornado intensity scale.

In the aftermath of the tornadoes, the Building and Fire Research Laboratory Structures Division sent a team to investigate the damage to engineered structures in the Oklahoma City area. The damage reconnaissance included an aerial survey of the largest tornado tracks in central Oklahoma and a two-day ground survey. The ground survey included visits to eight damage sites with twelve damaged engineered structures. This report provides an overview of observed damage to engineered structures, including schools, hotels, and industrial buildings, reports observations on debris accumulation, briefly discusses the tornado rating, and recommends actions to reduce future losses. 


\section{ACKNOWLEDGEMENTS}

This disaster reconnaissance and reporting were supported by the Structures Division, Building and Fire Research Laboratory, National Institute of Standards and Technology, U.S. Department of Commerce. The author wishes to thank the Oklahoma City emergency coordinator, Oklahoma County Sheriff's Department, and the Office of the Oklahoma State Fire Marshal, which assisted with this investigation by providing personnel, access to otherwise closed sites, transportation, and guidance. The author gratefully acknowledges the help of meteorologists from the National Weather Service, and the Civil Air Patrol, which provided the means for the aerial portion of the survey. Members of the Texas Tech University disaster investigation team provided guidance and assistance in locating many of the damage sites. Finally, the author wishes to thank Emil Simiu for his assistance with the preparation of this report. 


\section{CONTENTS}

Abstract iii

Acknowledgements. v

Contents. vii

List of Figures.............................................................................................. ix List of Tables........................................................................................................ Xi

1 Introduction .....................................................................................1

1.1 The Tornado O utbreak .......................................................................................... 1

1.2 NIST Reconnaissance ............................................................................................. 3

1.3 Overview of Report....................................................................................... 6

2 Damage to Schools........................................................................................9

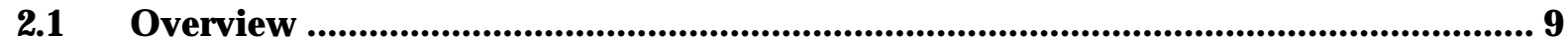

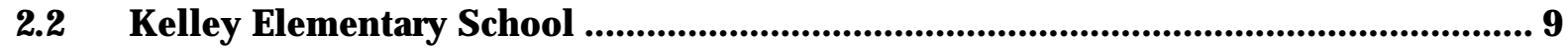

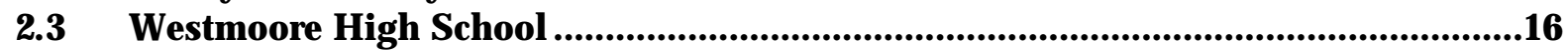

3 D amage to H otels.....................................................................................21

O.1 Overview ...................................................................................................21

Clarion Inn ..................................................................................................21

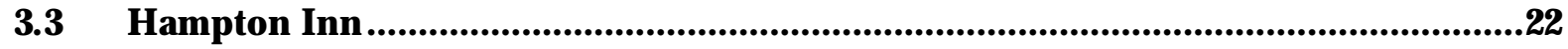

4 D amage to Industrial and Commercial Buildings ...............................27

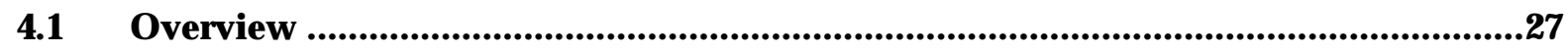

4.2 Tinker Industrial Park .........................................................................................27

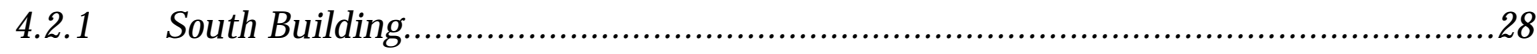

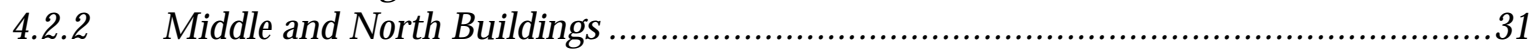

4.3 Peach A uto Painting

4.4 A merican Freightways Depot...................................................................................34

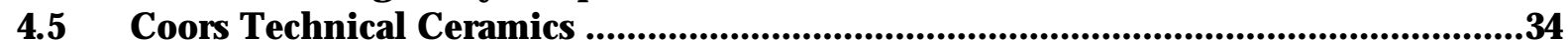

5 Damage to Other Engineered Structures...............................................37

6 Conclusions and Recommendations ......................................................43

7 References $\ldots \ldots \ldots \ldots \ldots \ldots \ldots \ldots$ 


\section{LIST OF FIGURES}

Figure 1-1. Map of Tornado Damage Paths and F-scale Ratings in the Vacinity of Oklahoma City, 01 July, 1999 Revision. (Courtesy of the NWS)....................................... 1

Figure 1-2: Tornado Vortex Scars in a Field near Crescent, Oklahoma. ................................. 3

Figure 1-3. Damage to Structures along the Tinker Diagonal, Midwest City......................... 4 Figure 1-4. Damaged Housing Complex South of Westmoore High School, Oklahoma City. .. 5 Figure 1-5. Damage to Westmoore High School and Surrounding A reas, Oklahoma City. ...... 6 Figure 1-6: Damage to the American Freightways Terminal and Coors Ceramics Factory,

Oklahoma City........................................................................................ 7

Figure 2-1: Map of Damaged Schools in South Oklahoma City and Moore............................. 9

Figure 2-2: Remains of N orthern End of the Front Section of Kelly Elementary School. ...........10

Figure 2-3: Damage to Southern End of Front Section of Kelly Elementary School. ..................11

Figure 2-4: South Side of the Center Section of Kelly Elementary School. ...............................12

Figure 2-5: N orth Side of the Center Section of Kelly Elementary School. ..............................12

Figure 2-6: South Side of the East Section of Kelly Elementary School ..................................13

Figure 2-7: Collapsed Wall on West Side of the East Section of Kelly Elementary School.........13

Figure 2-8: Collapsed Wall at N orth End of West Section of Kelly Elementary School. ............14

Figure 2-9: Detail of Mortar and Reinforcement in the Collapsed Wall at N orth End of West

Section of Kelly Elementary School. ...............................................................14

Figure 2-10: Detail of the Cornice and Soffit on East Side of Kelly Elementary School.............15

Figure 2-11: Broken Windows on East Side of Kelly Elementary School................................15

Figure 2-12: Aerial View of Westmoore High School. ........................................................16

Figure 2-13: Detail of Roof Damage to Westmoore High School. .............................................17

Figure 2-14: Damage to Westmoore High School Classroom Roof (Inside View).....................18

Figure 2-15: Damaged, But Intact, Cladding on Westmoore High School ...............................18

Figure 2-16: Damage to Cladding on East Side of Westmoore High School. ............................19

Figure 2-17: Damage to Westmoore High School and Vehicles, View From South. ..................19

Figure 2-18: Debris on North Side of Westmoore High School ...........................................20

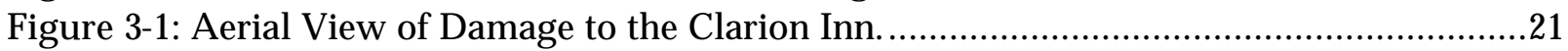

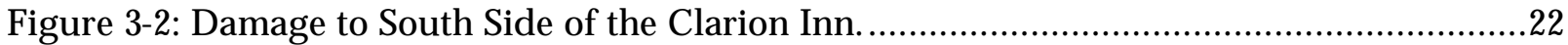

Figure 3-3: Damage to N orth Side of the Southwest Corner of the Clarion Inn. .....................23

Figure 3-4: Damage to Western Section of the Clarion Inn. .............................................23

Figure 3-5: A erial View of Damage to the Hampton Inn (long rectangular building)..............24

Figure 3-6: Damage to South Side of the Hampton Inn. ...................................................25

Figure 3-7: Damage to N orth Side of the Hampton Inn. .....................................................25

Figure 3-8: Detail of Damage to Masonry at the Hampton Inn............................................26

Figure 4-1: Simplified Plan View of Tinker Industrial Park ...............................................27

Figure 4-2: Damage to Western Section of the South Building at Tinker Industrial Park. ........28

Figure 4-3: Collapsed Eastern Section of the South Building at Tinker Industrial Park (View

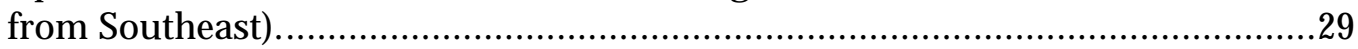

Figure 4-4: N orth Side of the South Building at Joint between Sections................................29

Figure 45: Detail of Failed Column and Collapsed Roof at the Southeast Corner of the South

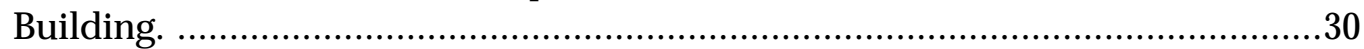

Figure 4-6: Reinforced Masonry Wall that Failed at South Building. ...................................30

Figure 47: Damage to the East Side of the Middle Building at Tinker Industrial Park. ...........31

Figure 48: Detail of Damage to the Roof of the Middle Building. ........................................32 
Figure 4-9: Detail of Damage to Western Wall of the Middle Building. ................................32

Figure 4-10: Damage to the East Side of the North Building at Tinker Industrial Park. ...........33

Figure 4-11: Roof Framing and Collapsed Walls (foreground) at Peach A uto Painting.............33

Figure 4-12: Detail of Base of Failed Wall at Peach A uto Painting. ...........................................34

Figure 4-13: Damage to Coors Technical Ceramics Factory..................................................35

Figure 5-1: A erial View of Damage to Hangars at Chickasha Airport ...................................37

Figure 5-2: Damage to the Roof of the Regency Park Baptist Church. .....................................38

Figure 5-3: Debris Damage to Building Adjacent to Regency Park Baptist Church...................38

Figure 5-4: A erial View of Damage to the Tanger Outlet Center Mall. ...................................39

Figure 5-5: Destroyed Transmission Tower near Crescent, Oklahoma. .................................40

Figure 5-6: Damage to Mulhall, Oklahoma, and United Cooperative Silos. ............................40

Figure 5-7: Damage to Farm buildings and Silos near Crescent, Oklahoma. ...........................41 


\section{LIST OF TABLES}

Table 1-1: List of Storm Supercells (Courtesy of the NWS) ................................................. 2 


\section{INTRODUCTION}

On 3 May 1999, a major storm passed through the mid-west, spawning at least 76 tornadoes, and killing 55 people. The Oklahoma City, Oklahoma metropolitan area was the hardest hit, with 43 fatalities, and 10000 homes destroyed or severely damaged. Losses from the storm exceeded $\$ 1.1$ billion. The National Weather Service (NWS) rated the tornado that struck Oklahoma City as a F5, the highest rating on the Fujita tornado intensity scale, with an estimated maximum associated wind speed of $142 \mathrm{~m} / \mathrm{s}$.

In the aftermath of the tornadoes, the Structures Division, Building and Fire Research
Laboratory, NIST, sent a structural engineer to investigate the damage to engineered structures in the Oklahoma City area. The damage reconnaissance included an aerial survey of the largest tornado tracks in central Oklahoma and a two-day ground survey. The ground survey included visits to eight damage sites in which nine damaged engineered structures were observed. This report presents damage observations for schools, hotels, and industrial buildings.

\subsection{The Tornado Outbreak}

The Storm Prediction Center of the National

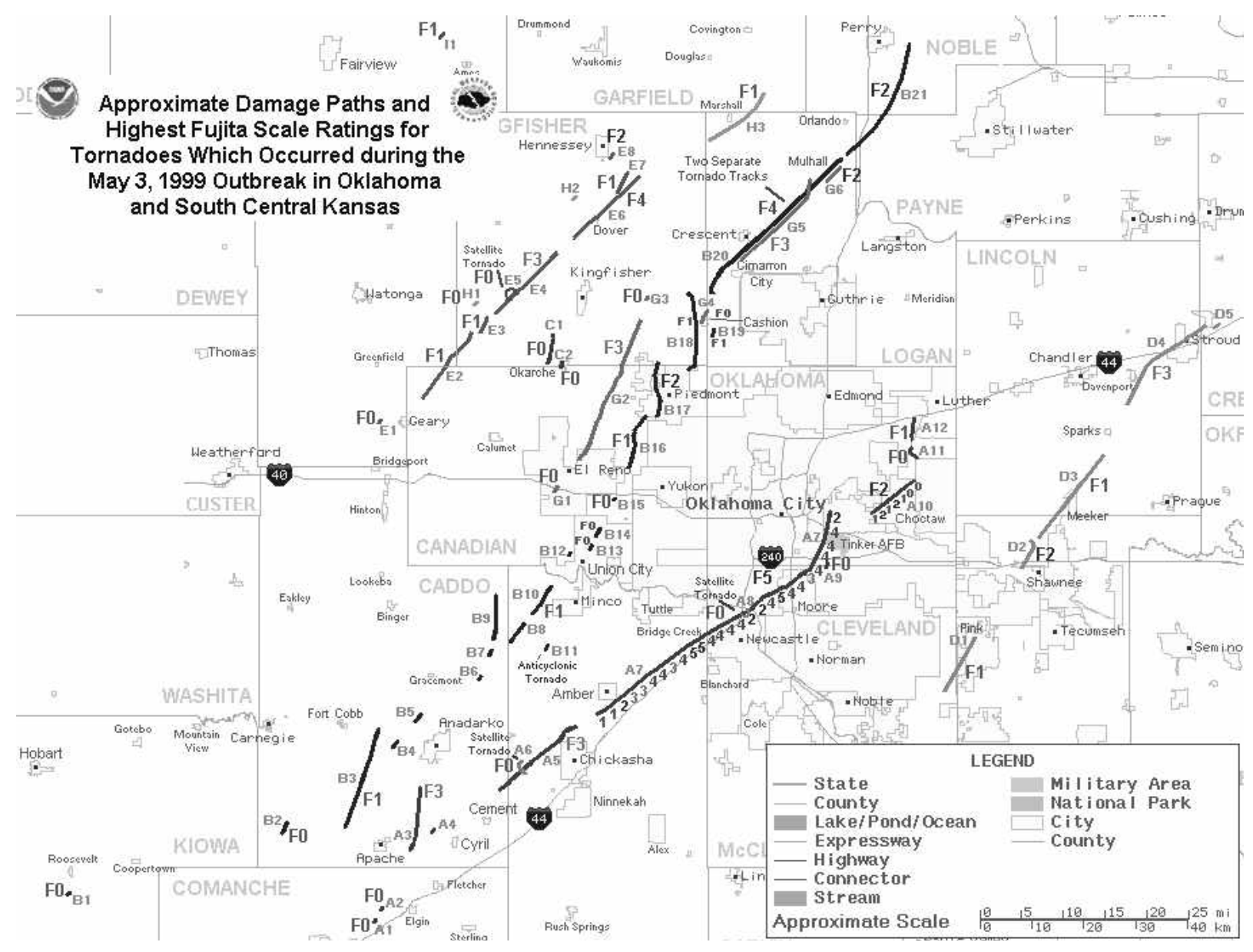

Figure 1-1. M ap of Tornado Damage Paths and F-scale Ratings in the Vacinity of Oklahoma City, 01 July, 1999 Revision. (Courtesy of the N WS). 
Table 1-1: List of Storm Supercells (Courtesy of the N WS).

\begin{tabular}{|c|c|c|c|c|c|}
\hline Supercell & $\begin{array}{l}\text { Number of } \\
\text { Tornadoes }\end{array}$ & $\begin{array}{l}\text { Highest } \\
\text { F-Scale } \\
\text { Rating }\end{array}$ & Fatalities & Storm Name & Notes \\
\hline Storm A & 12 & F5 & 38 & $\begin{array}{l}\text { Elgin - Chickasha - Bridge } \\
\text { Creek - Moore - Choctaw } \\
\text { Storm }\end{array}$ & $\begin{array}{l}\text { Storm that dam- } \\
\text { aged Oklahoma } \\
\text { City. }\end{array}$ \\
\hline Storm B & 21 & F4 & 2 & $\begin{array}{l}\text { Anadarko - Minco - Union } \\
\text { City - Piedmont - Mulhall - } \\
\text { Perry Storm }\end{array}$ & \\
\hline Storm C & 2 & F0 & 0 & Okarche Storm & \\
\hline Storm D & 8 & F3 & 1 & $\begin{array}{l}\text { Pink - Shawnee - Stroud - } \\
\text { Tulsa Storm }\end{array}$ & \\
\hline Storm E & 8 & $\mathrm{~F} 4$ & 1 & Geary - Dover Storm & \\
\hline Storm G & 6 & F3 & 0 & $\begin{array}{l}\text { El Reno - Cashion - Crescent } \\
\text { - Mulhall } 2 \text { Storm }\end{array}$ & \\
\hline Storm H & 3 & $\mathrm{~F} 1$ & 0 & $\begin{array}{l}\text { Omega - Hennessey - Mar- } \\
\text { shall Storm }\end{array}$ & \\
\hline Storm I & 1 & $\mathrm{~F} 1$ & 0 & Fairview Storm & \\
\hline Storm J & 3 & $\mathrm{~F} 1$ & 0 & $\begin{array}{l}\text { Boynton - Peggs - Chewey } \\
\text { Storm }\end{array}$ & \\
\hline Storm K & 3 & $\mathrm{~F} 4$ & 5 & $\begin{array}{l}\text { Conway Springs - Wichita - } \\
\text { Augusta Storm }\end{array}$ & \\
\hline Storm L & 1 & F0 & 0 & Henryetta Storm & \\
\hline Total & 68 & & $47^{1}$ & & \\
\hline
\end{tabular}

Weather Service identified the threat of tornadoes in the storm developing over the Midwestern US at 1:00 AM on 3 May 1999. The center issued the first tornado watch for the storm at 4:30 PM, and the first, weak tornado (A1 in Figure 1-1) was reported at 4:51 PM. During a ten-hour period that afternoon and evening, the National Weather Service Forecast Office in Norman, Oklahoma issued 116 warnings for tornadoes and severe thunderstorms.

The National Weather Service investigation of storm and tornadoes identified 68 unique tornadoes caused by 11 distinct supercells that occurred in Oklahoma and Kansas. Additional tornadoes were caused by the storm as it moved through Texas and Tennessee.

1 The official death toll includes additional fatalities that are not included in this table.
Figure 1-1 shows a map of the tornado damage paths in central Oklahoma. The largest of these tornadoes (A 7 in Figure 1-1), which passed though Oklahoma City, was rated as an F5 by the NWS. The other tornadoes were rated from F0 to F4. Table 1-1 lists the storm supercells identified by NWS, the number of distinct tornadoes that could be identified for each, the highest Fscale rating for tornadoes generated by that supercell, and the number of fatalities.

The vast majority of the fatalities were caused by tornadoes generated by the first storm (Storm A), which passed through the heart of the Oklahoma City metropolitan area. Storms B and G followed the same track, with storm $G$ generating tornadoes that paralleled or crossed the tracks of storm B tornadoes, about 1-1/ 2 hours after the first storm. 


\subsection{NIST Reconnaissance}

On 4 May 1999, the morning after the tornado outbreak, the initial damage reports indicated that the damage was unusually severe and that some significant structures had been damaged; however, the full magnitude of the damage was not apparent. The damage investigation reported herein began on the morning of 5 May 1999.

The first phase of the reconnaissance consisted of an aerial survey conducted with meteorologists from the $\mathrm{N}$ ational Weather Service. The N orman, Oklahoma squadron of the Civil Air Patrol (CAP) provided a plane and pilot. The survey consisted of two flights between 8:00 AM and 2:00 PM CDT on 5 May 1999. During the first flight the team surveyed the damage caused by two storm cells (storms A and D), between Chickasha and Stroud, and including Southern Oklahoma City, Moore, Del City, Midwest City, and Choctaw. (In Figure 1-1 Chickasha is located near the bottom center of the map; Stroud is located near the mid right side of the map.) During the second flight, the team surveyed the damage caused by two additional storm cells (storms B and G), between Perry (near the top center of the map) and Union City (near the center of the map), including Mulhall, Crescent, and Piedmont. The observations from this survey were used to determine where the damage was heaviest and to bcate significant structural damage that should be investigated more thoroughly.

The tornadoes caused a wide range of dam-

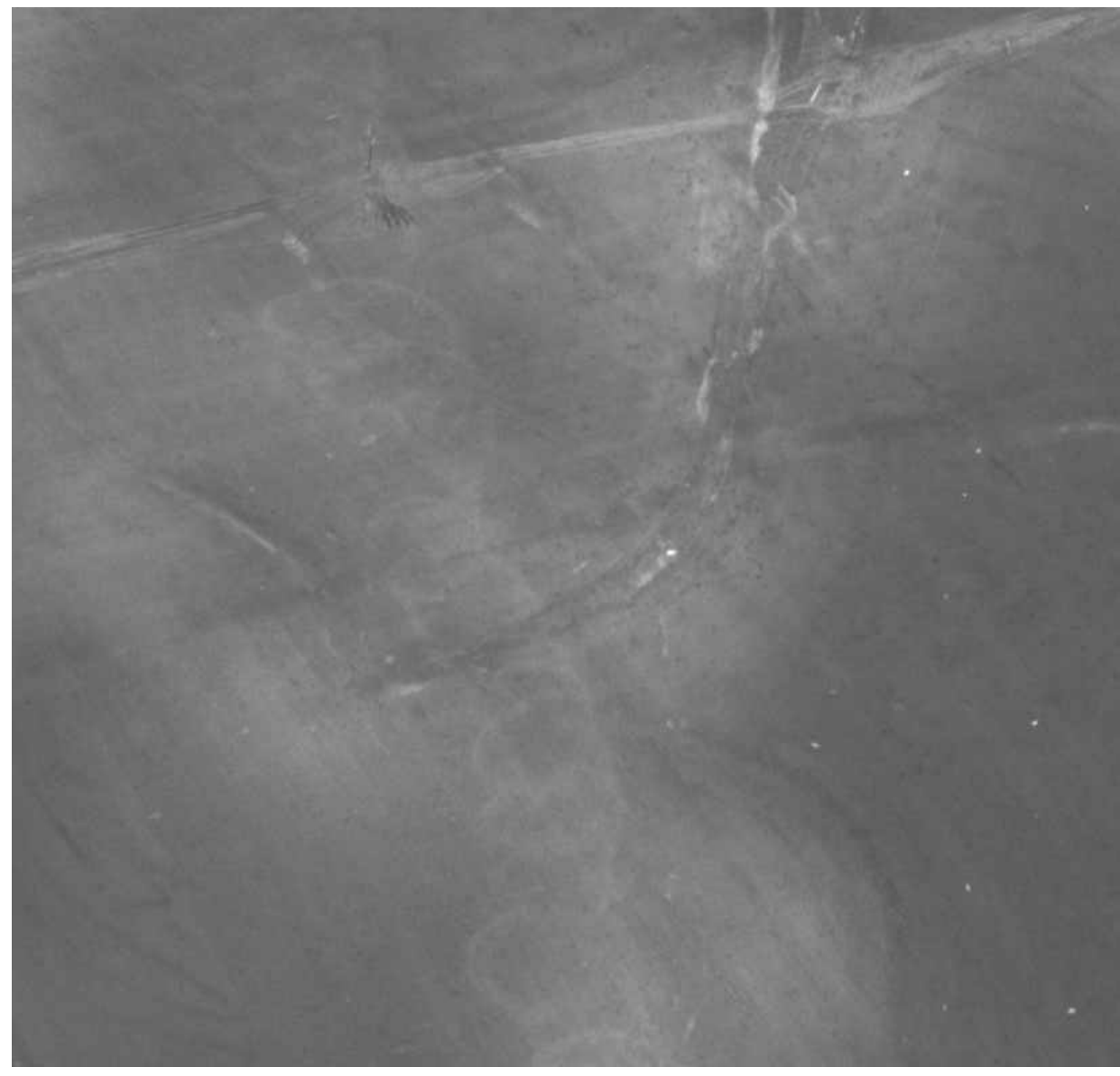

Figure 1-2: Tornado Vortex Scars in a Field near Crescent, 0 klahoma. 
age and destruction in addition to the structural damage described in detail in this report. Figure 1-1 shows the distinct scars left by one of the tornadoes as it passed through a field near Crescent, Oklahoma.

The second phase of the reconnaissance consisted of a two-day (6-7 May 1999) ground survey by the author. On the morning of 6 May 1999, the Oklahoma County Sheriffs Department assisted the investigation by making a deputy available to act as a guide. The most heavily damaged areas of Midwest City were toured, including the heavily damaged area along the Tinker Diagonal, shown in Figure 1-3. In particular, damage to the Clarion Inn and Hampton Inn, both on the north-east side of the
Tinker Diagonal, and the Peach Auto Painting garage, on the south west side of the Tinker Diagonal, was investigated. The survey also included a tour of the residential area of Midwest City, north of SE 15th Street, which was heavily damaged.

The ground survey was continued on the afternoon of 6 May 1999 with the assistance of a State Fire Marshall. Efforts were focused on surveying the damage to South Oklahoma City, particularly the area around Westmoore High School. The high school had suffered roof damage, while the surrounding residential areas were devastated. Figure 1-4 and Figure 1-5 show the damage to the housing development south of the school, the apartment complex to the

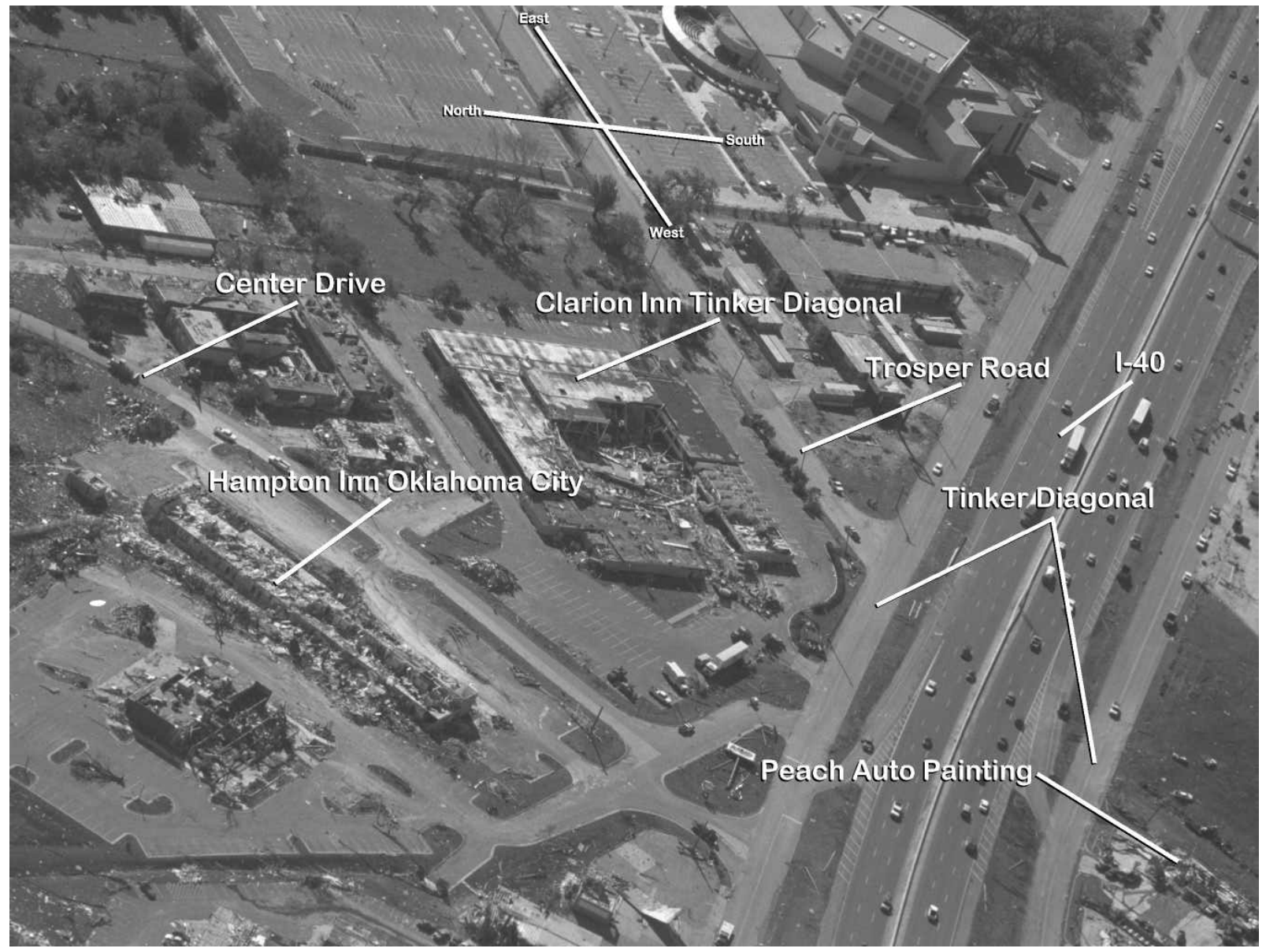

Figure 1-3. D amage to Structures along the Tinker Diagonal, Midwest City. 
east of the school, and the school itself. For safety reasons access to the high school was limited. Access was allowed to the classroom portions of the building, which had moderate damage and only small sections of roof covering missing. However, access was not permitted to the auditorium, which had lost a large portion of its roof.

The last day of the reconnaissance, Friday, 7 May 1999, concluded the ground survey. By this time, much of the emergency phase of the clean-up operation was complete. All streets were open, which reduced traffic congestion and eased travel between sites. One damaged structure of interest had aready been bulldozed, and some rubble had al ready been removed at other sites.

The morning of 7 May 1999 was spent in- vestigating the damage to the Tinker Industrial Park in Midwest City. The three buildings at this site had all been damaged, and one building had partially collapsed. Although, the partially collapsed building could not be entered, extensive information on the damage could be obtained by observing the building from the outside, and there was access to the other two buildings.

Next, the damage investigation was conducted in an industrial section of Oklahoma City. The American Freightways terminal, shown in Figure 1-6, could not be investigated because the cleanup of the debris was already at an advanced stage, and most of the wreckage had been moved. Of the remaining buildings damaged in that industrial section it was possible to investigate only the Coors Ceramics factory (Figure

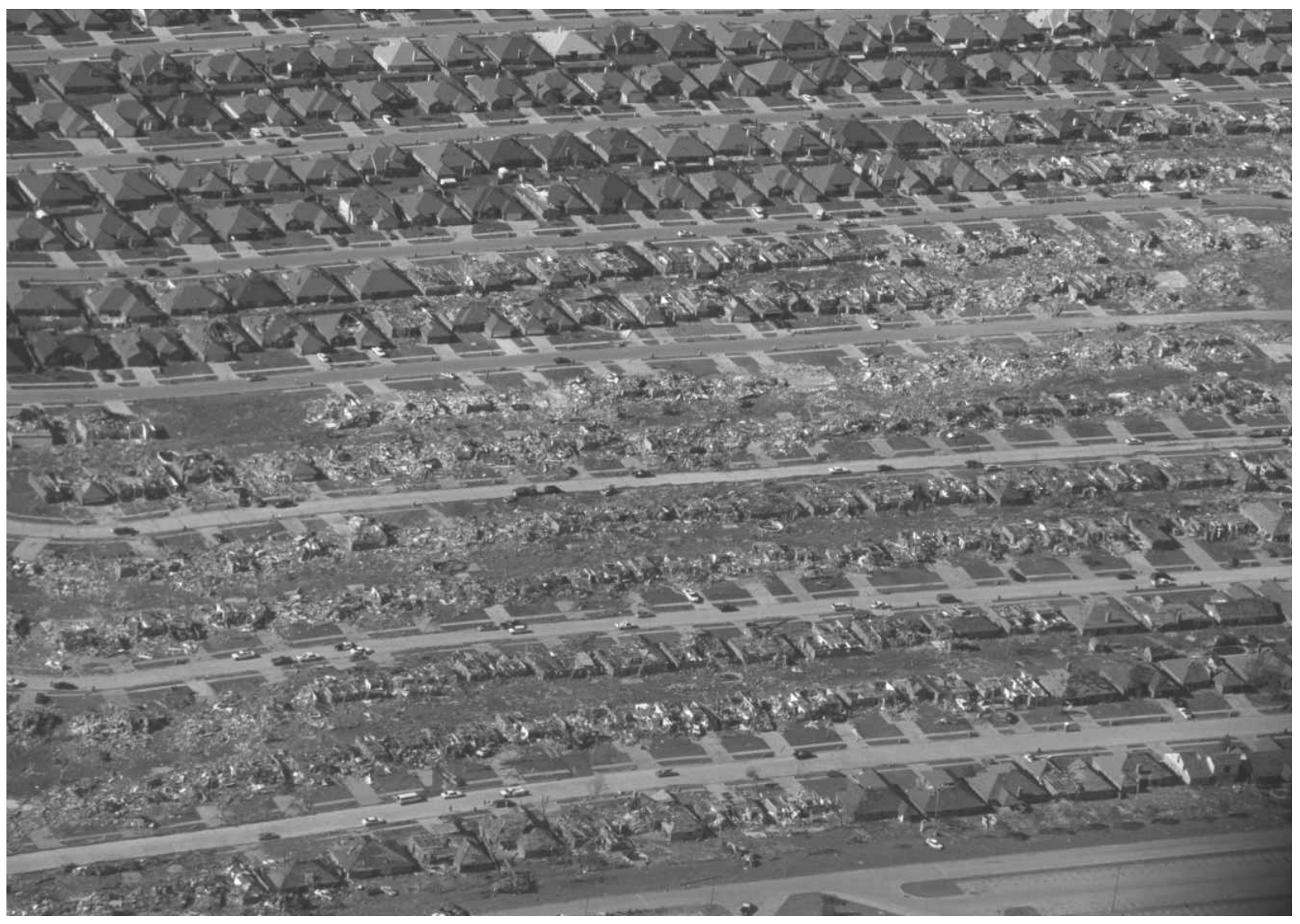

Figure 1-4. D amaged H ousing Complex South of Westmoore High School, Oklahoma City. 
1-6).

The investigation was concluded in Moore and was focused on Kelley Elementary School. Many surrounding buildings were damaged or destroyed, and a most of the school was leveled. The damage to the remaining portion of the school was so severe that no one was allowed access within ten meters of the building.

The Regency Park Baptist Church, located a few blocks from the school, also suffered significant damage, although it was not in the direct path of the tornado.

\subsection{Overview of Report}

The purpose of this report is to detail findings from the NIST damage reconnaissance. Information on the tornadoes based on information issued by NOAA is shown in Fig. 1-1. Section 2 describes observations of damage suffered by schools: the Kelly Elementary School and the Westmoore High School. Section 3 describes observations of damage to hotels: the Clarion Inn and the Hampton Inn. Section 4 is concerned with damage to: three buildings in Tinker Industrial Park; the Peach Auto Painting building; and the Coors Technical Ceramics building. Section 5 describes observations of damage to a limited number of other engineered

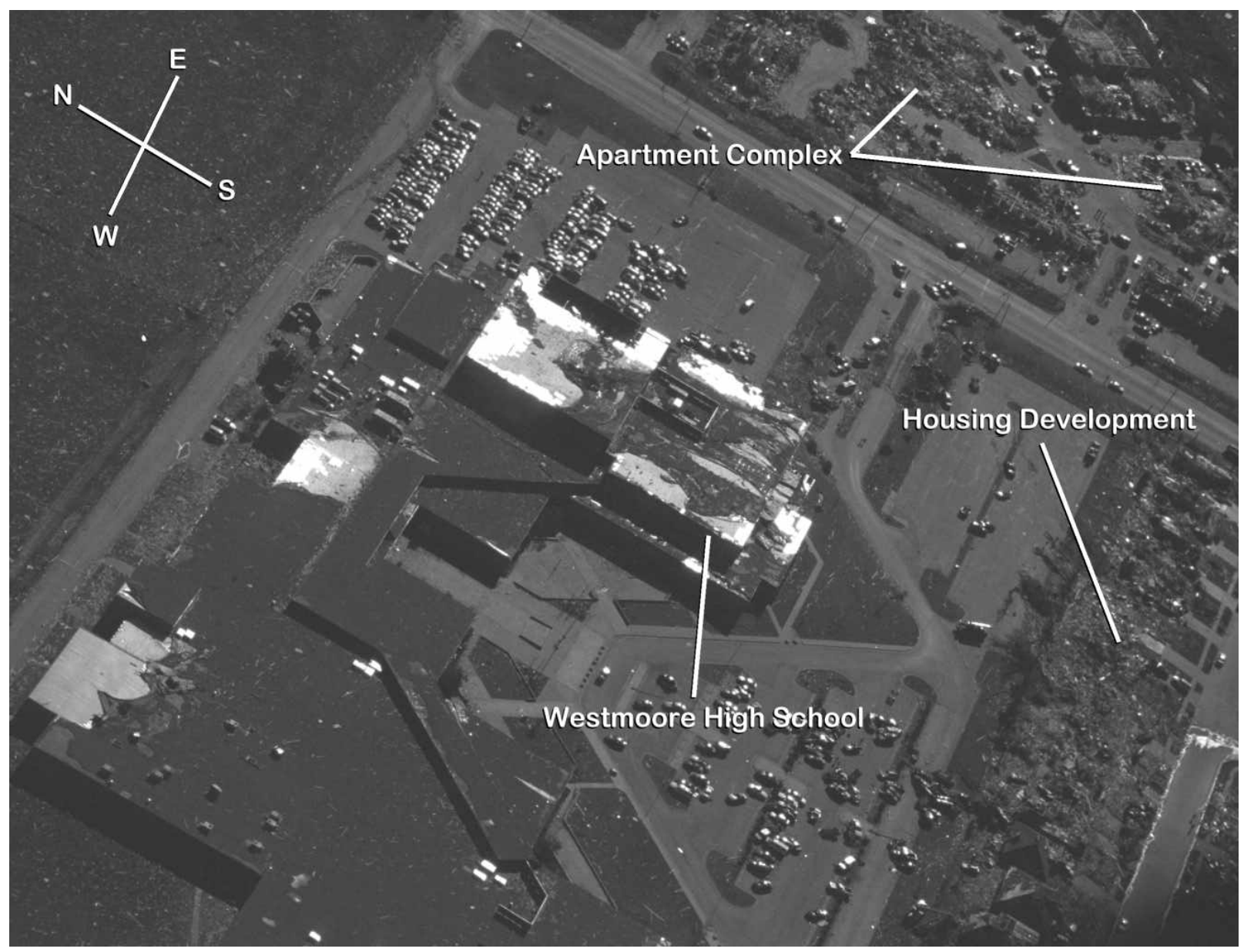

Figure 1-5. Damage to Westmoore High School and Surrounding Areas, Oklahoma City. 
structures. A large number of other buildings and structures suffered damage, but were not inspected or assessed in detail.

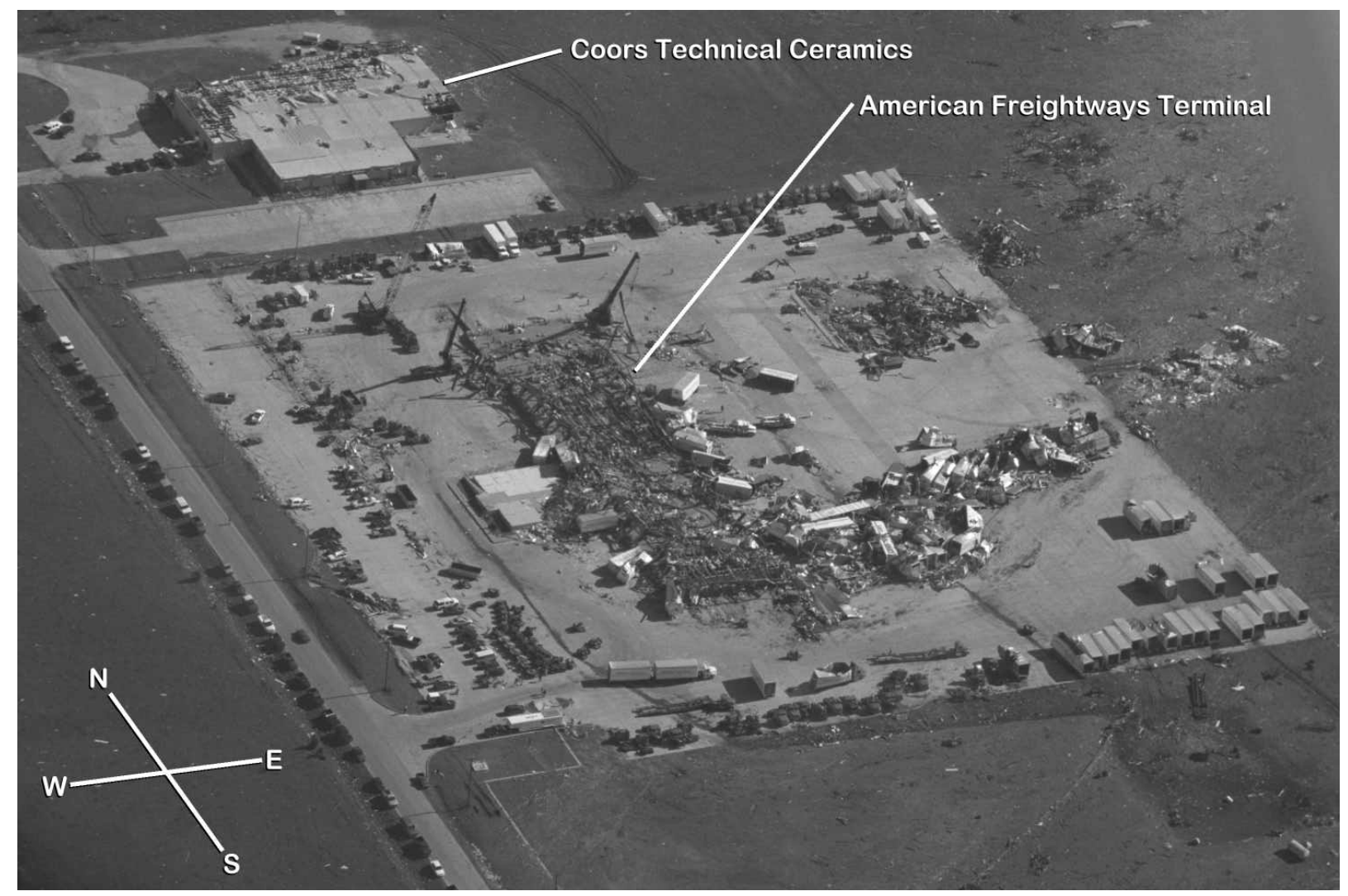

Figure 1-6: Damage to the American Freightways Terminal and Coors Ceramics Factory, Oklahoma City. 
This page intentionally left blank. 


\section{DAMAge to SchOOLS}

\subsection{Overview}

Three schools were heavily damaged or destroyed by tornadoes, two in the Moore school district and one in Mulhall.

The Kelley Elementary School in Moore was destroyed, while the nearby Westmoore High School lost part of its roof and had significant interior damage. The locations of these schools are shown in Figure 2-1, along with the approximate tornado path. This tornado (A7 in Figure 1-1) was rated F5 by NWS, and was near its peak strength when it passed through South Oklahoma City and Moore.

The Mulhall-Orlando Elementary School in
Mulhall was destroyed by a tornado rated F4 by NWS (B20 in Figure 1-1) that touched down south of Crescent and continued through Mulhall. News reports indicated that the brick building was partially leveled. The section that housed most of the classroom space was destroyed. A single classroom and the school library were the only rooms that survived. Owing to time constraints NIST was unable to investigate the damage to this school.

\subsection{Kelley Elementary School}

The Kelley Elementary School was located at $1900 \mathrm{~N}$ Janeway Ave. in Moore. According to school district personnel at the site, this steel and masonry building was con-

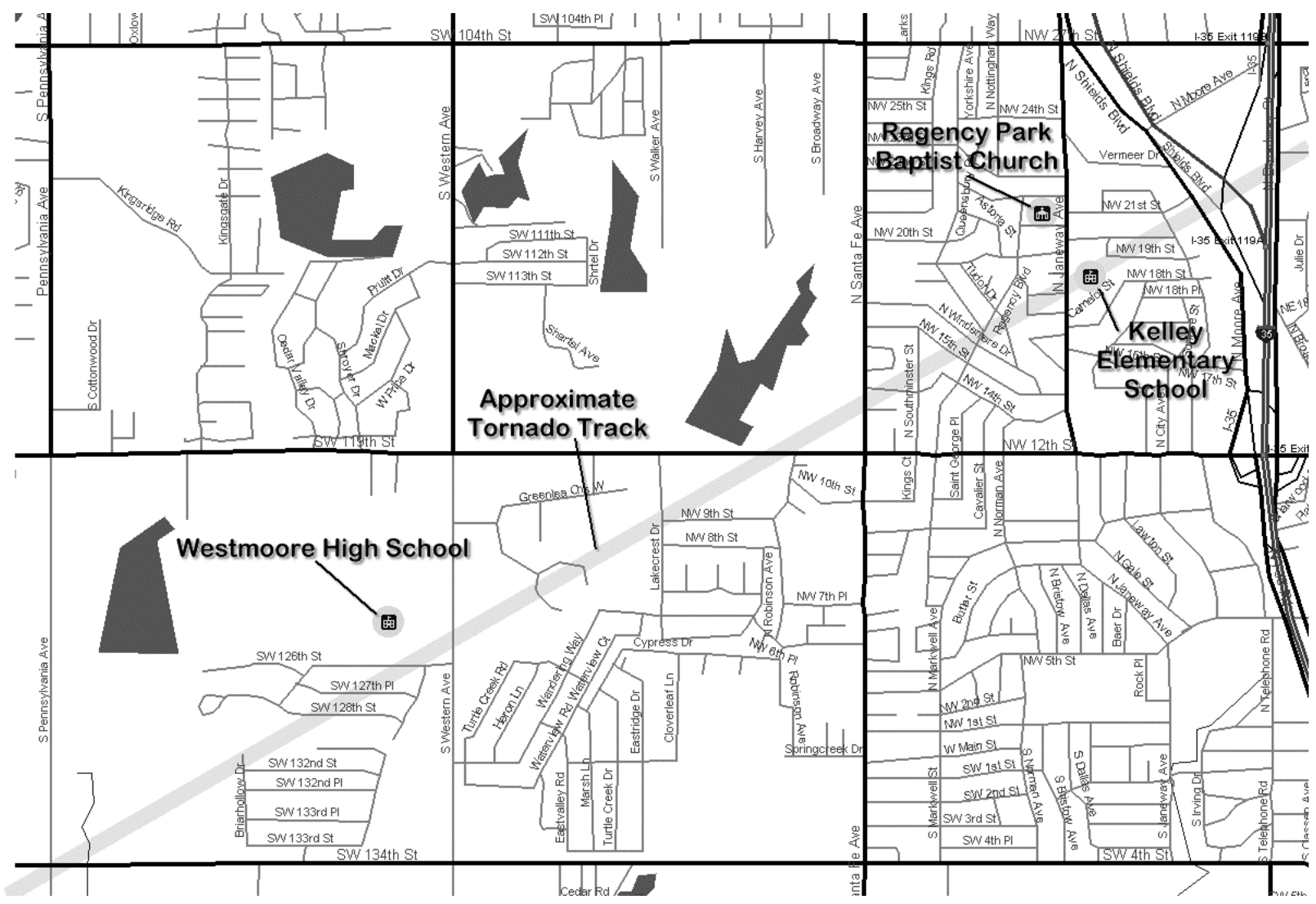

Figure 2-1: Map of Damaged Schools in South Oklahoma City and M oore 
structed around 1960. The building was struck directly by the tornado, which leveled part of the building and severely damaged the rest. Almost the entire roof was torn away, and no safe spaces remained.

The site was visited on May 7 PM. At that time, close access to the building was restricted due to the possibility of falling debris. Reconnaissance was performed from the site perimeter, and close inspection to determine member sizes was not possible.

The building was constructed with steel frames and masonry walls. Many of the exterior walls were load bearing, with reinforced concrete cap beams. The roof was constructed with corrugated steel panels supported by steel trusses. An overhanging cornice, constructed from timber and plywood, surrounded it.

The school building had three distinct sections, roughly forming an " $\mathrm{H}$ " in plan. The front section was at the western end of the building. This section housed the cafeteria, offices, and classrooms. The center section consisted of classrooms along a hall that ran east-west, and connected the front and back sections. The back section, at the western end of the building, consisted of additional classroom space on either side of a hall that ran north south.

The damage to the building ranged from complete destruction of some areas to the loss of roof panels and broken windows.

The front section of the building suffered varying damage. The main entrance was near the center of this section, and most of the structure north of the entrance was severely damaged or destroyed. As shown in Figure 2-2, most of the walls and the roof in this part of the building collapsed. The damage was less severe near and south of the entrance. Here some walls and some parts of the roof survived. Figure $2-3$ shows the damage to the southern end of the front section. The front wall of the cafeteria had collapsed inward and a portion of the roof has collapsed, but much of the roof sur-

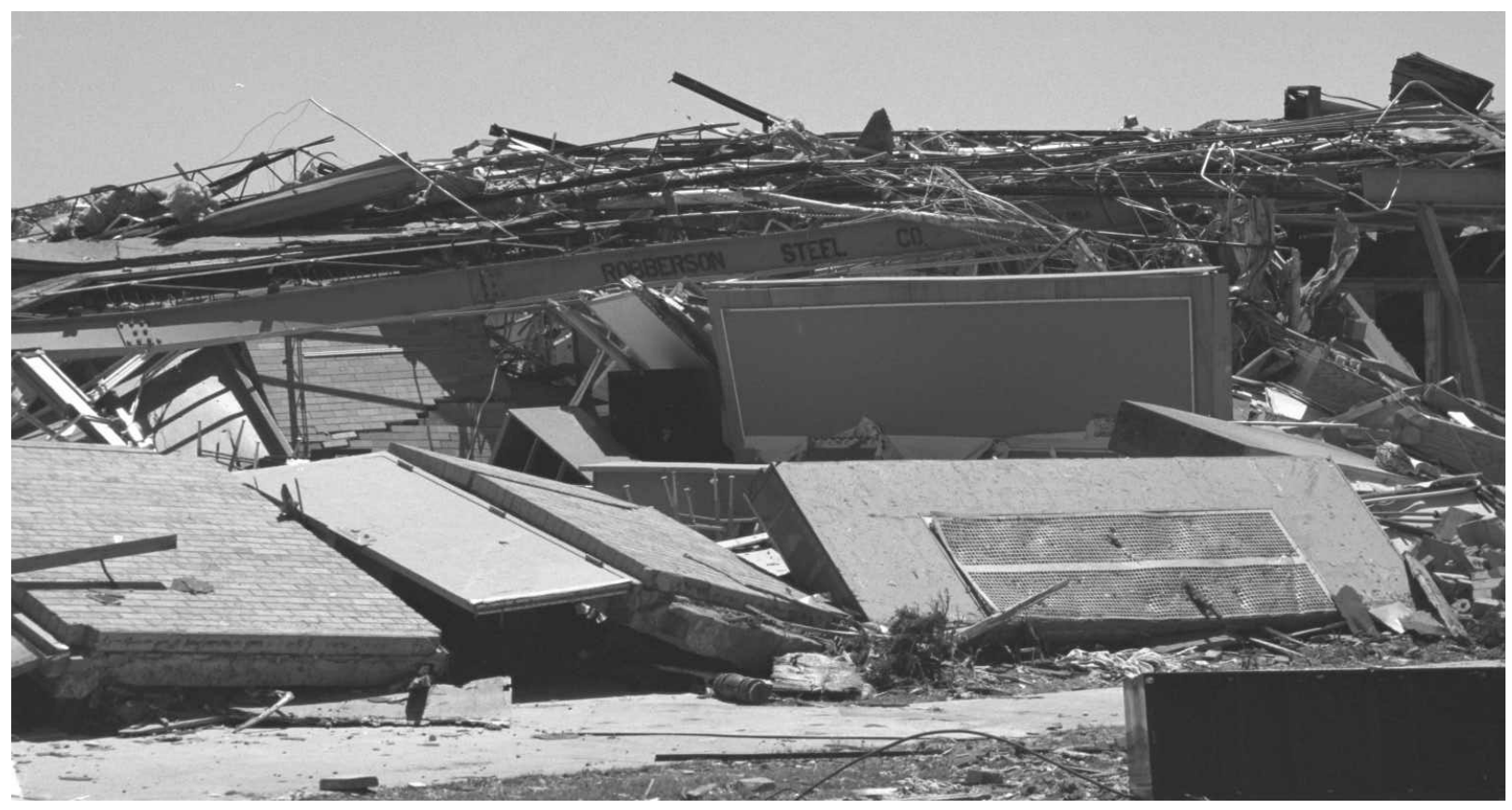

Figure 2-2: Remains of N orthern End of the Front Section of Kelly Elementary School. 
vived. South of the cafeteria, the roof was severely damaged, but most of the walls had survived.

The center section of the building was the most severely damaged. Here the roof trusses ran north-south, with the southern ends supported by a steel beam on steel columns. The northern ends of the centermost trusses were supported by a reinforced concrete cap beam on a concrete block wall with brick facing, while the eastern and western trusses were supported on steel beams supported by the cap beam and the end walls. Both the southern and northern walls were destroyed and nearly all roof covering was removed. The steel columns along the south wall, visible in Figure 2-4, bent, but did not fail. The loss of the north wall, however, removed all support for the north side of the roof leading to its collapse, as shown in Figure 2-5.

The eastern section of the building lost nearly its entire roof and a section of the western wall collapsed. Many of the roof trusses were lifted off and every window was broken. Although most of the walls survived, this section of the building could not have provided a safe space for the $\propto$ cupants. Figure 2-6 shows the south entrance to the central hallway in this section. Figure 2-7 shows the western side of the northern end of this section, where the wall and part of the roof collapsed.

This school had numerous structural weaknesses, which contributed to the destruction. The most significant weakness that was observed was the inadequate reinforcement in the masonry walls. The walls had only minimal horizontal reinforcement and no vertical reinforcement. Inspection of one collapsed wall, shown in Figure 2-8, revealed that only every third course of the concrete block was reinforced. Moreover, the mortar was poorly bonded to both the reinforcing bars and the blocks (Figure 2-9).

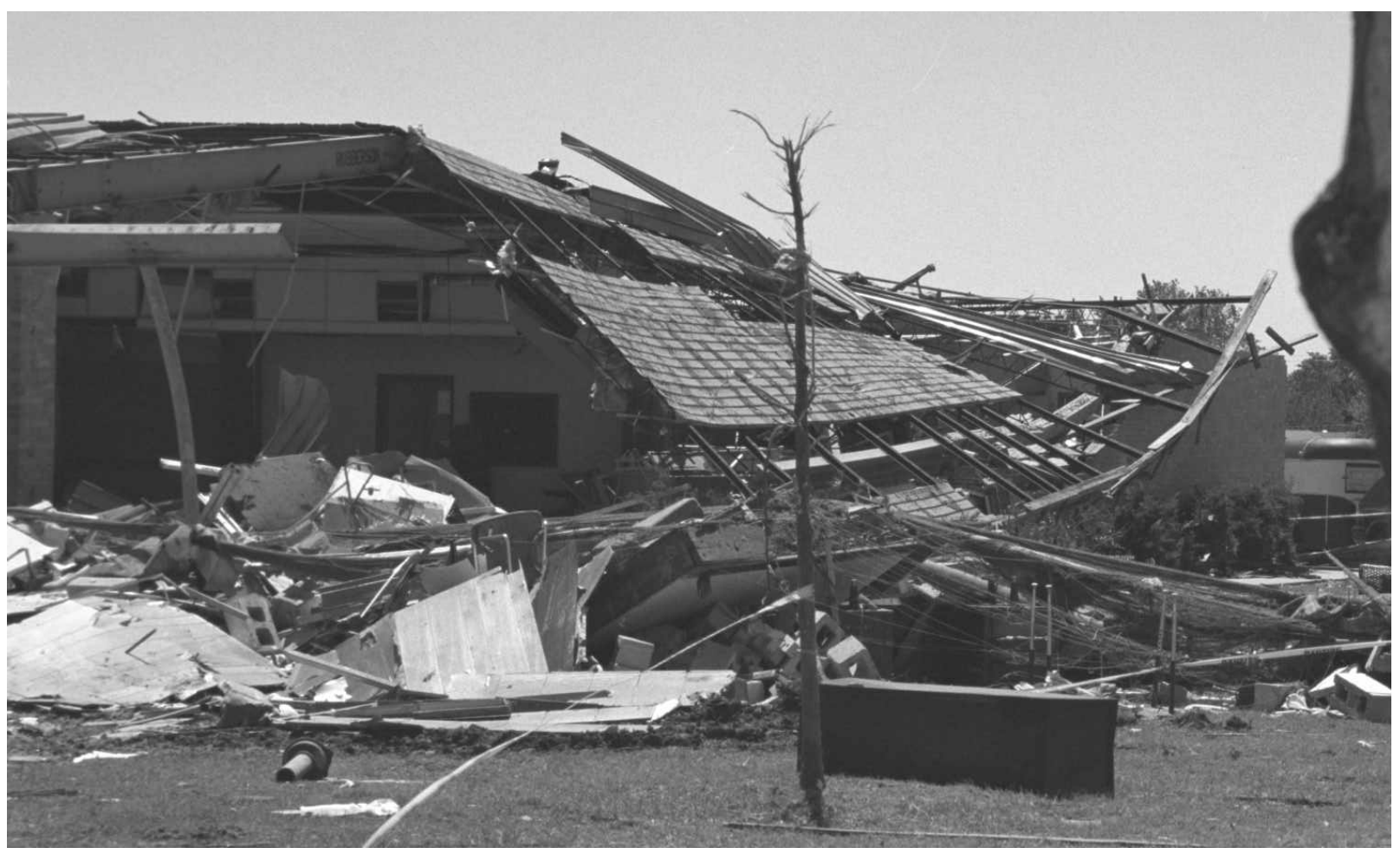

Figure 2-3: D amage to Southern End of Front Section of Kelly Elementary School. 
Additional horizontal reinforcement, vertical reinforcement, and a better bond with the mortar would all have significantly increased the strength of the walls.

A nother significant weakness was the wooden soffit beneath the cornice, shown in Figure 2-10. The failure of the soffit allowed the wind to penetrate under the roofing, thereby increasing the total wind load on the roof. The wood studs used to support the soffit were simply toenailed to the sup- porting member. These connections could not withstand extreme loads, and failure of sections of the soffit contributed to the roof failures.

A third major weakness was the glazing. The glazing appeared to be standard weight, monolithic annealed glass, which was shattered by the wind and flying debris as shown in Figure 2-11. The glazing fragments would have posed a severe hazard to the building occupants.

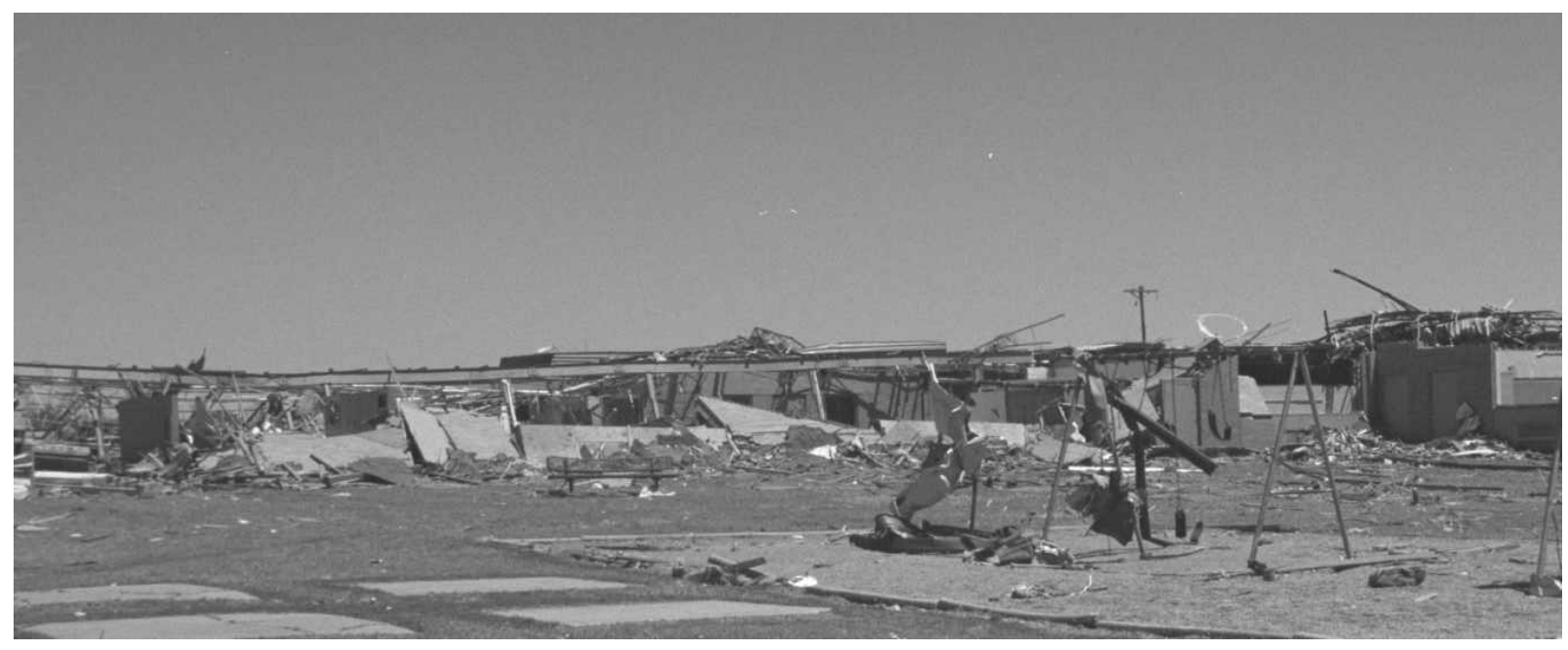

Figure 2-4: South Side of the Center Section of Kelly Elementary School.

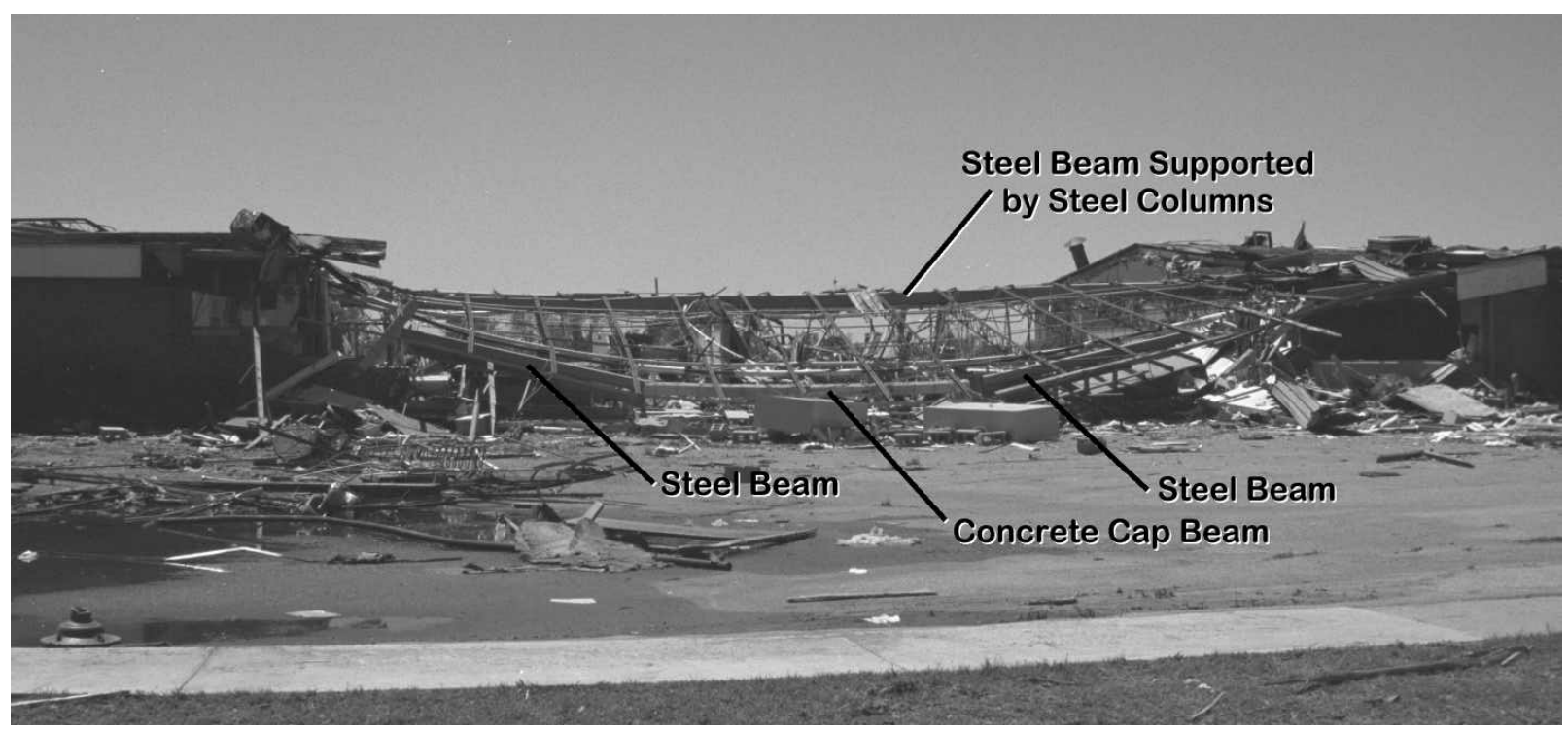

Figure 2-5: N orth Side of the Center Section of Kelly Elementary School. 
Given the age of this building and its unsatisfactory construction, its failure is not surprising. This is not to say that the school did not meet building codes, or that its design and construction were deficient as compared to conventional practice, but the design and construction of this school were not nearly sufficient to withstand the tornado wind loads. Better built structures would have suffered lesser damage and

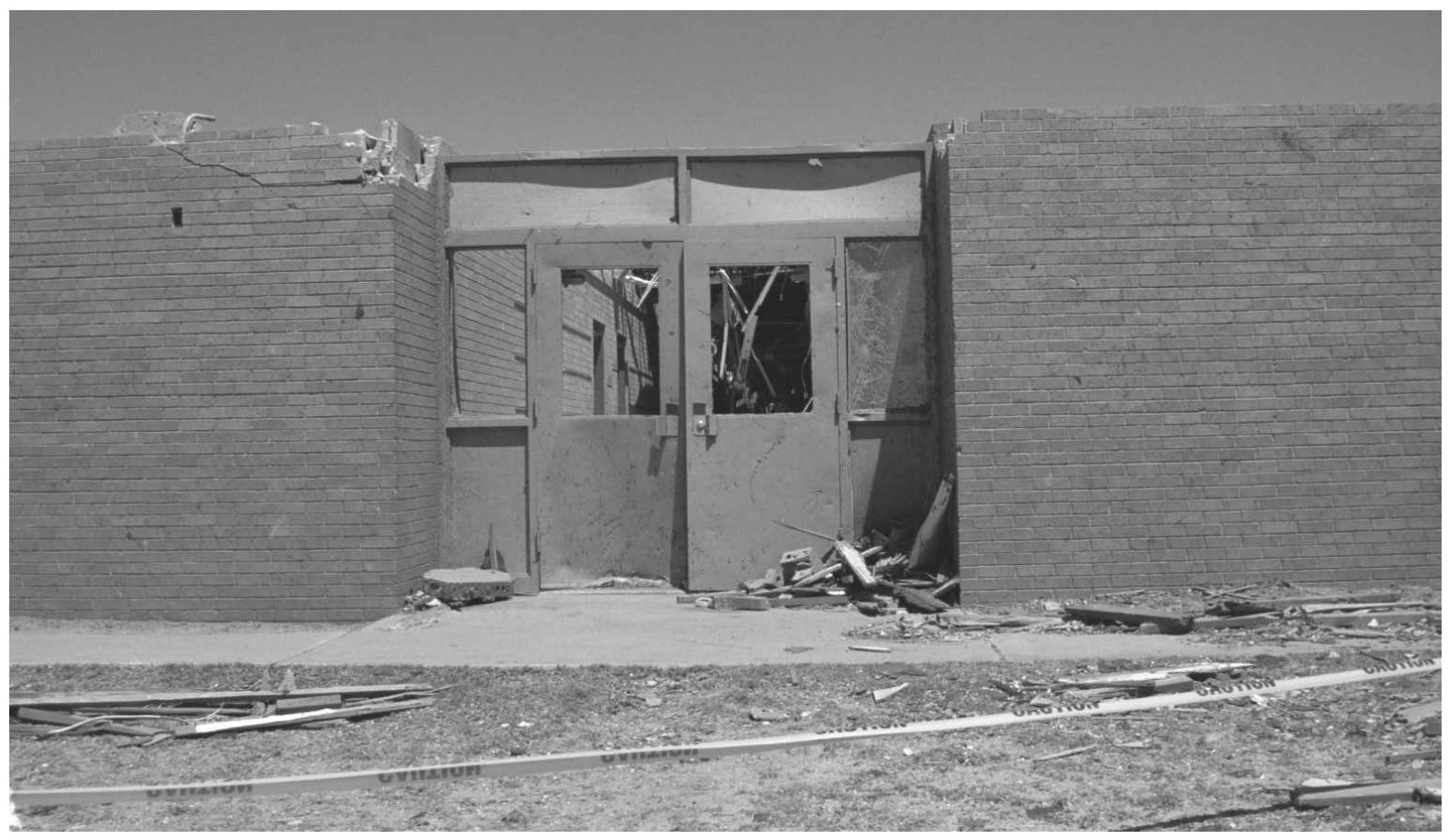

Figure 2-6: South Side of the East Section of Kelly Elementary School.

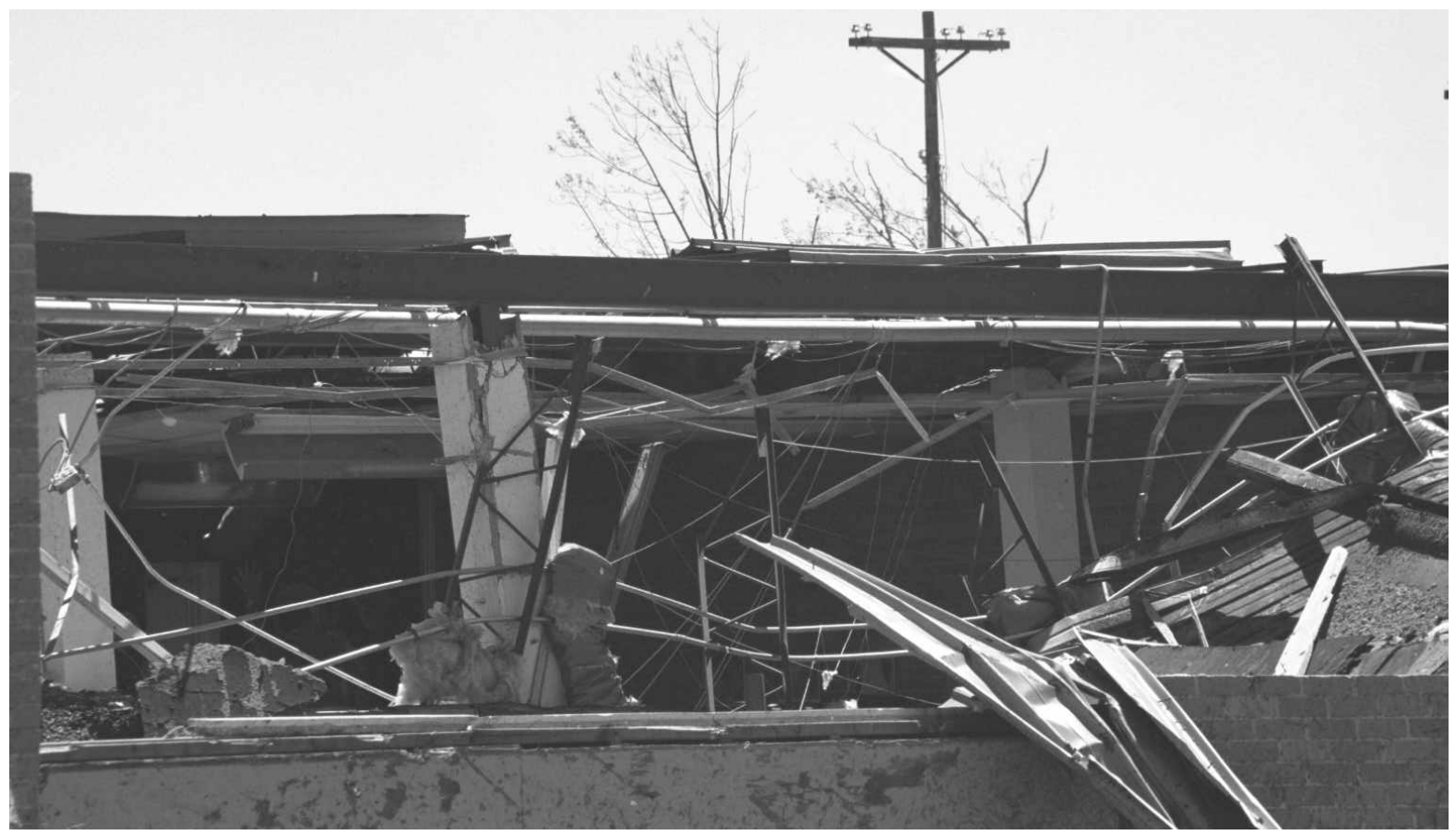

Figure 2-7: Collapsed Wall on West Side of the East Section of Kelly Elementary School. 
posed a lesser hazard to their occupants, particularly since the true intensity of the tornado may have been less than F5 (see, e.g., Phan and Simiu, 1998a).

We note the lack of a safe space in this school. If the tornado had struck while

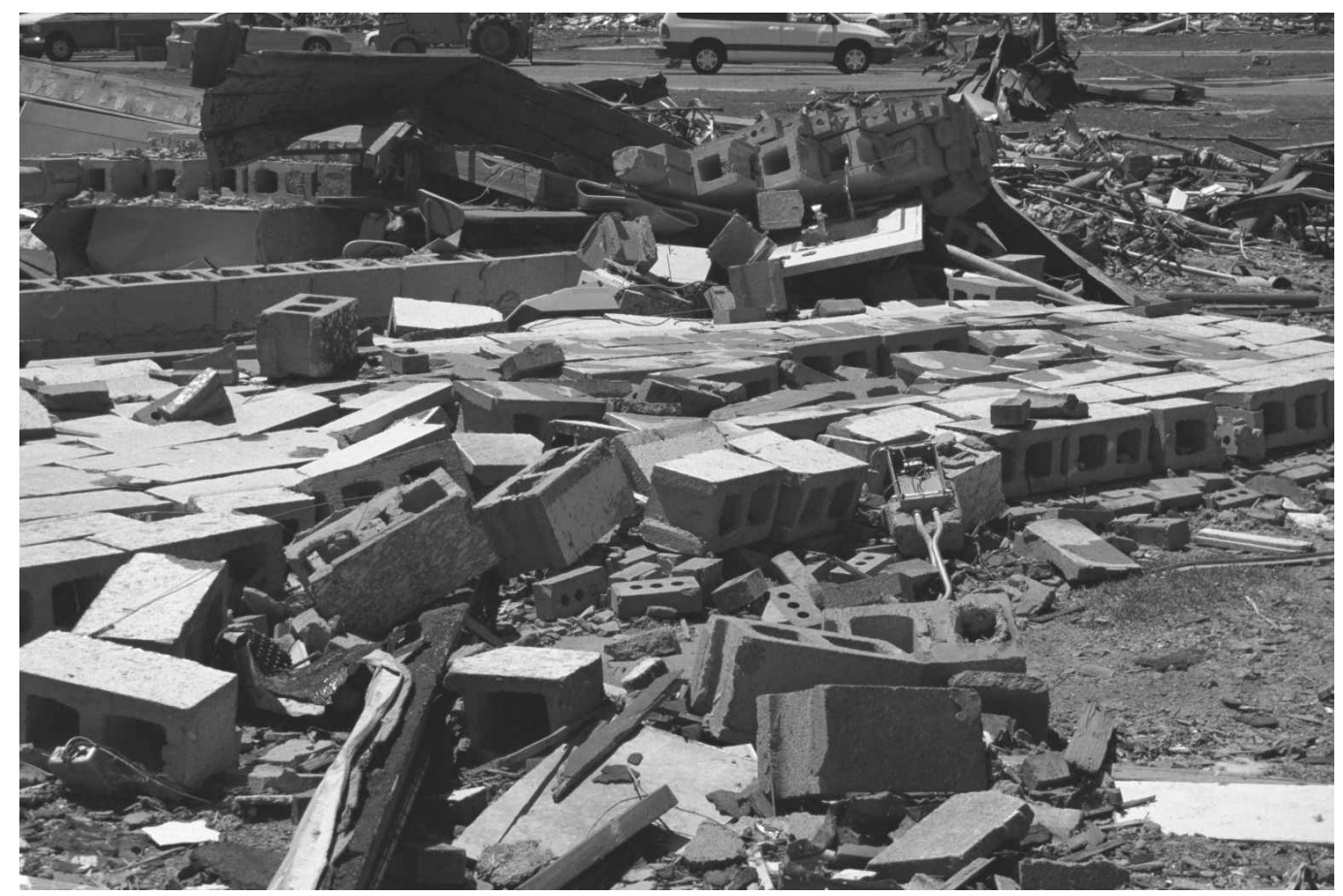

Figure 2-8: Collapsed Wall at North End of West Section of Kelly Elementary School.

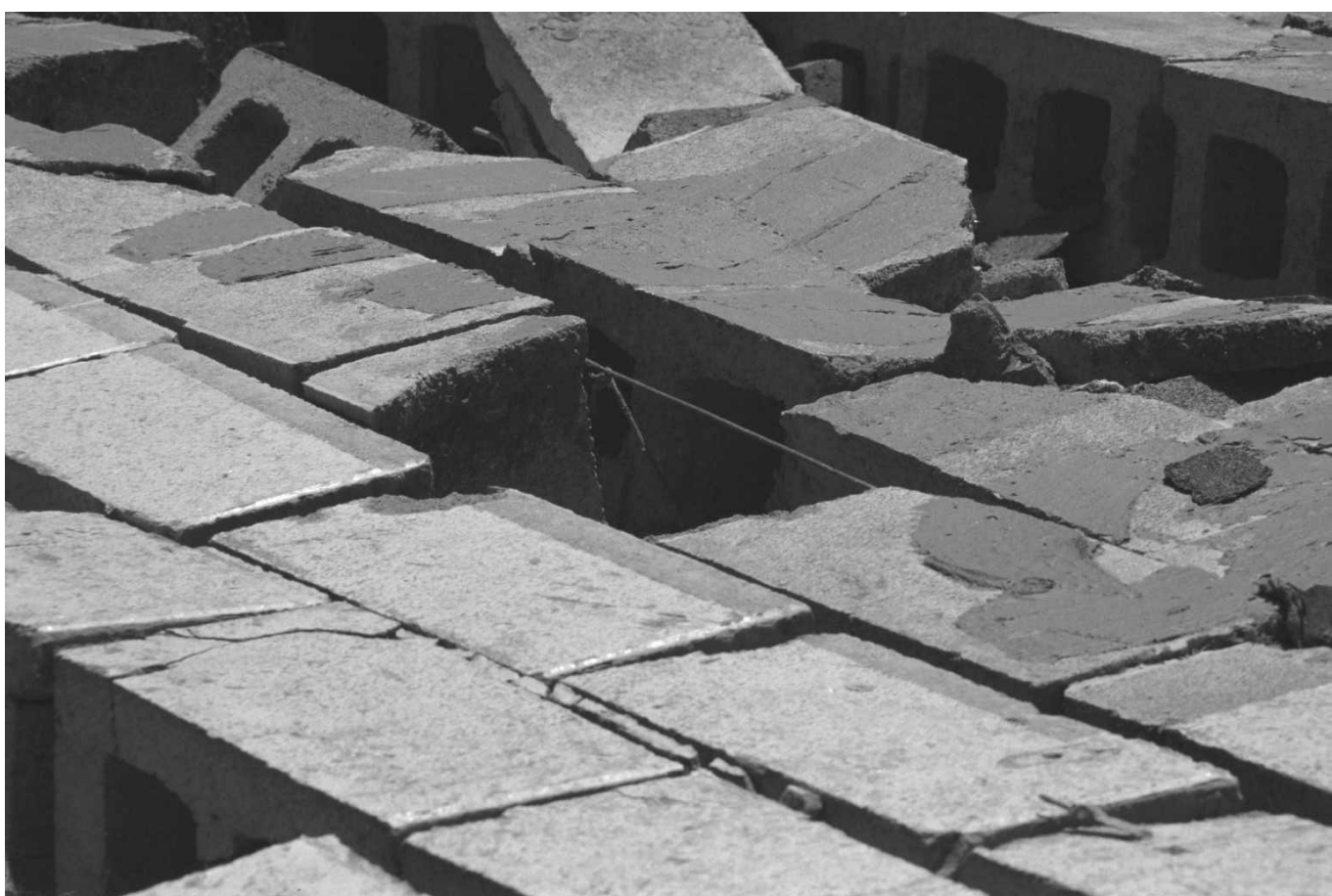

Figure 2-9: D etail of M ortar and Reinforcement in the Collapsed Wall at $\mathrm{N}$ orth End of West Section of Kelly Elementary School. 
classes were in session, many of the students might have been seriously injured or lost their lives. In our opinion there is a definite need to identify and upgrade schools and other public buildings that are inadequately built and do not provide safe spaces for their occupants.

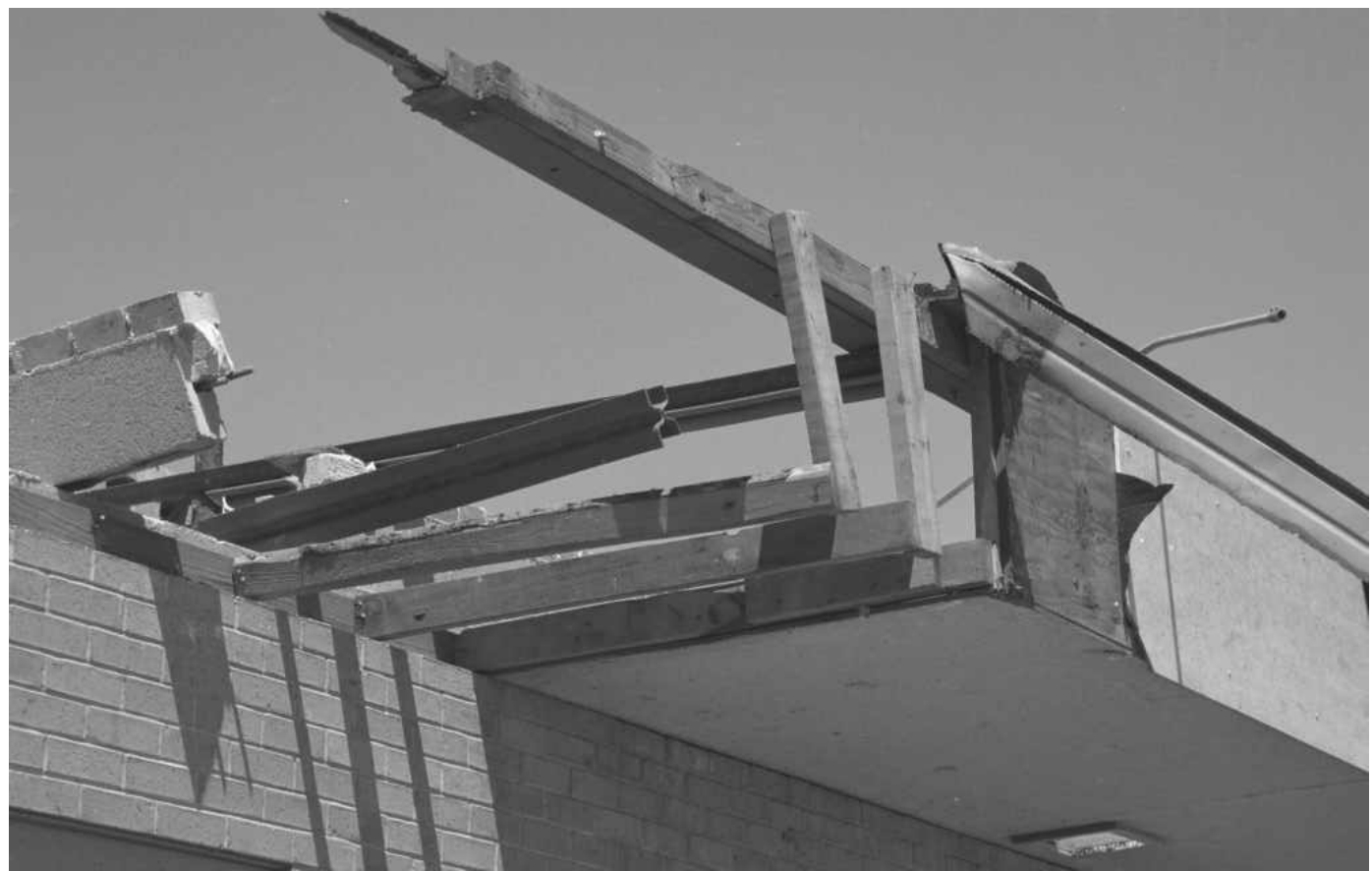

Figure 2-10: D etail of the Cornice and Soffit on East Side of Kelly Elementary School.

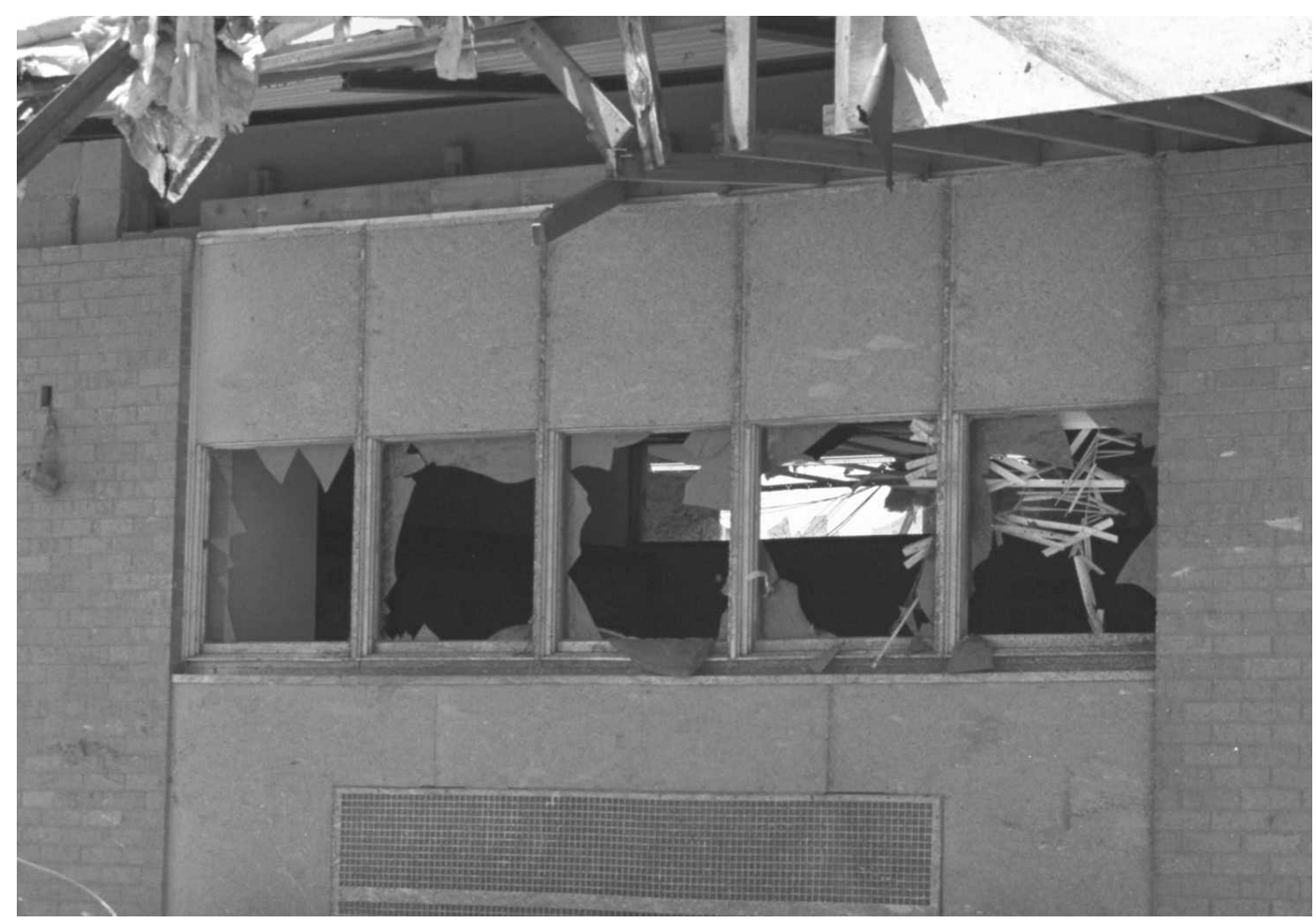

Figure 2-11: Broken Windows on East Side of Kelly Elementary School. 


\subsection{Westmoore High School}

The Westmoore High School is located at 12613 S Western Ave, Oklahoma City. The zone of largest wind speeds of the tornado passed less than 90 meters south of this school. Numerous homes in the housing development south of the school (See Figure 1-4) were destroyed, as were most of the buildings in the apartment complex to the east (See Figure 1-5). The school itself escaped destruction, sustaining primarily roof damage and loss of architectural cladding.

At the time the tornado struck, there were approximately 100 occupants inside the school. Eyewitnesses indicated that many of these people had been in the school auditorium at the time the NWS tornado warning was received. By the time the tornado struck, the auditorium had been evacuated, and everyone had moved to interior corridors. A large section of the auditorium roof was blown off and smaller areas of the roof over corner classrooms were also lifted off. Fortunately, the school's structure remained intact, preventing any loss of life.

The damage to the school included the loss of some roof sections, significant damage to the roofing material over large portions the building, loss of architectural cladding, and significant wind and water damage to the contents of rooms that lost portions of their roofs or windows.

The school's roof had a wide variety of types of damage, as shown in Figure 2-12. As mentioned above and shown in Figure 2-13, a large section of the auditorium roof was destroyed. A smaller section of the northwest corner of the roof was also lost. The roof covering was heavily damaged in many locations, with the worst damage occurring in the southeast corner above the gymnasium and the auditorium. Many other sections of the roofing were damaged, including large sections near the center of

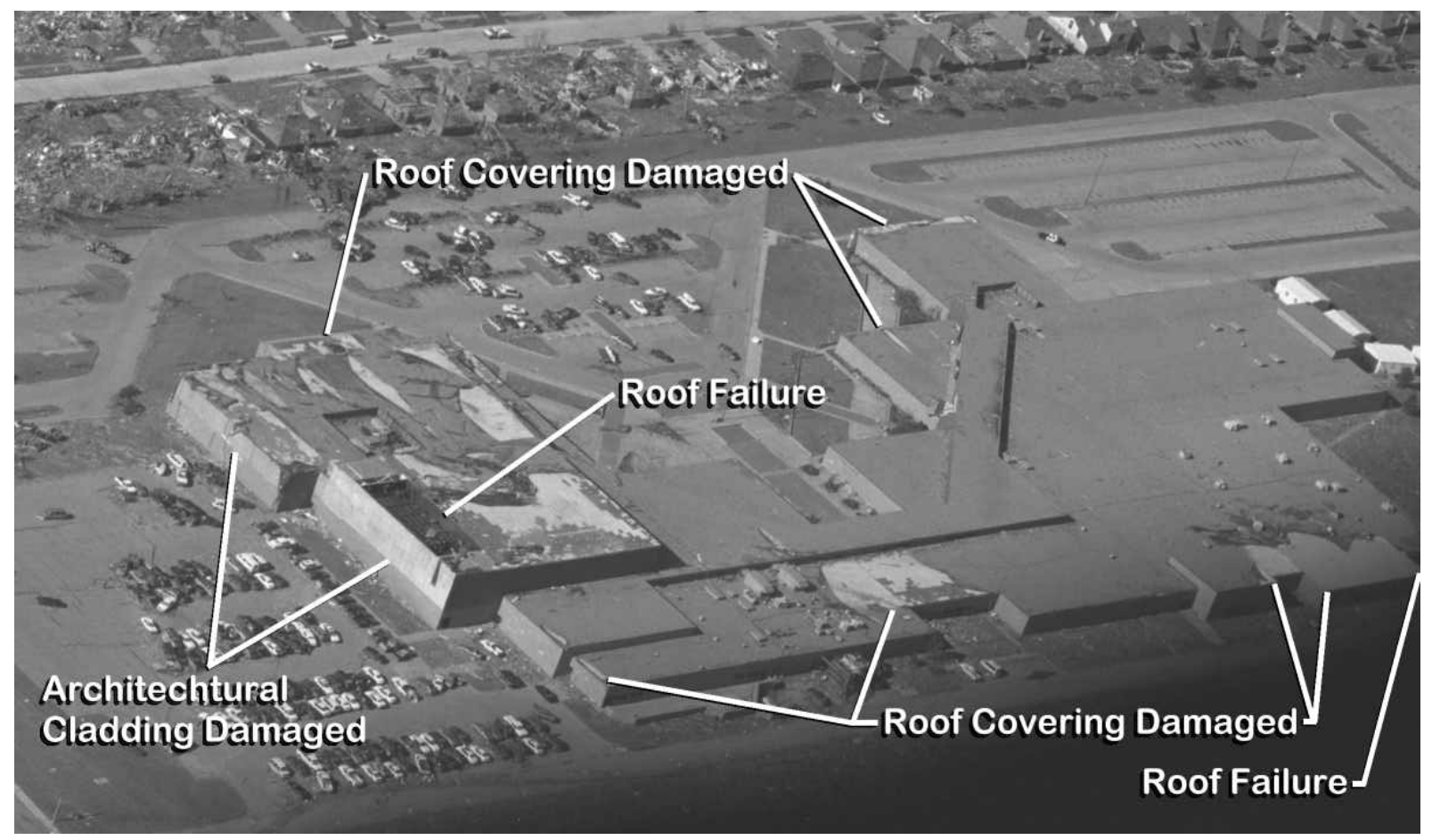

Figure 2-12: Aerial View of Westmoore High School. 
the school and near the northwest corner.

Figure 2-14 shows the section of roof that was lost from one classroom. This classroom was located near the northwest corner of the building, and had much of its contents damaged by the water and wind that entered through the damaged roof.

Steel architectural cladding, which appeared to be lightly attached, was also damaged. Figure 2-15 shows some of the damaged cladding on a North face of the building. This cladding appeared to be lightly connected only by nails and small diameter screws to the buildings' masonry. The tornado winds removed most of the cladding from the south and east faces of the building's southeast corner. This damage can be seen in Figure 2-16 and Figure 2-17.
Of particular interest was the large quantity of debris in the vicinity of the school. Figure 2-18 shows some of the debris that had collected on the north side of the building. Much of this debris was likely from the large number of homes south of the highschool that were destroyed by the tornado, as shown in Figure 1-4.

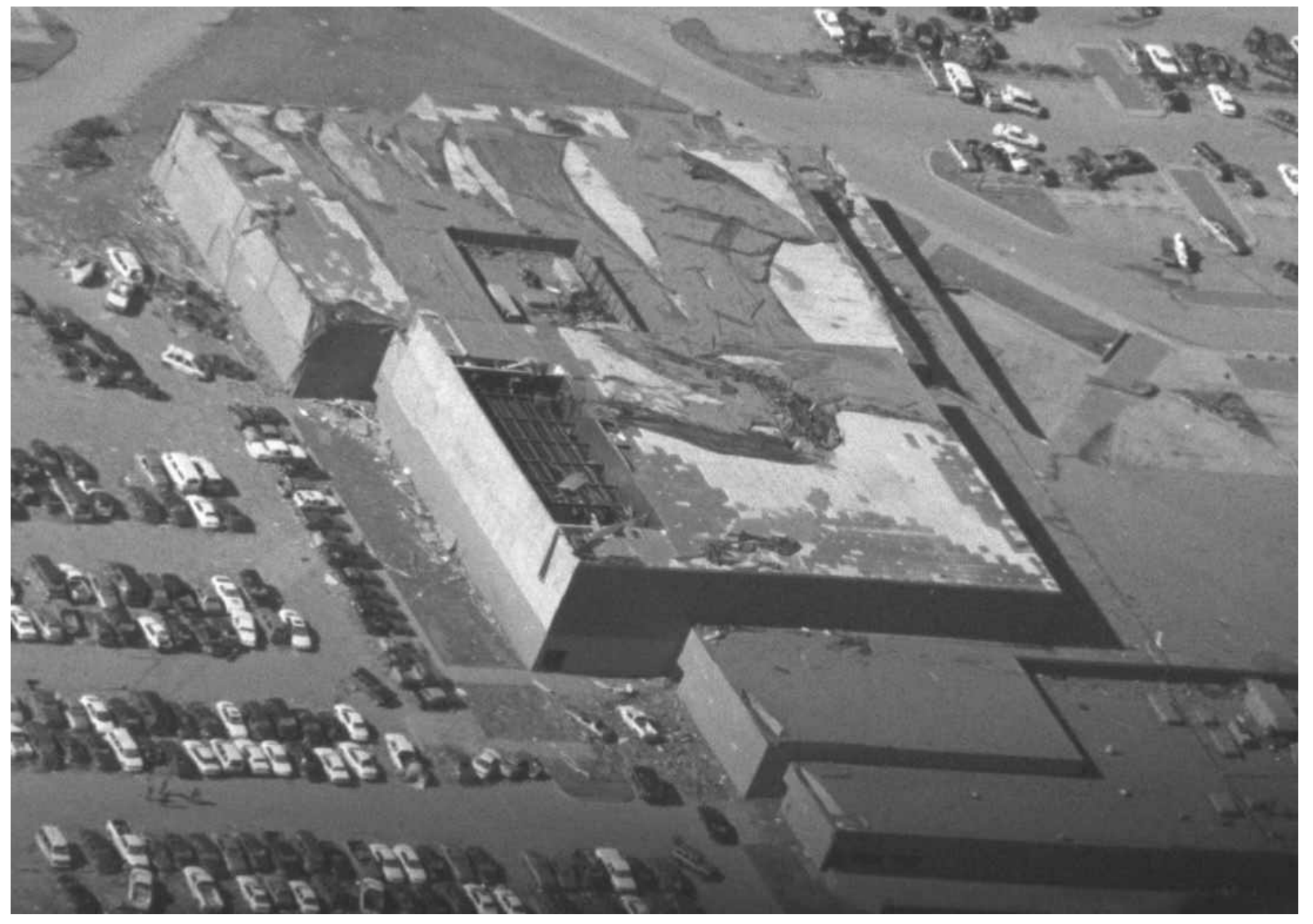

Figure 2-13: Detail of Roof Damage to Westmoore High School. 


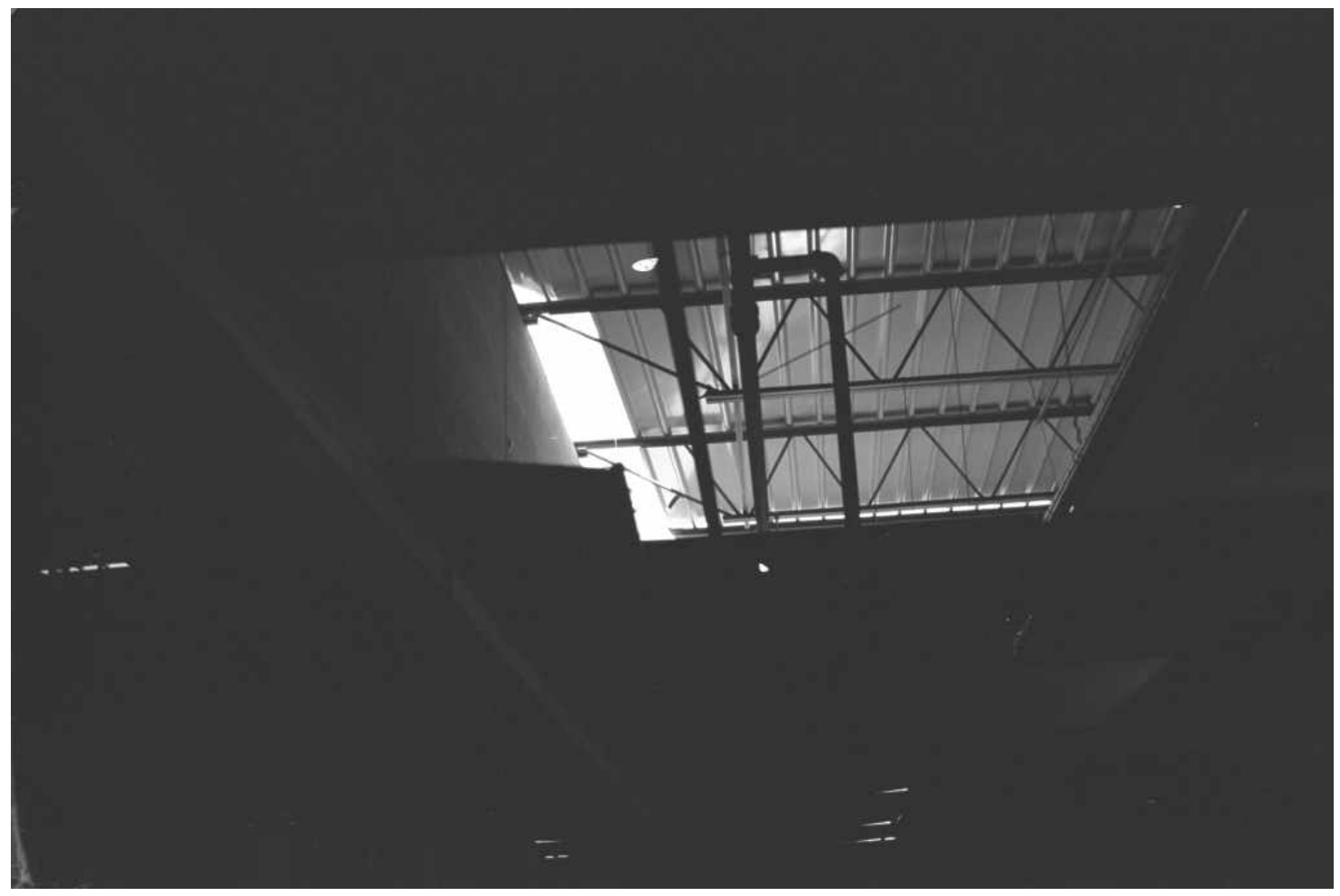

Figure 2-14: D amage to Westmoore High School Classroom Roof (Inside View).

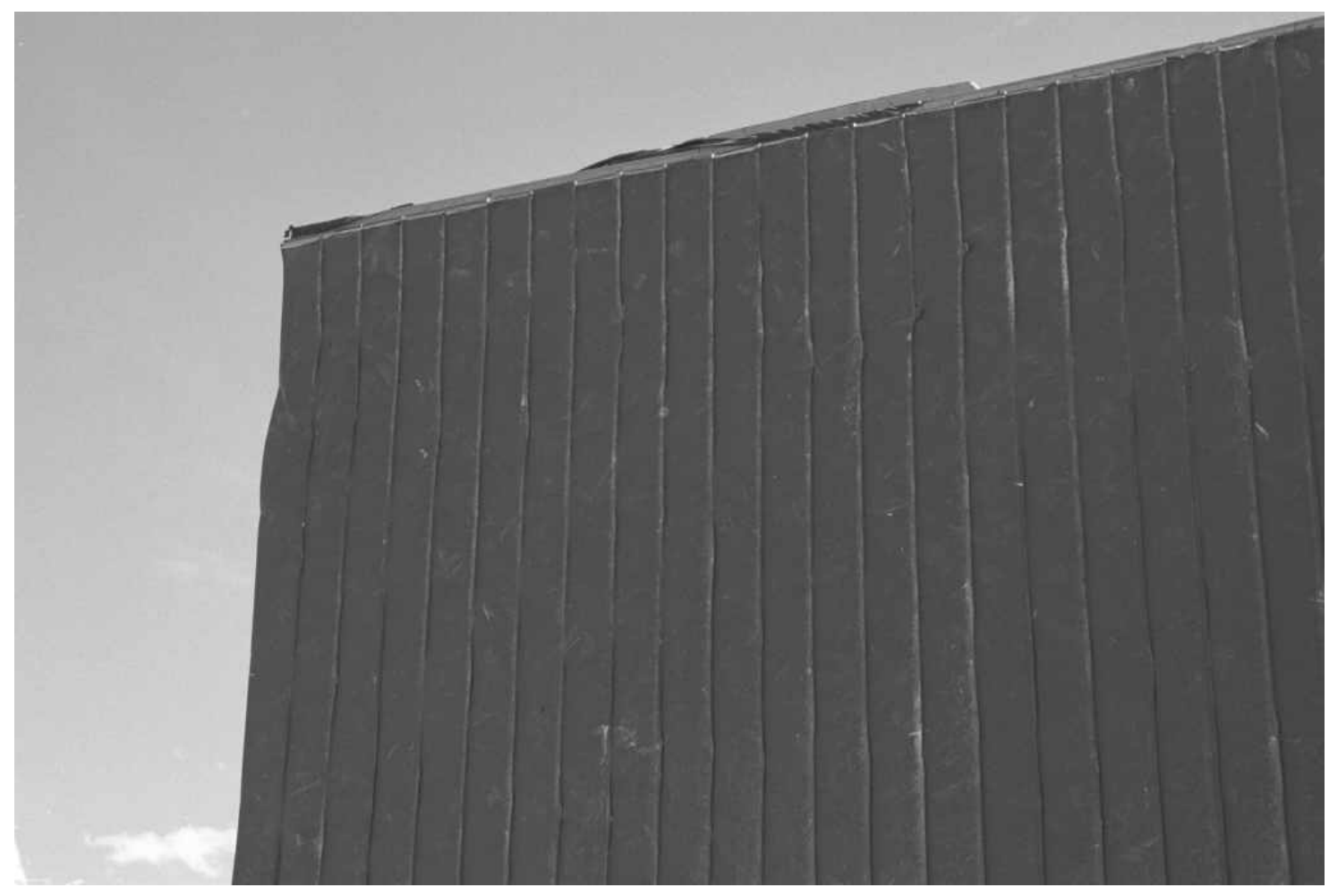

Figure 2-15: D amaged, But Intact, Cladding on Westmoore High School. 


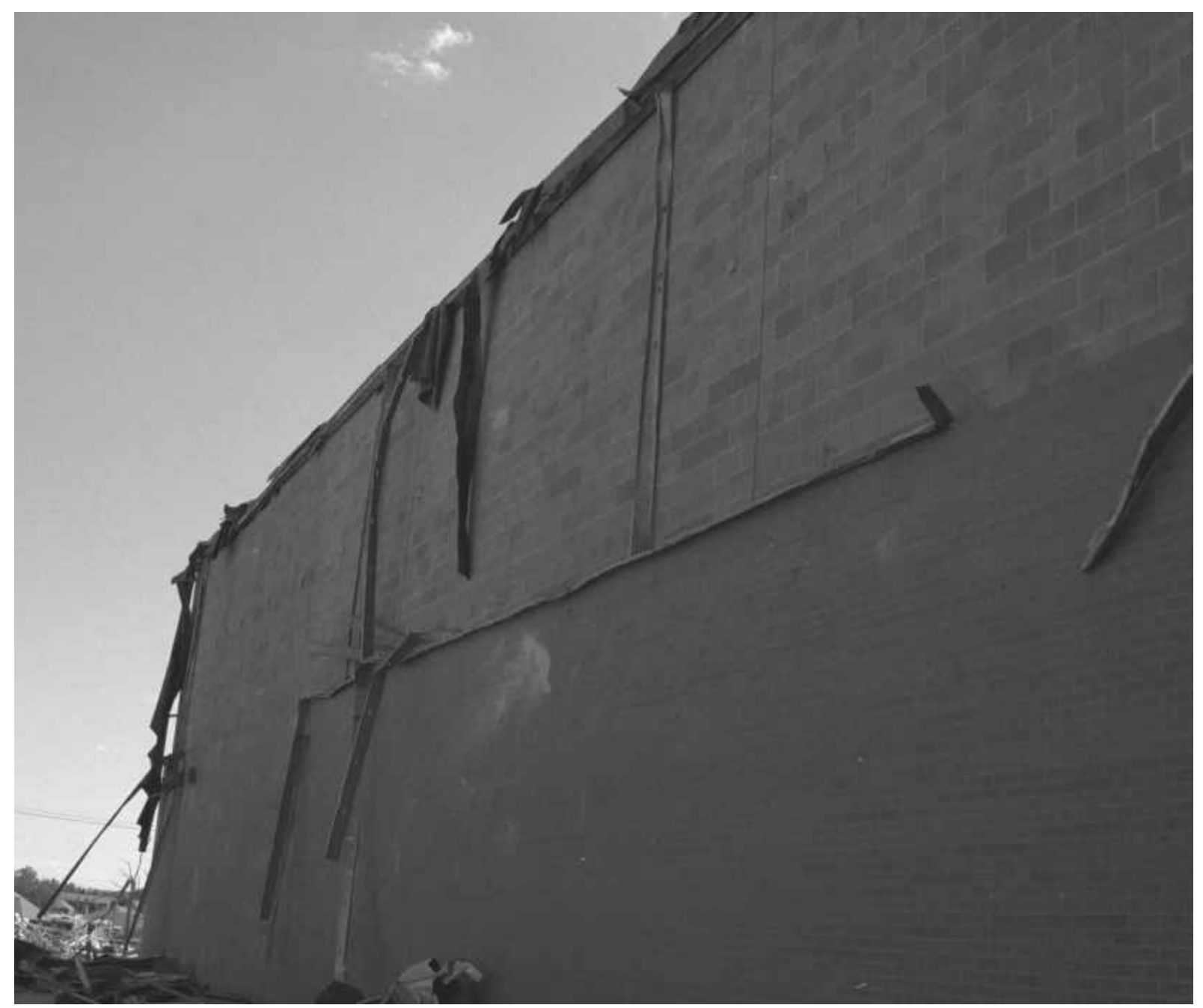

Figure 2-16: D amage to Cladding on East Side of Westmoore High School.

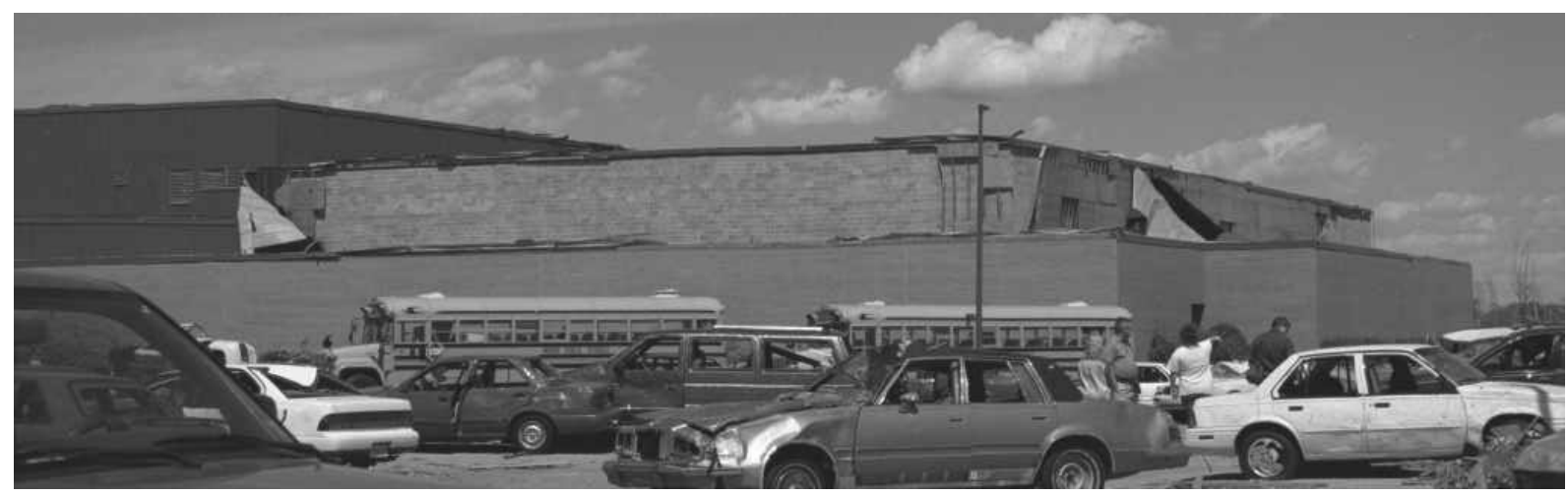

Figure 2-17: D amage to Westmoore High School and Vehicles, View From South. 


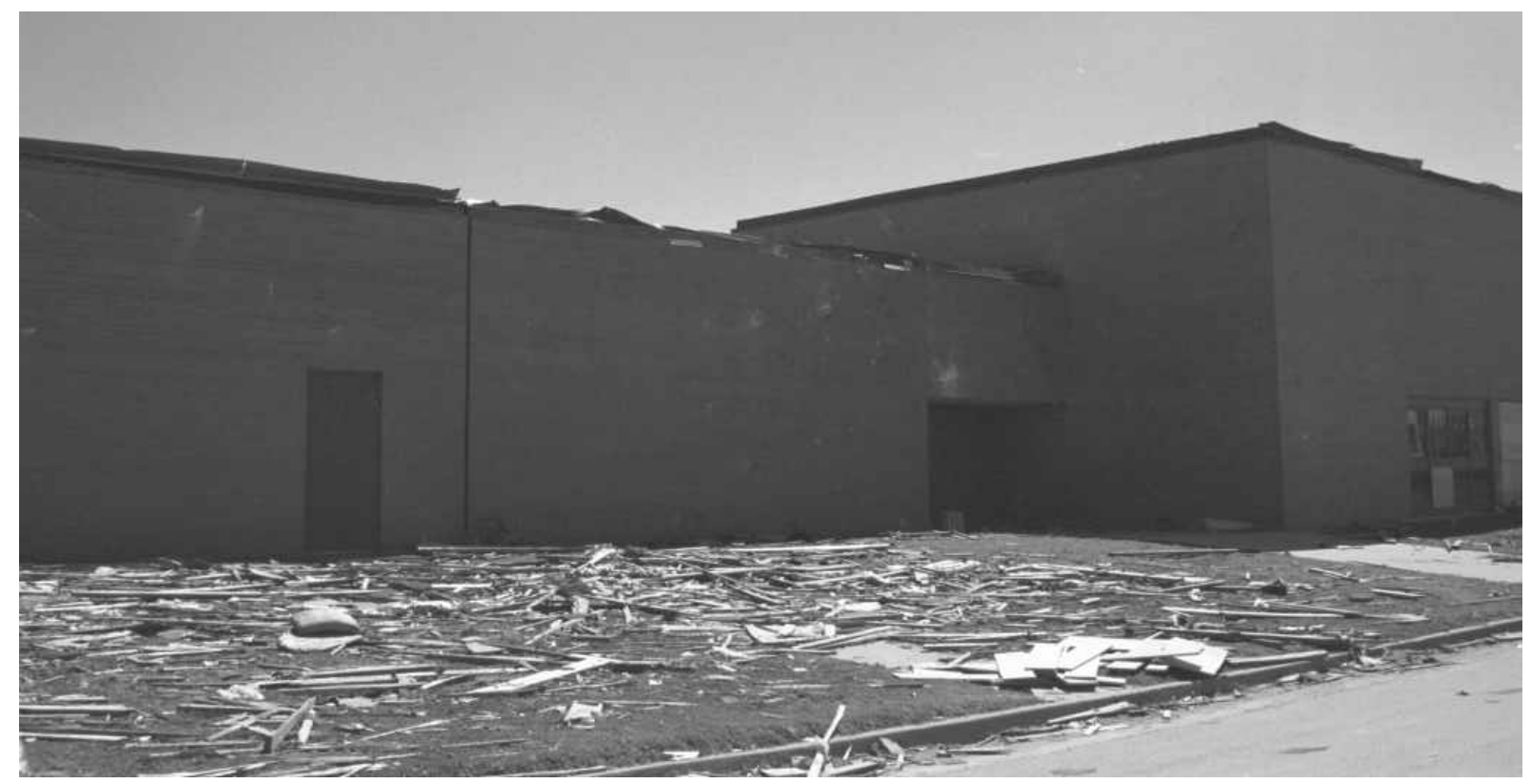

Figure 2-18: D ebris on N orth Side of Westmoore High School. 


\section{DAMAGe to Hotels}

\subsection{Overview}

At least three hotels were severely damaged or destroyed by the tornadoes. Two of these hotels, the Clarion Inn and the Hampton Inn, were located adjacent to each other on the north side of the Tinker Diagonal in Midwest City. The tornado appears to have crossed the highway moving primarily northward at this point. It appears to have passed over the southwest corner of the Clarion Inn, and directly over the Hampton Inn and an adjacent building.

The damage to these two hotels was surveyed on Thursday, May 6th. At this point some debris have already been cleared to allow for search and rescue operations; however, demolition of what remained of the hotels had not yet begun. The Clarion was heavily damaged, while the Hampton was demolished by the tornado.

\subsection{Clarion Inn}

The Clarion Inn had sections that used distinctly different construction. The lobby and some of the central portions of the building were constructed with steel framing, lightweight cladding, and a sheet metal roof. The two-story high accommodation areas were constructed with masonry walls between the rooms on the first floor, and wood and masonry walls on the second

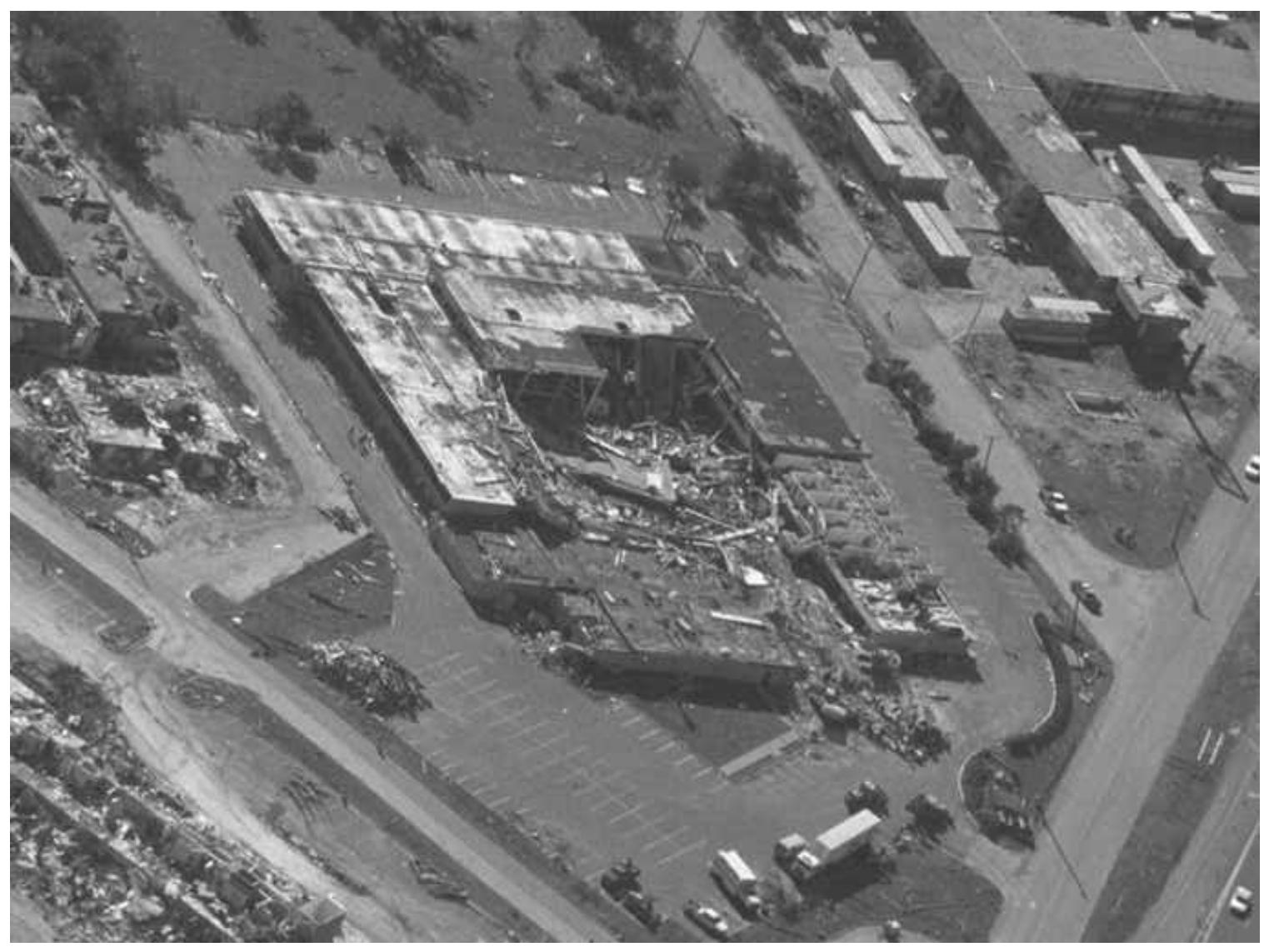

Figure 3-1: A erial View of Damage to the Clarion Inn. 
floor. The second floor slab and roof were precast concrete slabs. The exterior walls consisted of floor to ceiling glass windows.

This hotel had varied damage, as shown in Figure 1-3 and Figure 3-1. The southwest corner was destroyed, while the northeast corner had little damage. Some of the central areas of the hotel were also destroyed. Figure 3-2 shows the variation in damage along the southern side of the hotel's accommodation area. In the southwest corner, the roof slab had been lifted off and nearly every window broken on both floors. In addition, many of the interior walls on the second floor near the end of the building were destroyed as shown in Figure 3-3.

Much of the western and central section of the hotel was severely damaged. As can be seen in Figure 3-4, much of the cladding was removed from this steel framed section, and some two story high portions collapsed. In addition, a large volume of debris, from both the hotel and the nearby buildings, collected in the opened western and central sections of the hotel.

\subsection{Hampton Inn}

The Hampton Inn had a steel frame at the southwestern corner, where the hotel lobby was located. The two-story accommodation area of the hotel was constructed with heavily reinforced concrete block walls at both ends, and concrete block walls between the rooms on the lower floor. The partitions of the upper floor, and outside walls of both floors, were constructed of cold rolled steel studs, with gypsum board cladding on the inside and stucco cladding on the outside. The floors and roof were pre-cast concrete slabs.

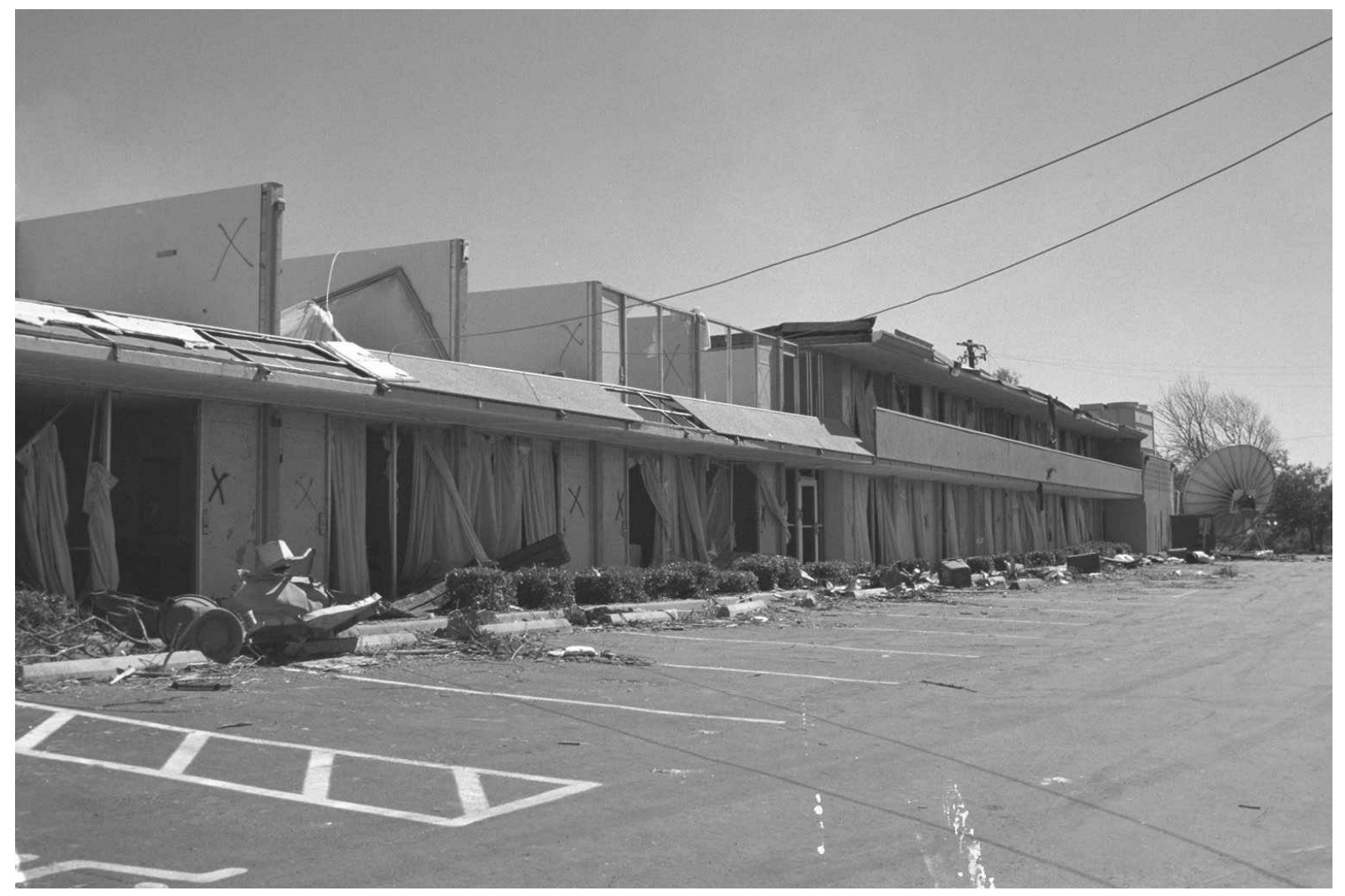

Figure 3-2: D amage to South Side of the Clarion Inn. 


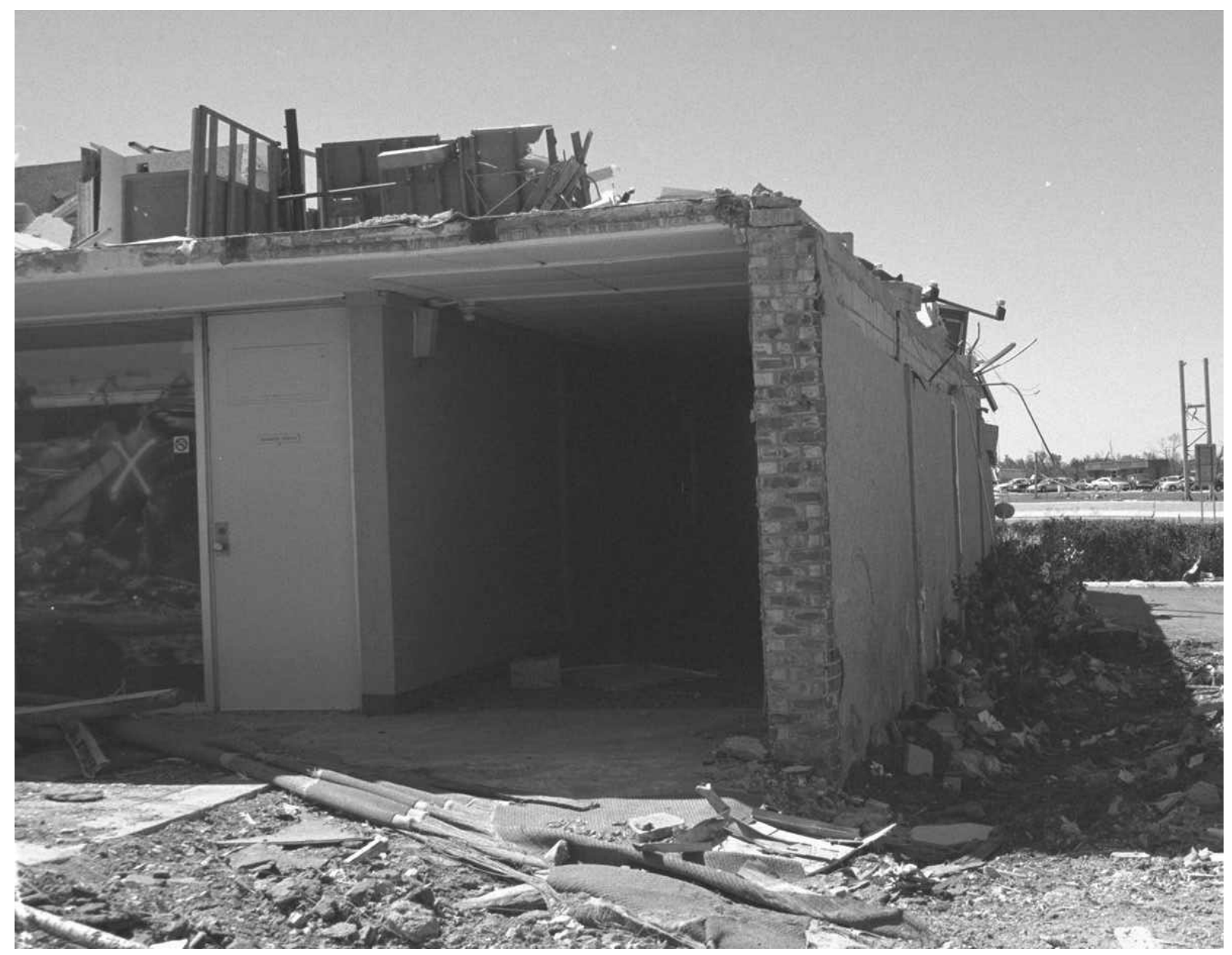

Figure 3-3: D amage to N orth Side of the Southwest Corner of the Clarion Inn.

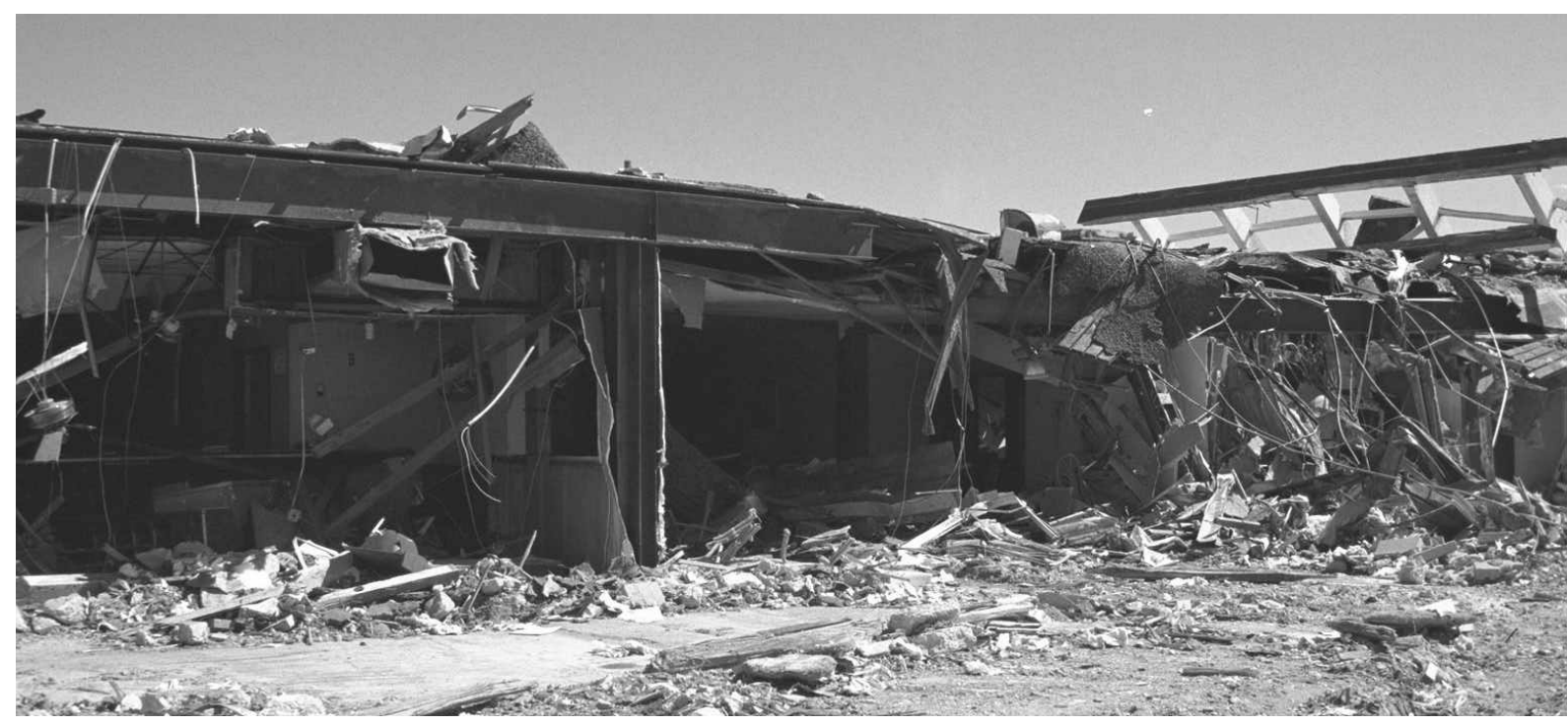

Figure 3-4: D amage to Western Section of the Clarion Inn. 
This hotel was completely destroyed as shown in Figure 1-3 and Figure 3-5. The precast concrete roof was lifted off and carried some distance. Much of the remainder of the second story collapsed and was swept off the floor slab. The outside walls of the south side of the lower floor were demolished, leaving only the masonry walls and the precast concrete floor slab of the second floor standing.

As shown in Figure 3-6 little of the structure remained intact and the rooms provided little protection from the wind and flying debris. Figure 3-7 shows the damage to the north side of the hotel. Here the exterior cladding was stripped away, but some of the interior wall cladding remained in place.

Figure 3-8 shows a detail of the damage to the masonry wall, including reinforcing bars that were exposed when the concrete block was demolished.

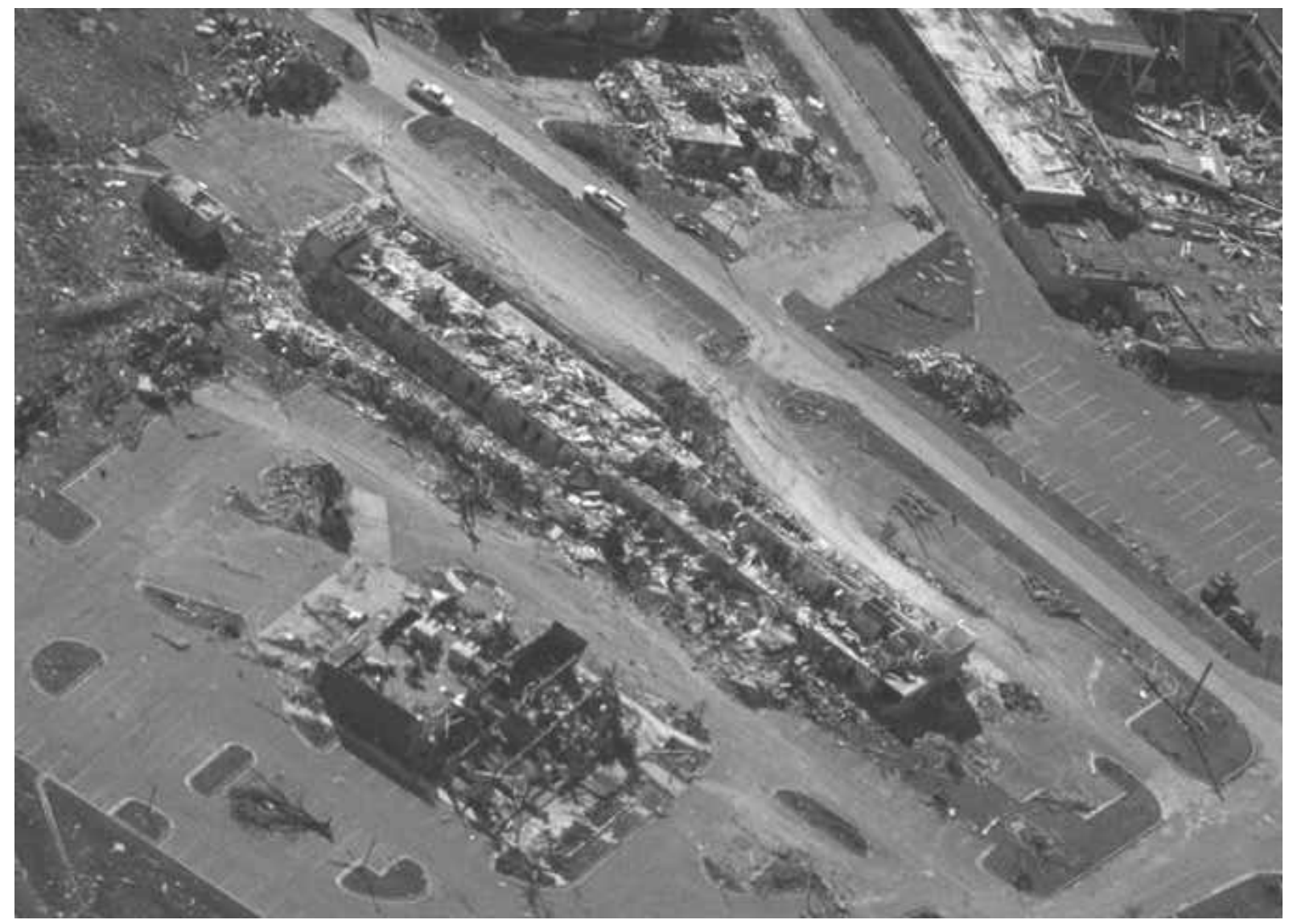

Figure 3-5: Aerial View of D amage to the Hampton Inn (long rectangular building). 


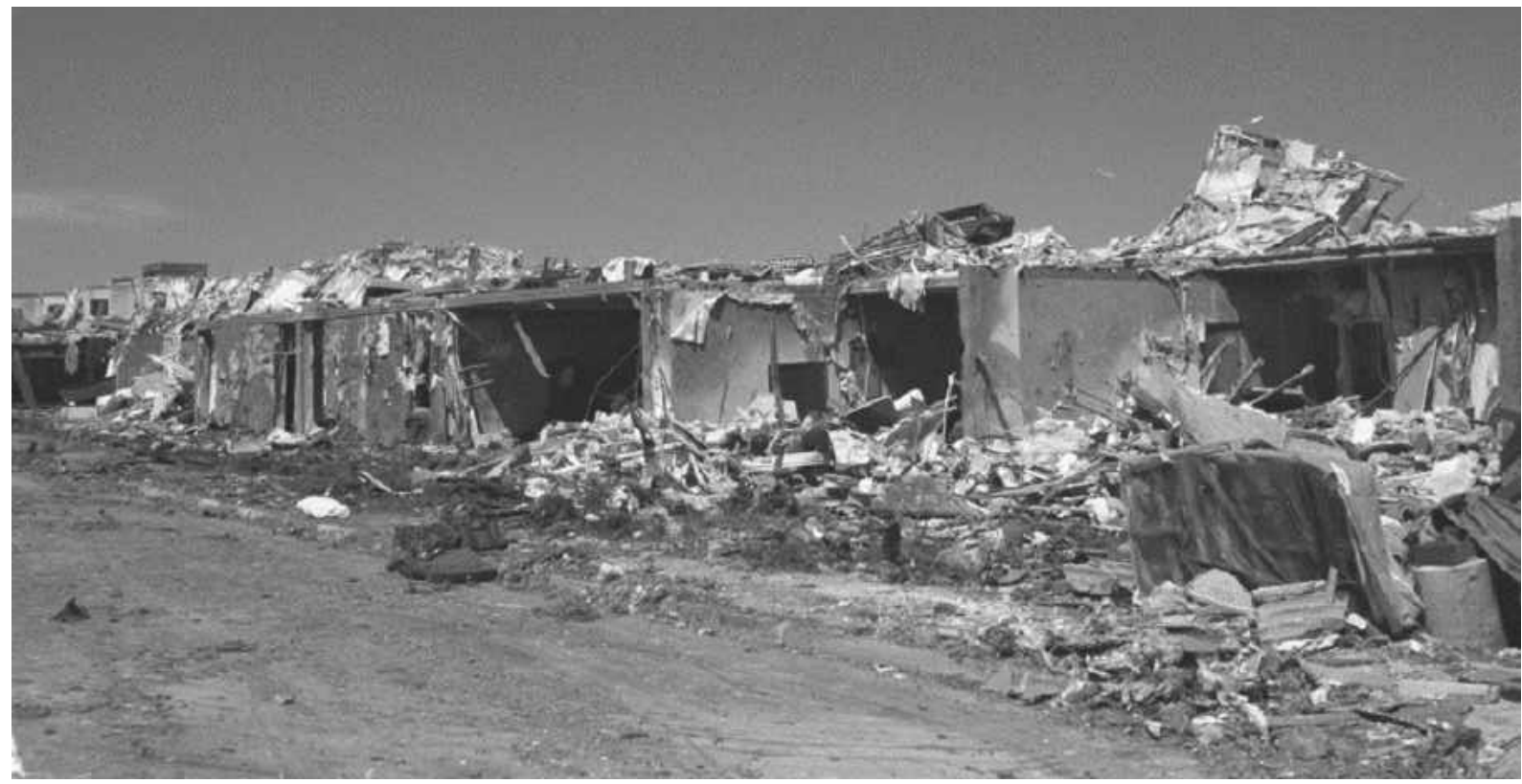

Figure 3-6: D amage to South Side of the Hampton Inn.

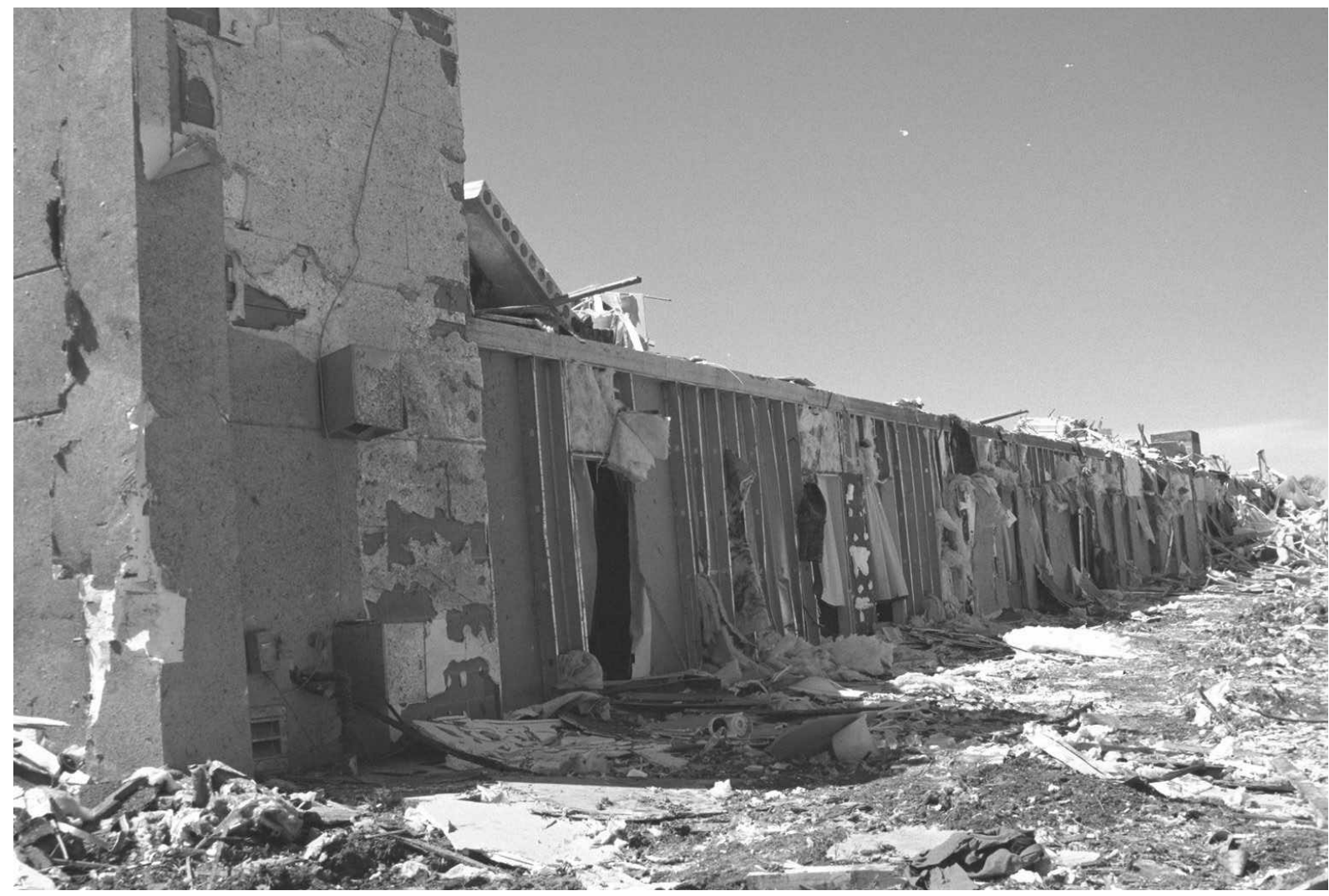

Figure 3-7: D amage to N orth Side of the H ampton Inn. 


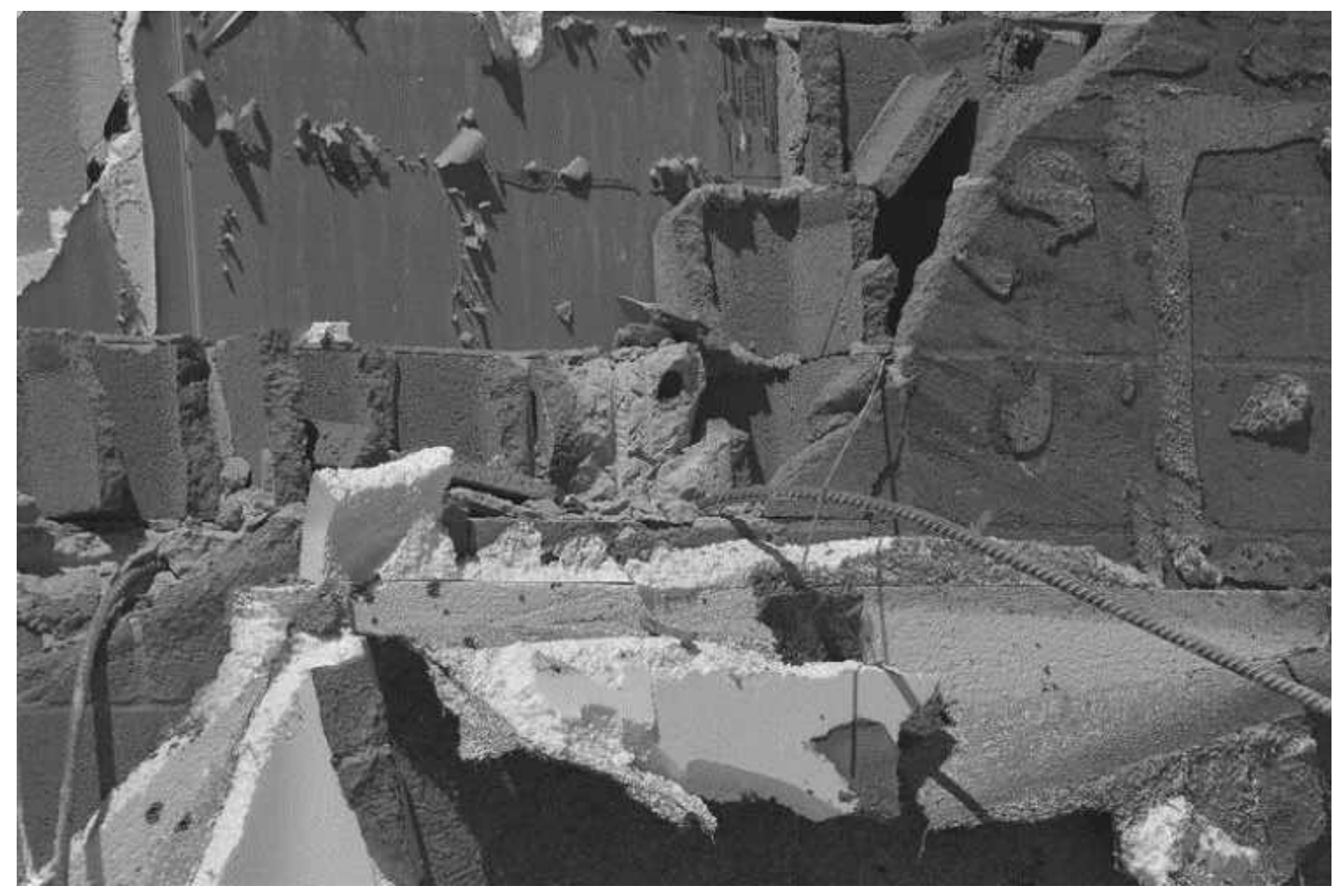

Figure 3-8: D etail of D amage to M asonry at the Hampton Inn. 


\section{DAMAge to Industrial AND COMMERCIAL BUILDINGS}

\subsection{Overview}

A large number of industrial and commercial buildings were damaged or destroyed by the tornadoes. Time constraints limited the number of damaged industrial buildings that could be surveyed. Damaged industrial buildings that were visited include Peach Auto Painting, three buildings at Tinker Industrial Park, Coors Ceramics, and the American Freightways Depot.

\subsection{Tinker Industrial Park}

This industrial park consisted of three buildings, all recently constructed. The two northern buildings are rectangular in plan, running east to west. The southernmost building was " $U$ " shaped. A simplified plan view of the industrial park site is shown in Figure 4-1.

All three buildings were single story; constructed with steel frames, steel truss roofs, and some reinforced concrete block walls. Portions of the buildings had either window walls or brick facing on steel stud walls.

The tornado passed just south of the industrial park, causing the most severe damage to the south building, while the north building was the least damaged.

By the time Tinker Industrial Park was visited on Friday morning, much of the exterior debris had been cleared away, particularly around the south building. Clean up and removal of salvageable items from the interiors of the middle and north buildings was underway, and construction crews
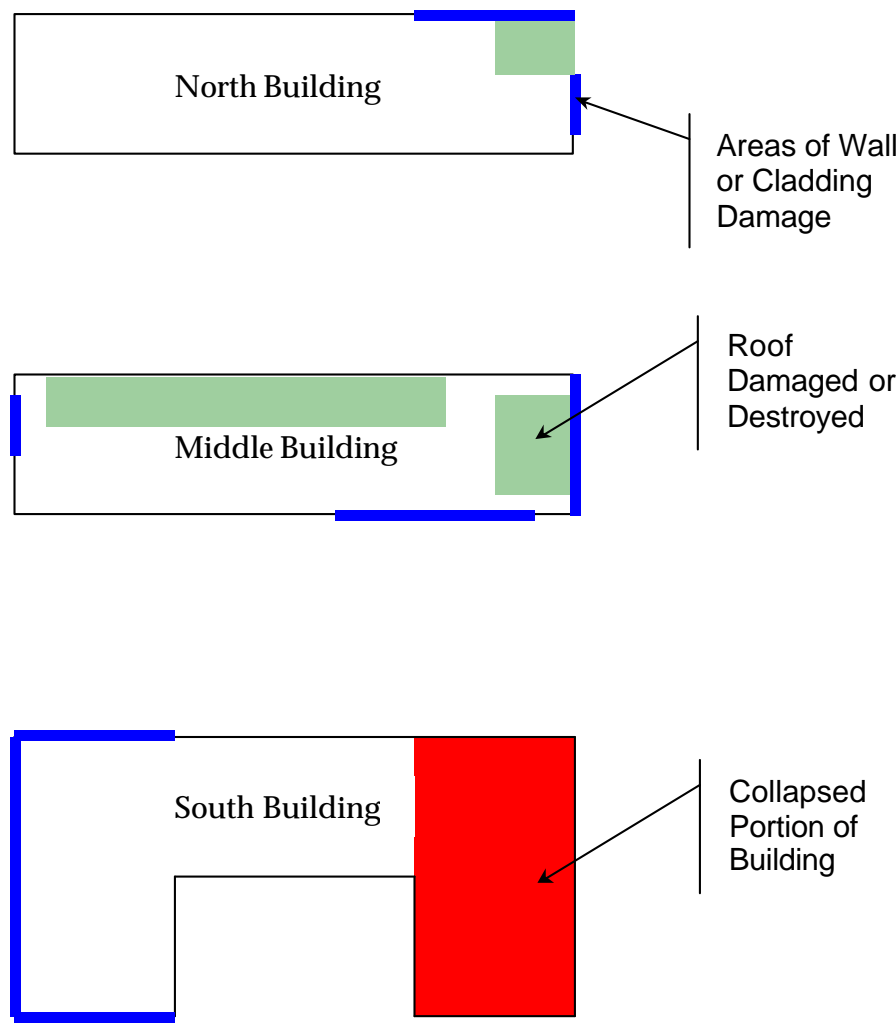

Figure 4-1: Simplified Plan View of Tinker Industrial Park 
were preparing to demolish what was left of the south building.

\subsubsection{South Building}

The south building was the newest of the three buildings. The main section had been completed less than one month before the tornado, and the foundation for an enlarged central section was under construction. The C-shaped portion, shown in Figure 4-1, was completed and the central and eastern portions were occupied. The structure and exterior of the western portion were complete, but the interior was still being finished.

The front, western, end of the building had a glass window wall around three sides. This wall did not have any vertical structural supports, and it was blown inward by the tornado, as shown in Figure 4-2. While the interior of this portion of the building was destroyed, the structure suffered only minor damage.

The central portion of the building suffered broken windows and roof damage, as well as severe damage to the interior and contents.

The eastern portion of this building collapsed, as shown in Figure 4-3. This part of the structure consisted of tubular steel columns, supporting heavy steel beams and roof trusses. The western wall of this section was constructed of heavily reinforced concrete blocks, while the other walls were constructed of lightweight steel studs and brick cladding.

The tornado appears to have pushed this portion of the building towards the northeast, rotating it counterclockwise. The largest deformations occurred along the southern edge, while the northeast corner moved only a bit, as can be seen in Figure 4-4.

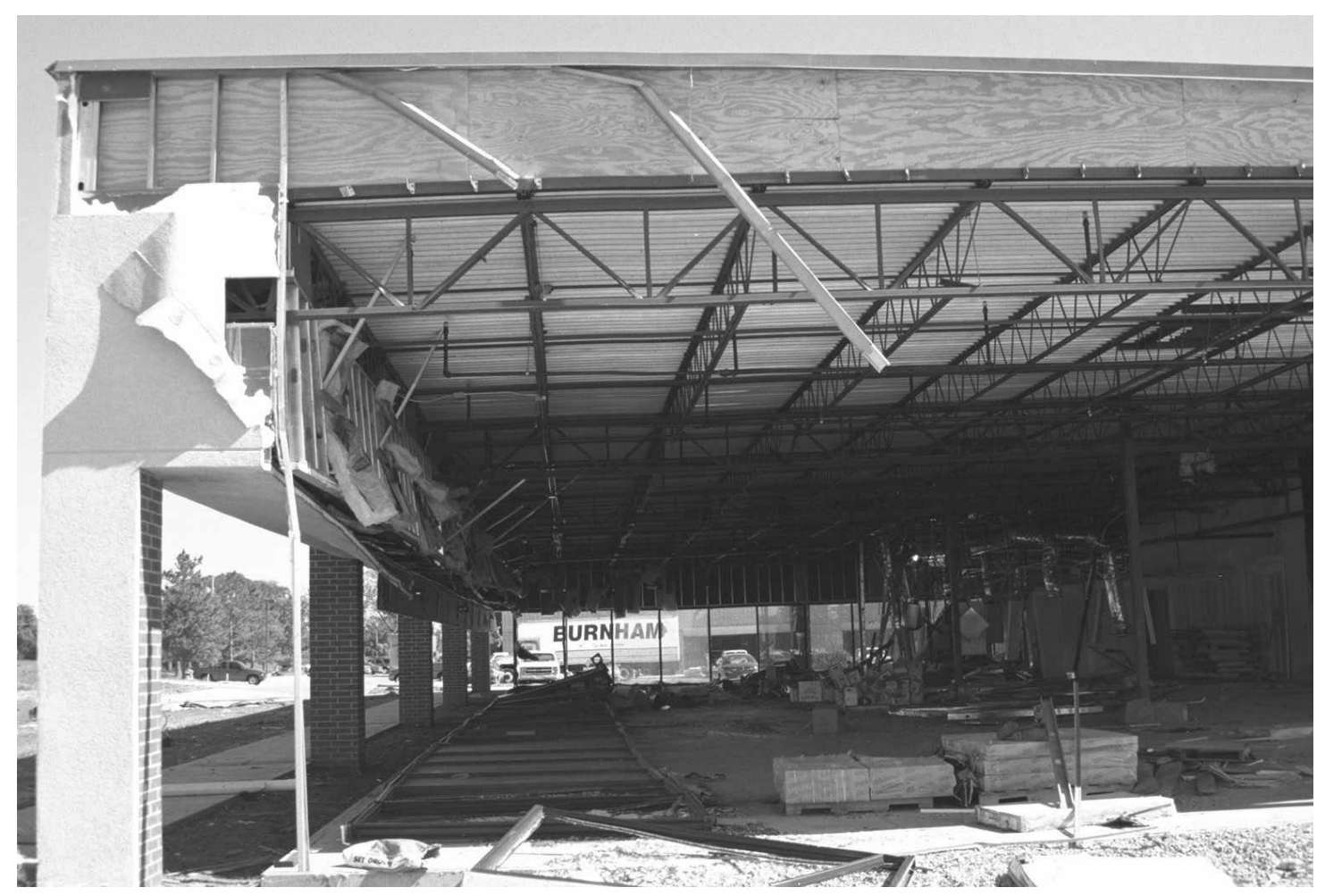

Figure 4-2: D amage to Western Section of the South Building at Tinker Industrial Park. 
The columns on the eastern and southern sides of this portion failed, as shown in Figure 4-5, and the entire section collapsed with the roof largely intact. The relatively well-reinforced masonry wall on the west- ern side of this section of the building, shown in Figure 4-6, collapsed to the east, and reinforcing bars that were anchored into the foundation pulled out or failed.

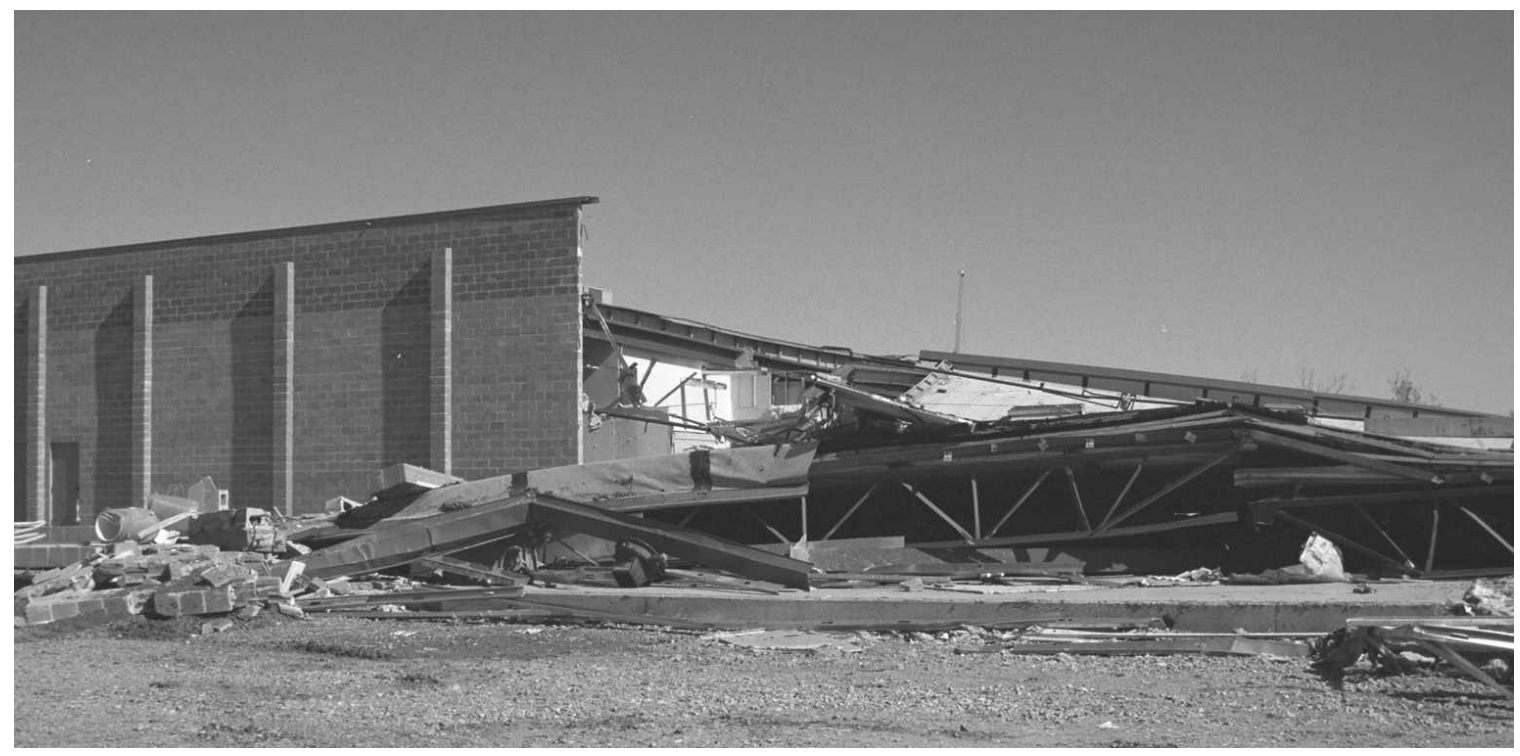

Figure 4-3: Collapsed Eastern Section of the South Building at Tinker Industrial Park (View from Southeast).

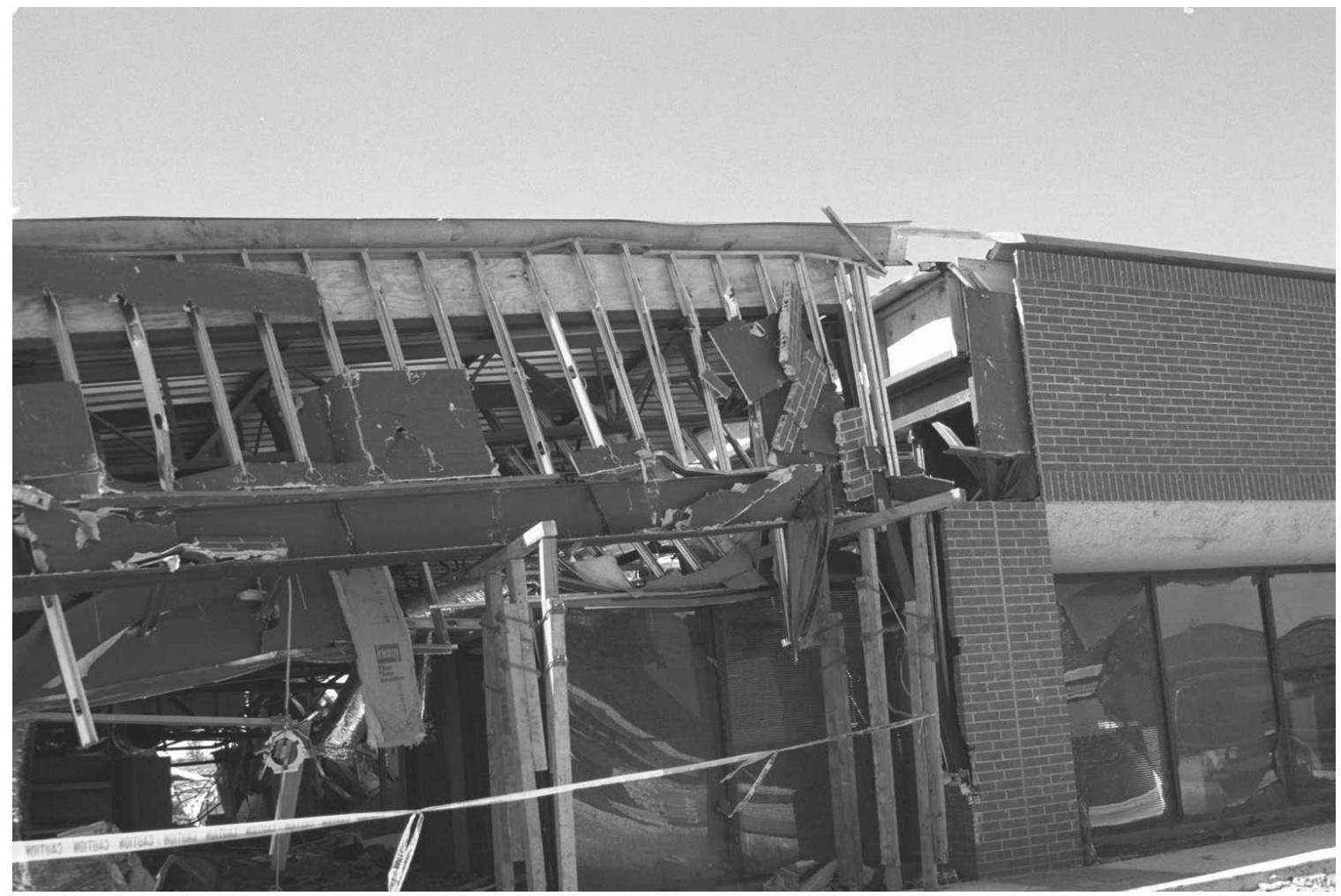

Figure 4-4: N orth Side of the South Building at Joint between Sections. 


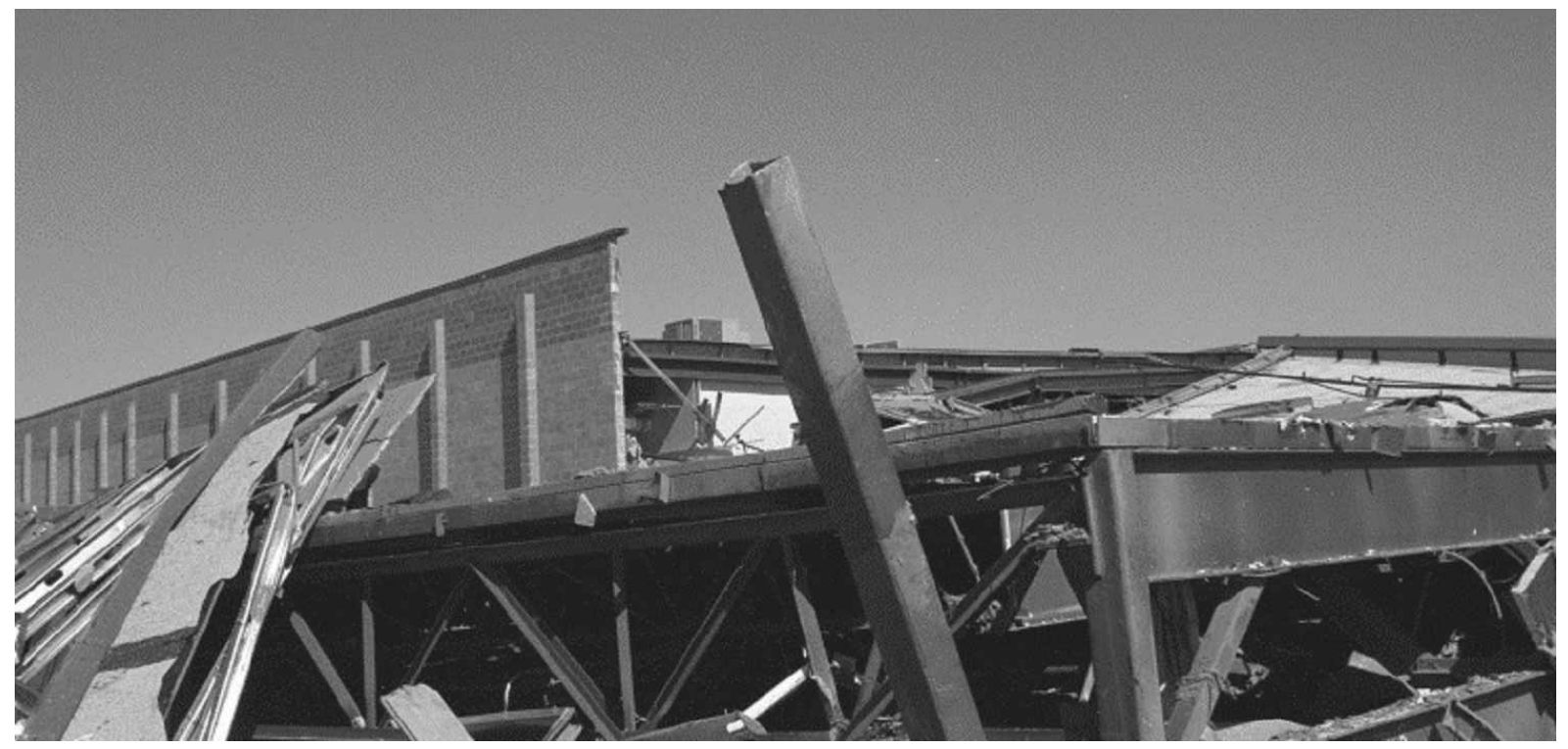

Figure 4-5: Detail of Failed Column and Collapsed Roof at the Southeast Corner of the South Building.

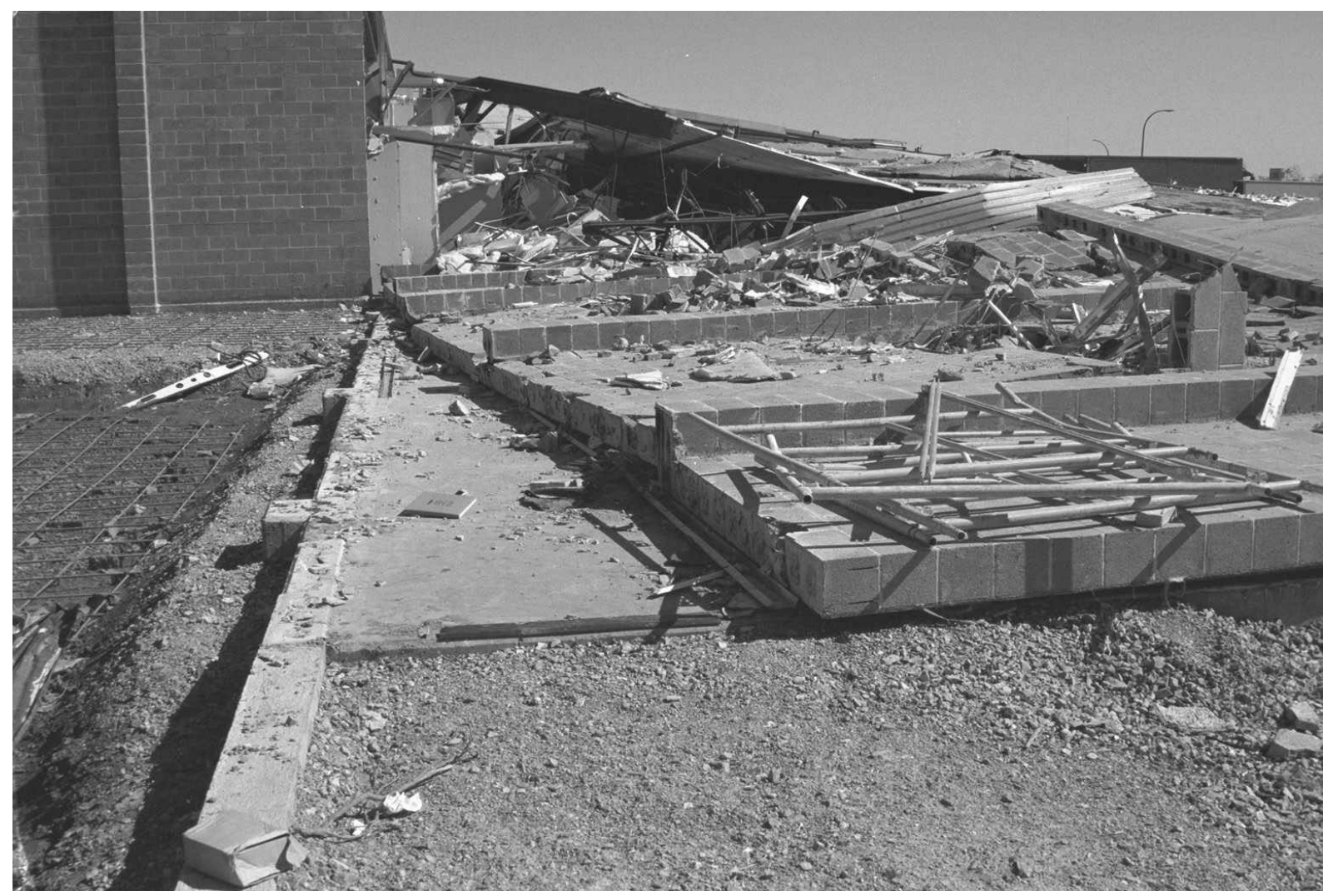

Figure 4-6: Reinforced M asonry Wall that Failed at South Building. 


\subsubsection{Middle and North Buildings}

The north and middle buildings were both severely damaged. They suffered broken windows, damaged window walls, loss of roof covering, masonry damage, and some structural damage. Air conditioning units and other mechanical equipment were blown off the roofs. Enough of the buildings' envelope was damaged that the interior partitions and building contents were severely damaged.

Figure 4-7 shows damage to the east face of the middle building. This building contained a mixture of office and warehouse space. In addition to losing a significant portion of its roof, as shown in Figure 4-8, the glazing and masonry cladding, of both the west and east ends of the building, were damaged. Damage to the exterior wall on the west side can be seen in Figure 4-9. Wind entering the damaged areas swept through the building, almost completely demolishing the interior space and contents.

Figure 4-10 shows damage to the East face of the North building. Most of the damage to this building occurred at the eastern end, with the worst damage occurring in the northeast corner.

\subsection{Peach Auto Painting}

This garage-type structure was constructed of pre-cast concrete with steel columns, heavy steel roof beams, cold rolled steel roof purlins, and sheet metal roof covering. This facility appeared to be reasonably well constructed, but it had been pushed over to the east and destroyed by a nearly direct hit from the tornado. The garage doors, located on the west side of the building appeared to have failed inward before the structure collapsed, which may have contributed to the failure. Figure 4-11 shows what remained of the facility as viewed from the south. Here the walls had collapsed outward, and the roof, which had lost its covering, collapsed towards the east. Figure 4-12 shows how part of the western wall failed. The section shown in this photo was located between two garage doors.

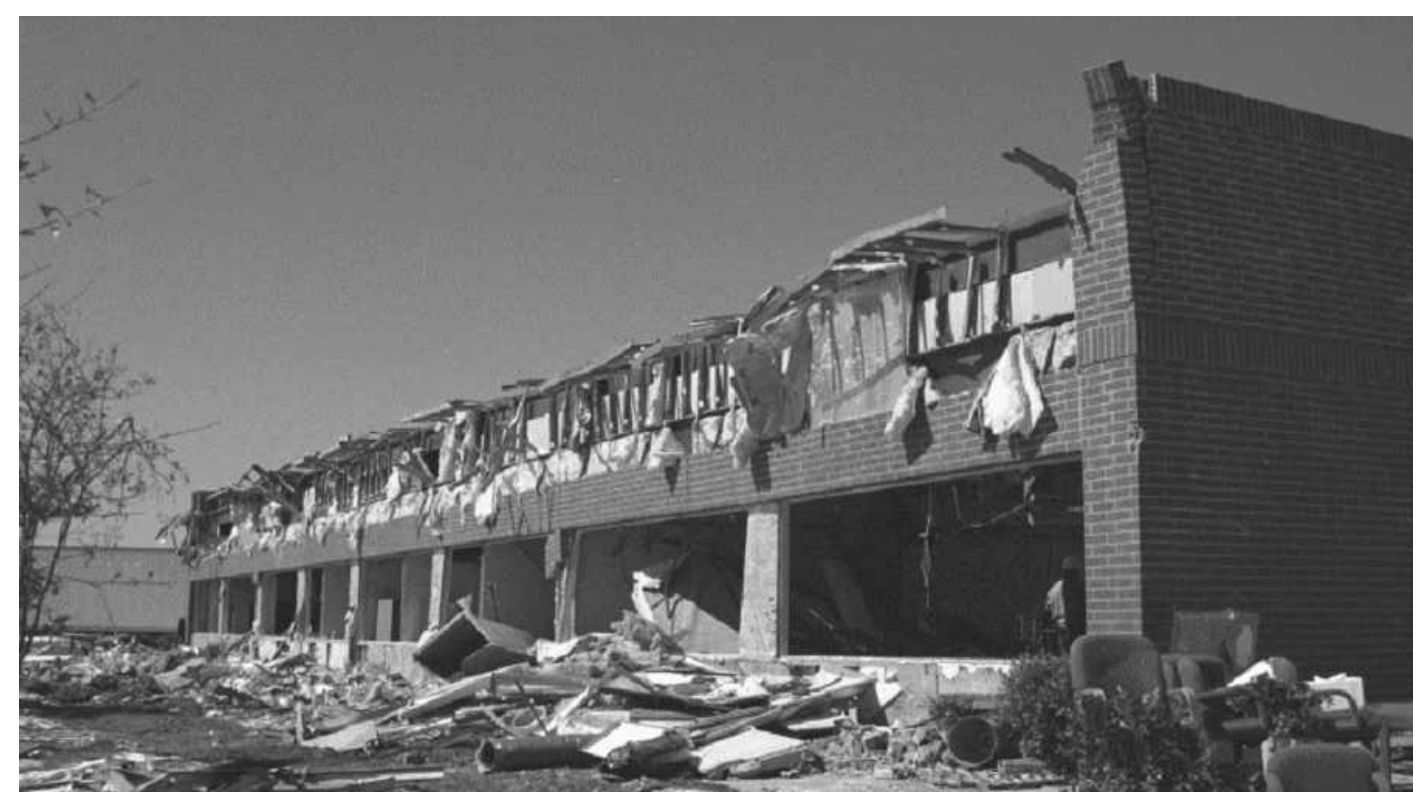

Figure 4-7: D amage to the East Side of the M iddle Building at Tinker Industrial Park. 


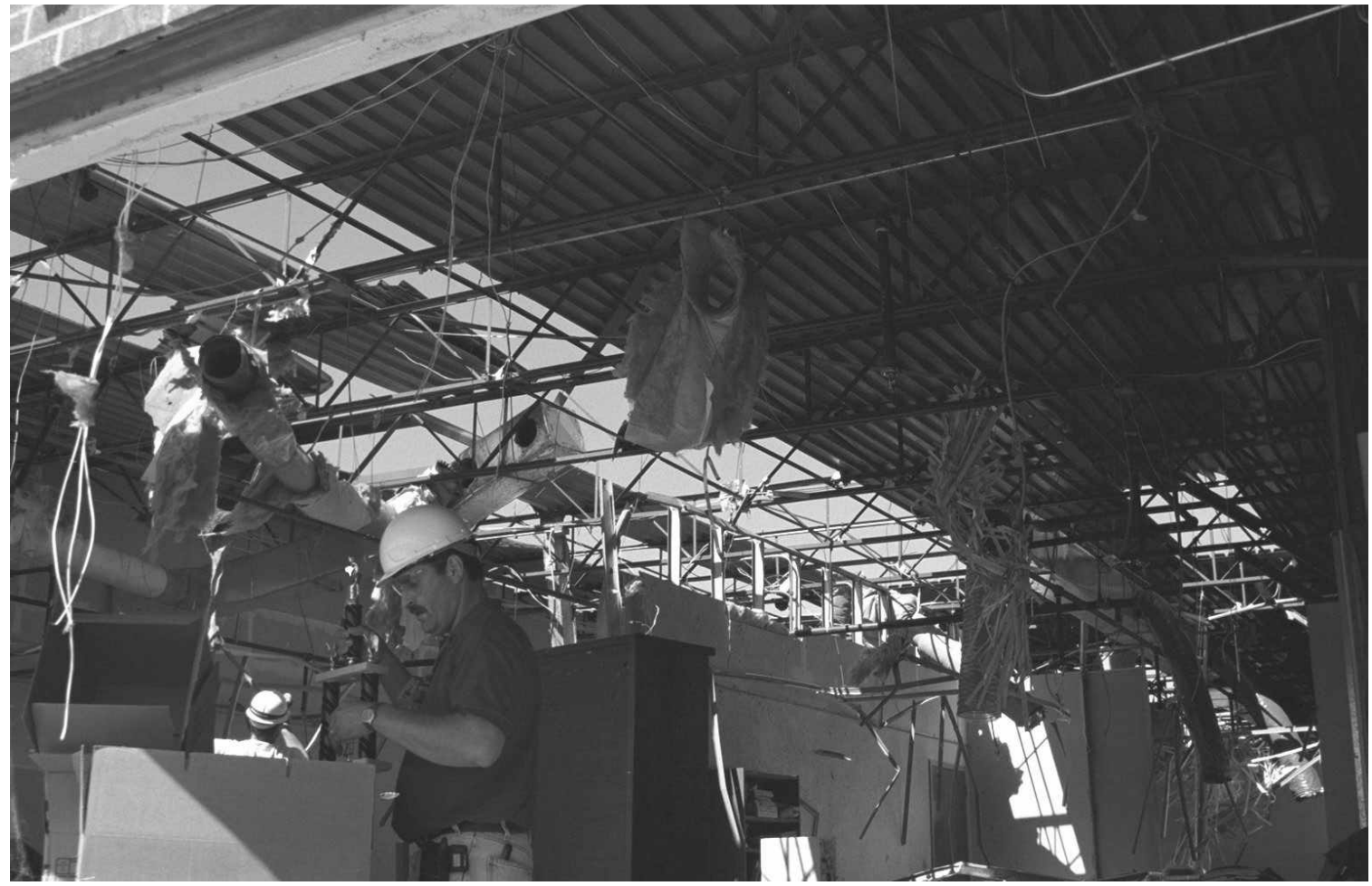

Figure 4-8: D etail of $D$ amage to the R oof of the M iddle Building.

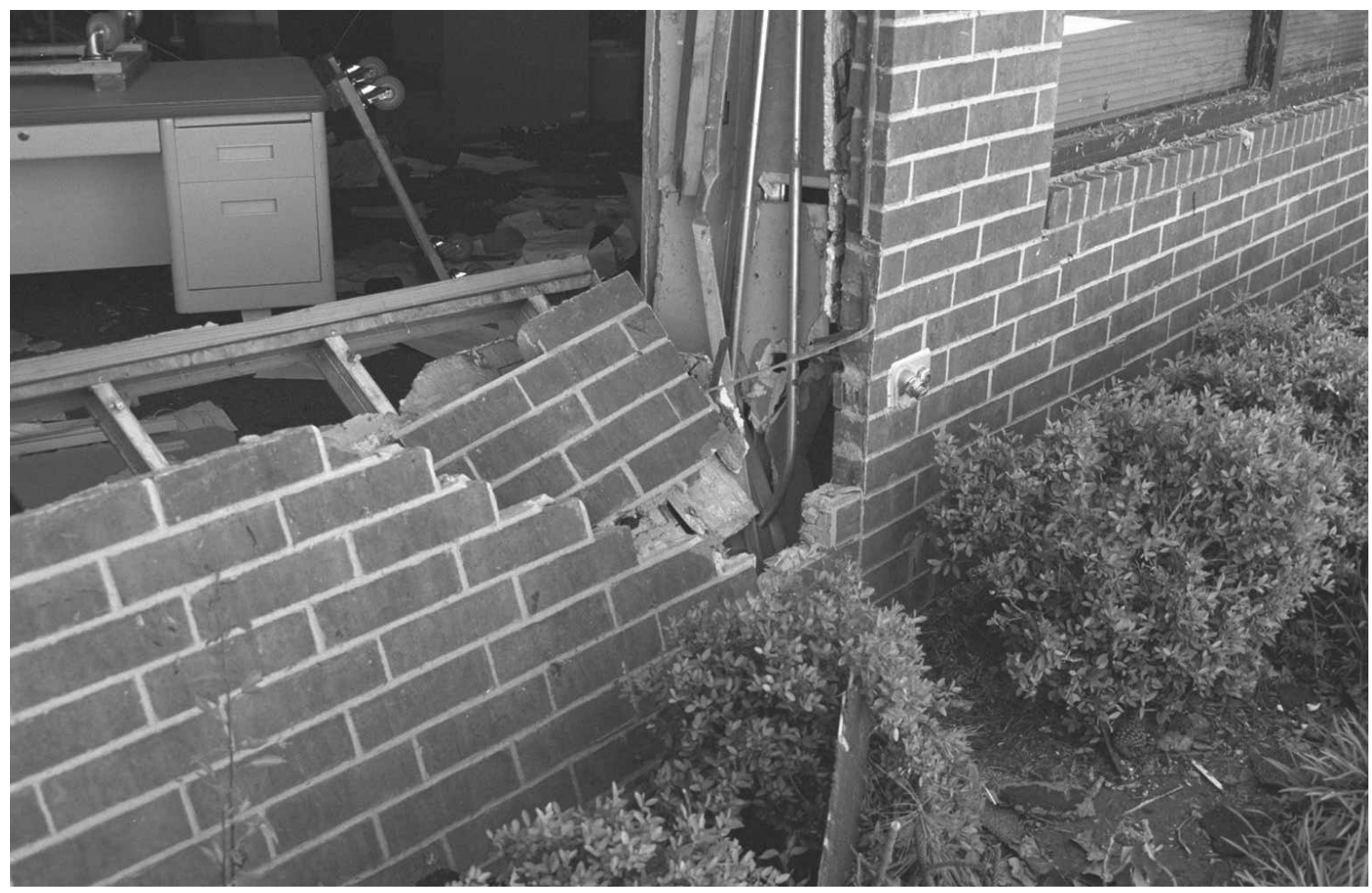

Figure 4-9: Detail of Damage to Western Wall of the M iddle Building. 


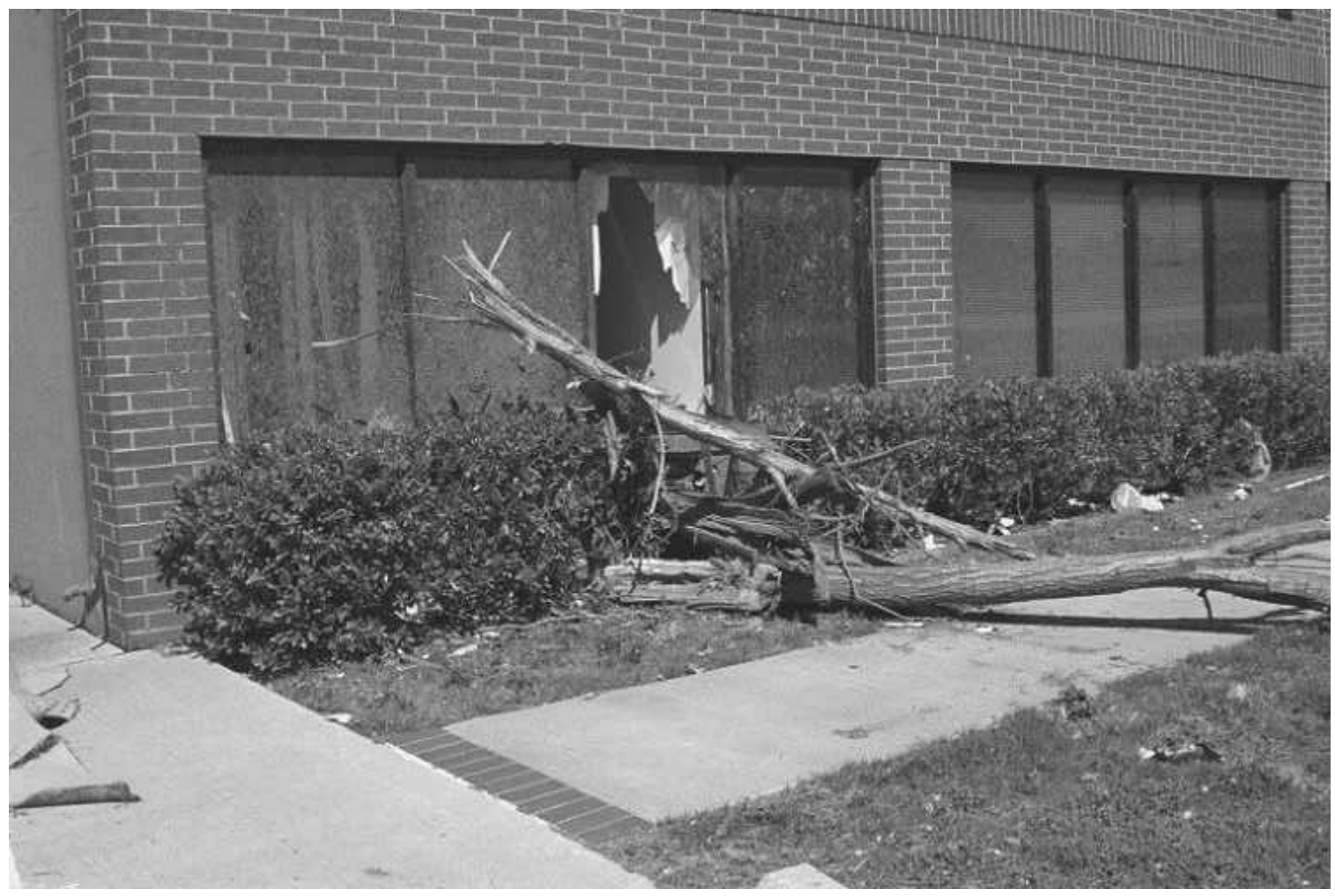

Figure 4-10: Damage to the East Side of the N orth Building at Tinker Industrial Park.

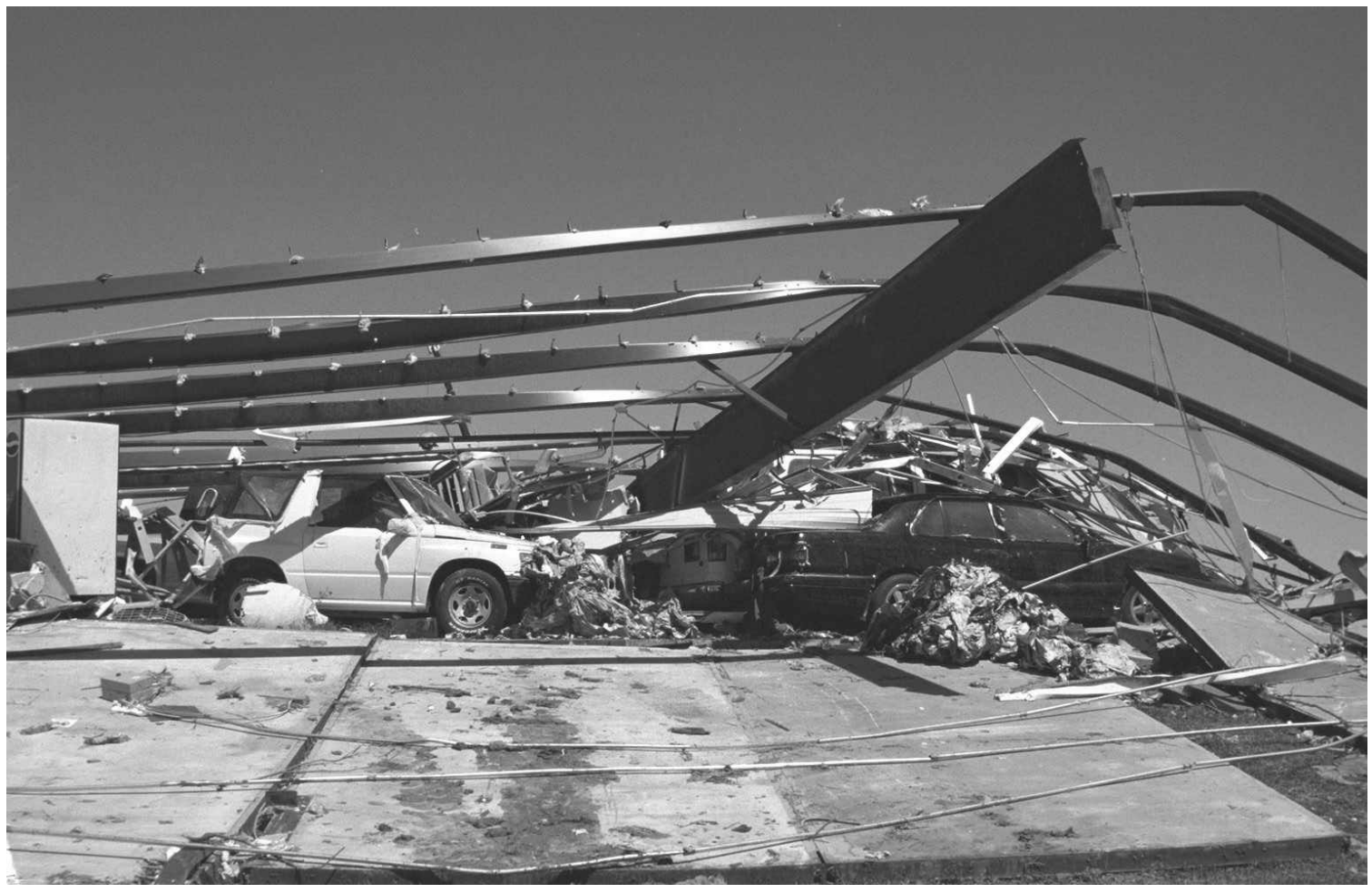

Figure 4-11: Roof Framing and Collapsed Walls (foreground) at Peach A uto Painting. 


\subsection{American Freightways Depot}

This facility, shown in the center of Figure $1-6$, was hit by the brunt of the tornado when it was near its strongest, and the facility was destroyed. Semi-tractors and trailers had been tossed on their sides and much of the structure was reduced to rubble. Unfortunately, by the time the site was visited on Friday morning, demolition of the remains of the building was nearly complete and it was not possible to gain any meaningful data about the structural damage. of heavy structural steel bents, with cold rolled girts and purlins, and steel cladding. An office area on the southern side of the building had masonry walls, and the structural system could not be identified. The tornado passed to the south and east of the factory, but nearly all of the damage was located in the northwest corner of the building. As shown in Figure 4-13, in this area of the structure the cladding, girts, and purlins failed, and the wind caused extensive internal damage. The heavy steel structural bents; however, were mostly undamaged.

\subsection{Coors Technical Ceramics}

The Coors Technical Ceramics factory, shown in the upper left of Figure 1-6, had two distinct types of construction. The main section of the factory was constructed

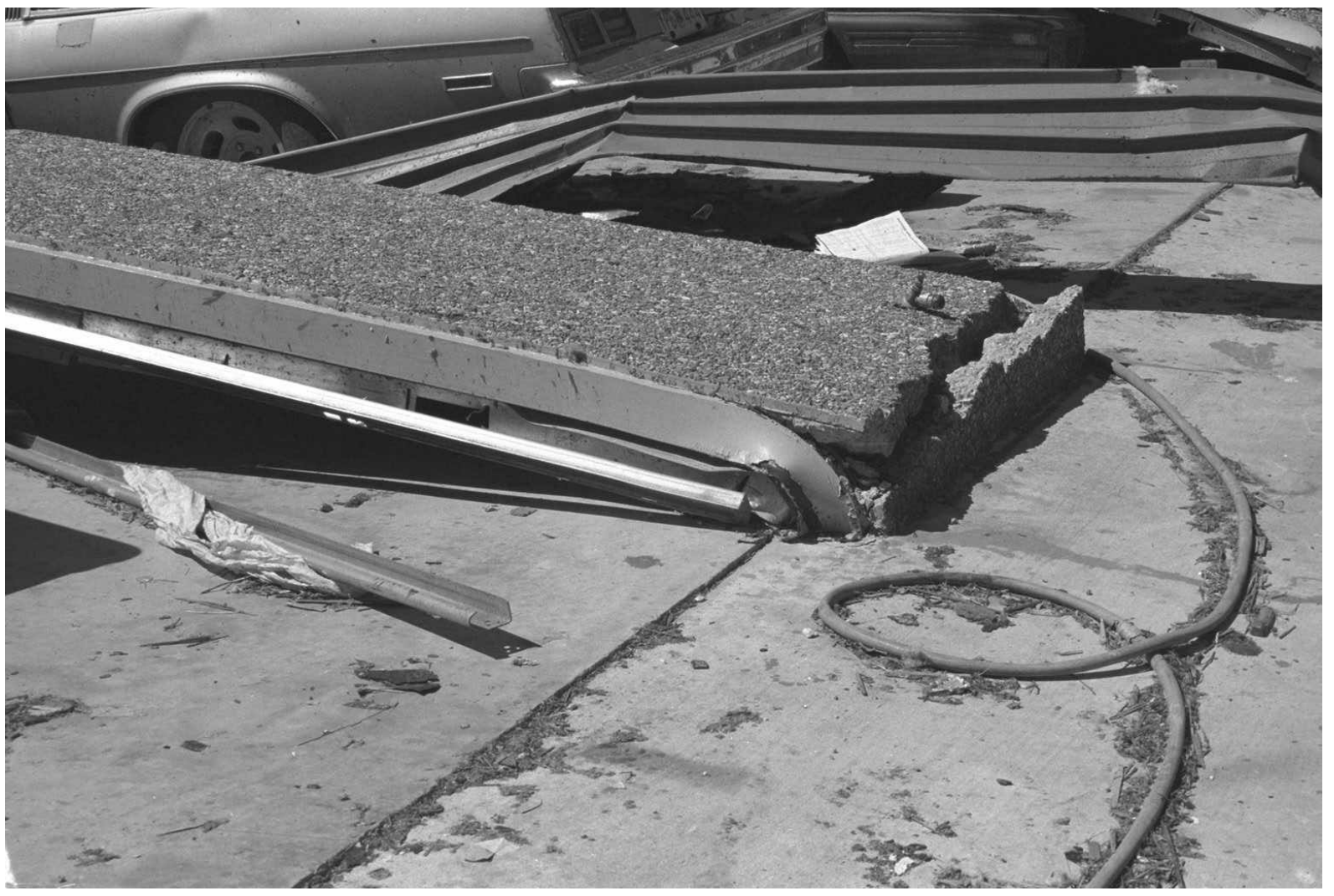

Figure 4-12: D etail of Base of Failed Wall at Peach A uto Painting. 


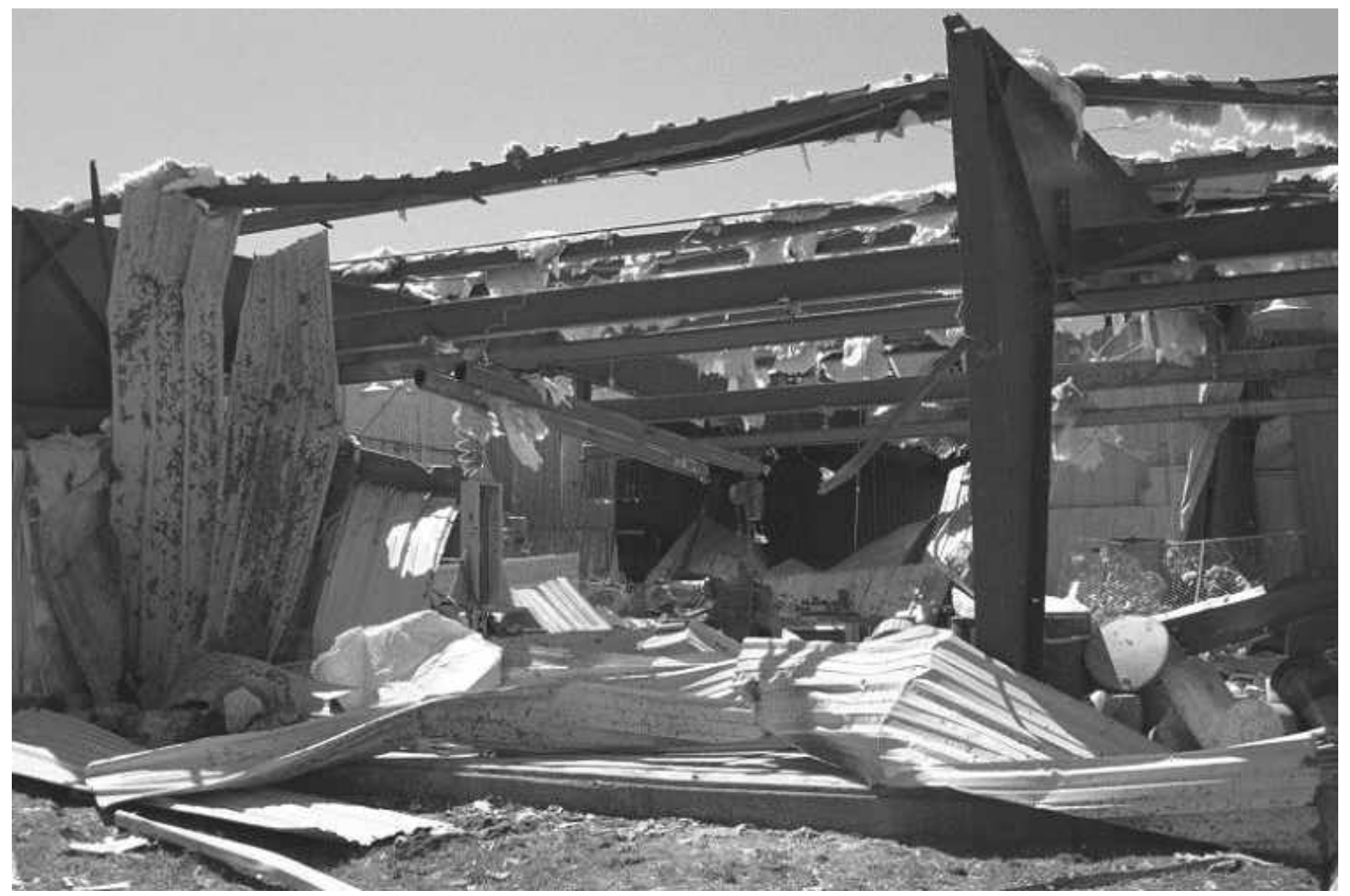

Figure 4-13: D amage to Coors Technical Ceramics Factory. 
This page intentionally left blank. 


\section{Damage to Other Engineered Structures}

The tornadoes that struck central Oklahoma damaged or destroyed a wide range of other types of structures.

Some of the first buildings to be damaged by the tornadoes were hangars at the Chickasha airport. As shown in Figure 5-1, a number of these hangars lost large portions of their roof covering. However, the tornado that struck the airport was relatively weak, and the structural systems appeared to have survived.

The Regency Park Baptist Church, which is located in Moore, about three blocks from the Kelly Elementary School, lost its roof, most of its windows, and suffered extensive damage from flying debris. The church was constructed of masonry walls, with glulam timbers supporting a wooden roof. The tornado, which passed some distance southeast of the church, lifted off the roof, but left the timber supports intact, as shown in Figure 5-2. The masonry walls appeared to suffer only minor damage near where the roof was connected. An attached building, located to the east of the church itself, suffered much more severe damage due to heavy debris loading. The large tire, shown in Figure 5-3, was one of the largest single pieces of debris observed.

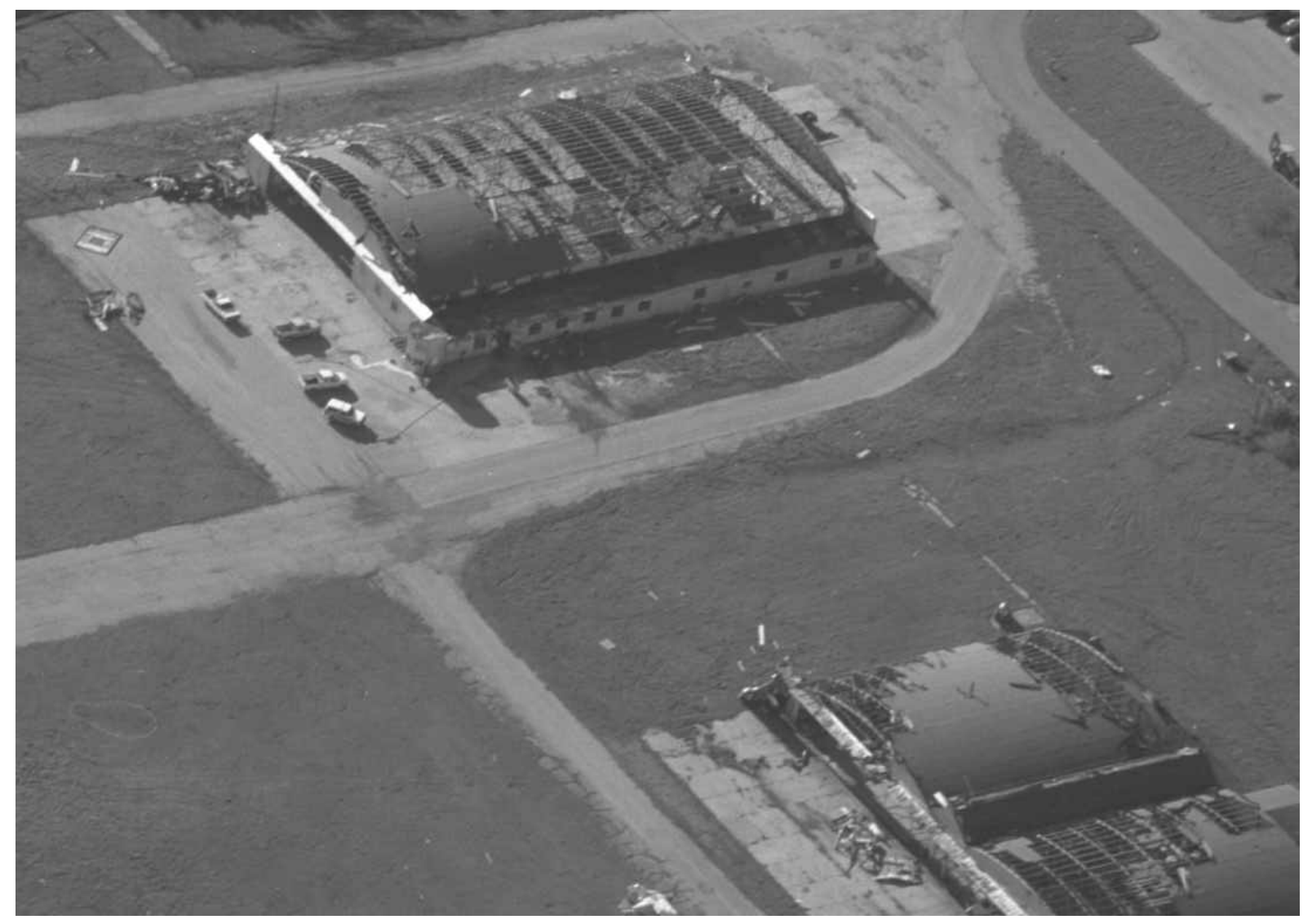

Figure 5-1: A erial V iew of Damage to Hangars at Chickasha A irport 


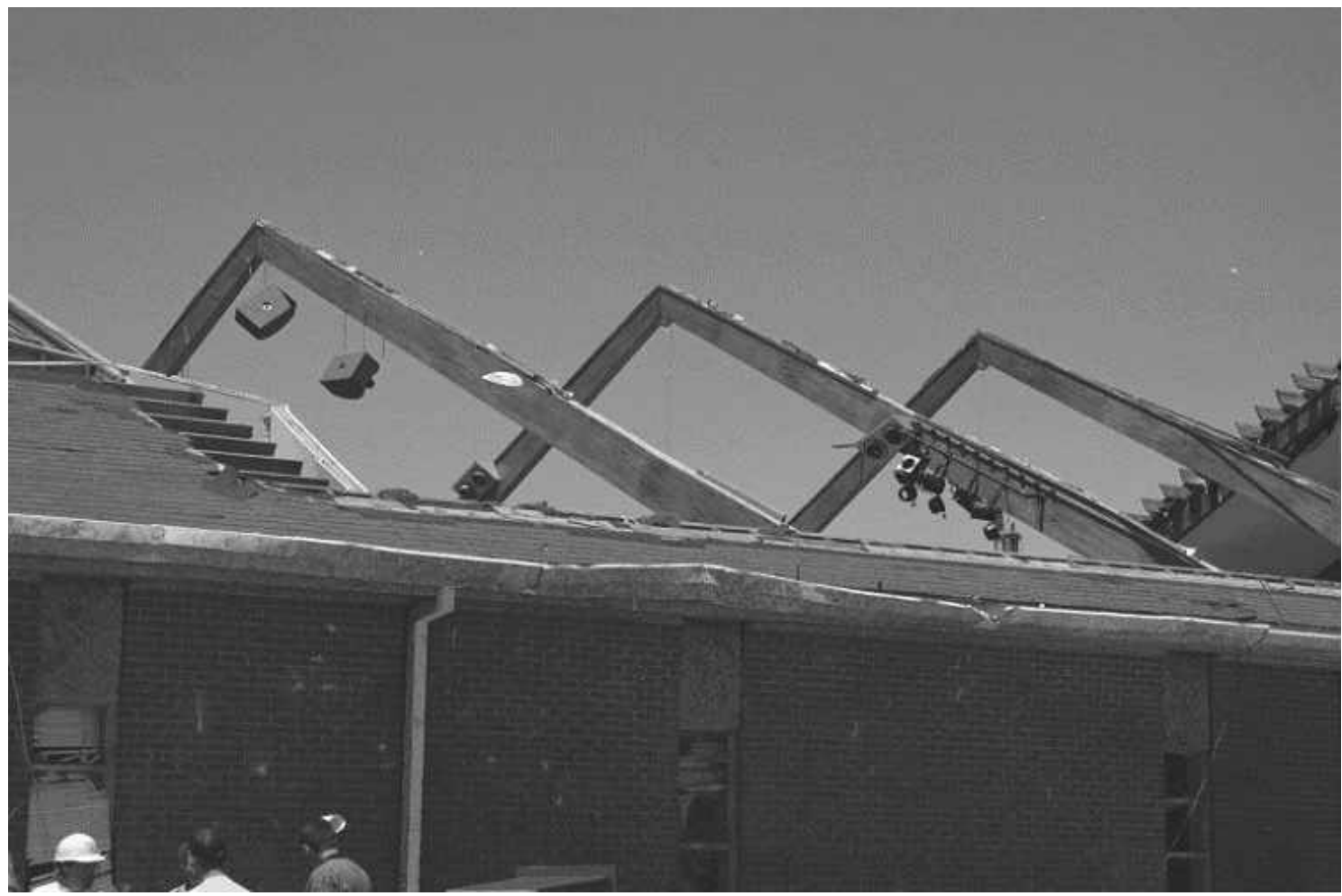

Figure 5-2: Damage to the Roof of the Regency Park Baptist Church.

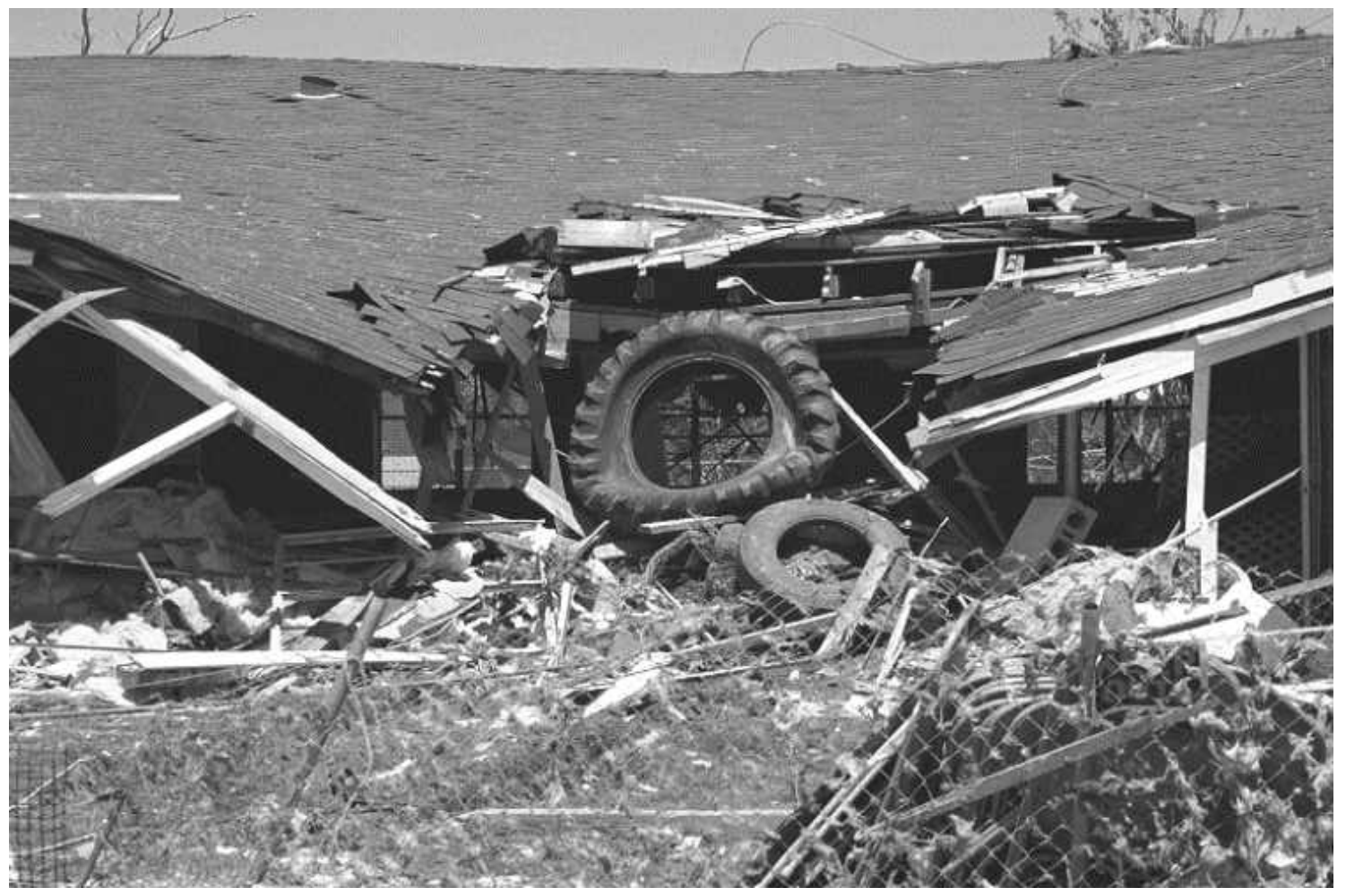

Figure 5-3: D ebris D amage to Building Adjacent to Regency Park Baptist Church. 
At the other extreme, the Tanger Outlet Center mall in Stroud was destroyed by tornado similar in size to the tornado that damaged the hangars at Chickasha airport. This tornado appeared to have passed $d$ rectly over the mall. As shown in Figure 5-4, nearly the entire mall was destroyed. At least 53 stores demolished, and most of the roof was lost.

Throughout the area struck by the tornadoes large numbers of telephone poles and power lines were brought down by the winds. In many places, large power transmission towers had collapsed from the wind loads on the towers and the power lines, as shown in Figure 5-5.
Finally, a wide variety of other infrastructure was damaged by the tornadoes. Extensive damage was observed to farm buildings and other agricultural related structures. Figure 5-6 shows some of the damage that occurred to the United Cooperative in Mulhall. A storage building and numerous grain silos (located in the lower left of the photo) were destroyed. The town of Mulhall (located in the center of the photo) was extensively damaged. Figure 5-7 shows the damage that occurred at one farm near Crescent. Here storage silos were overturned and destroyed, one farm building was leveled, and other buildings were damaged.

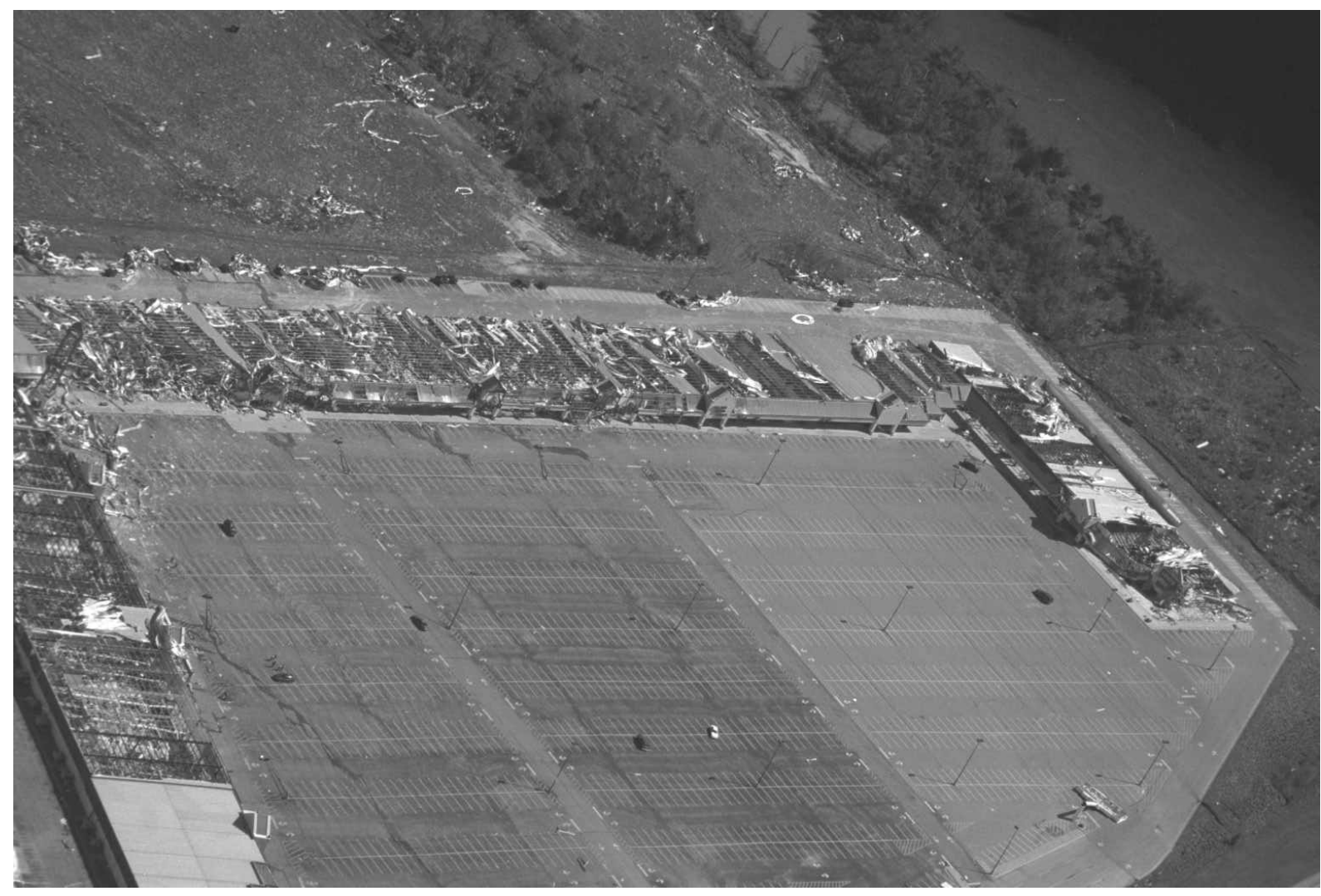

Figure 5-4: A erial View of D amage to the Tanger $O$ utlet Center $M$ all. 


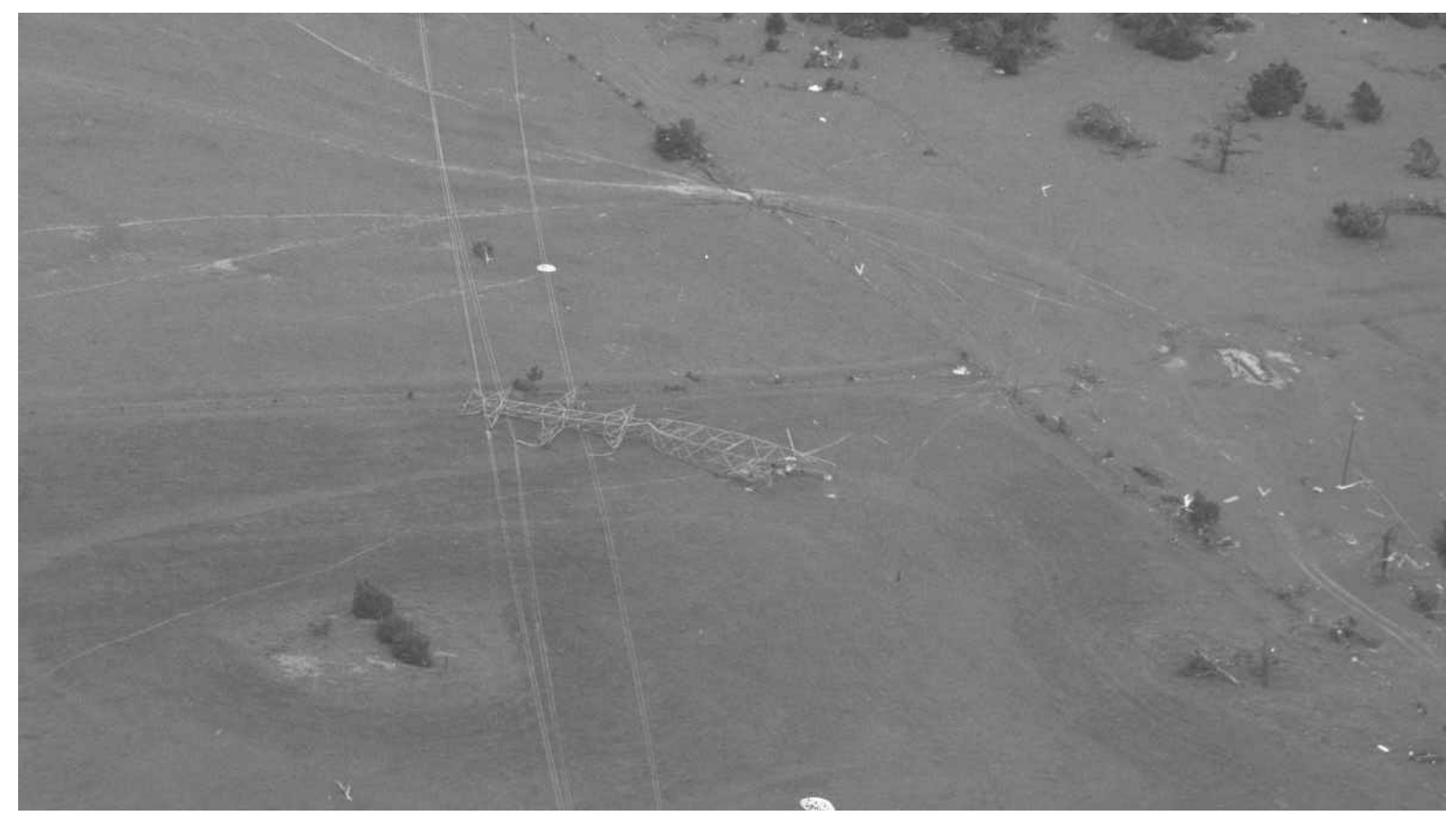

Figure 5-5: D estroyed Transmission Tower near Crescent, O klahoma.

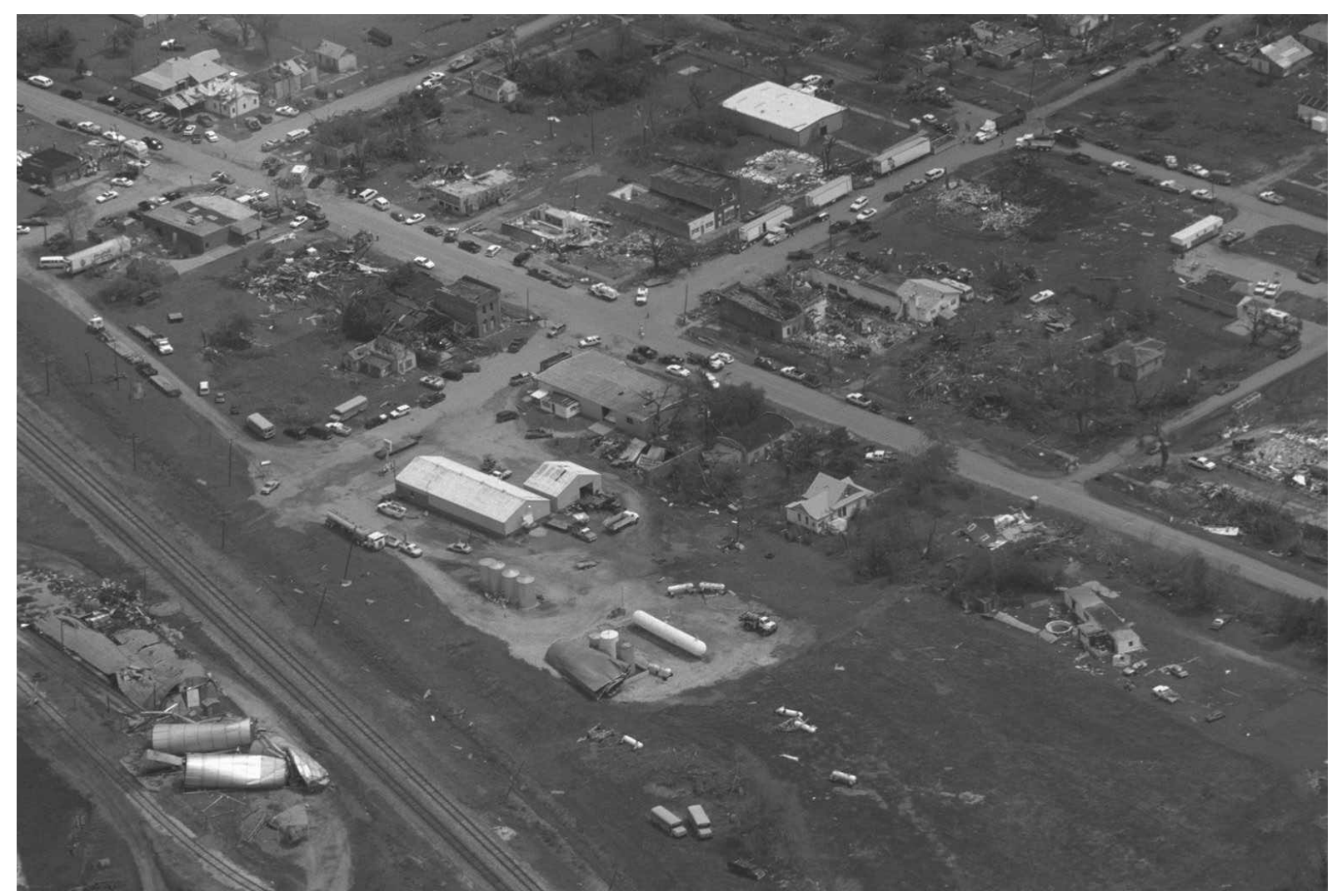

Figure 5-6: D amage to M ulhall, O klahoma, and United Cooperative Silos. 


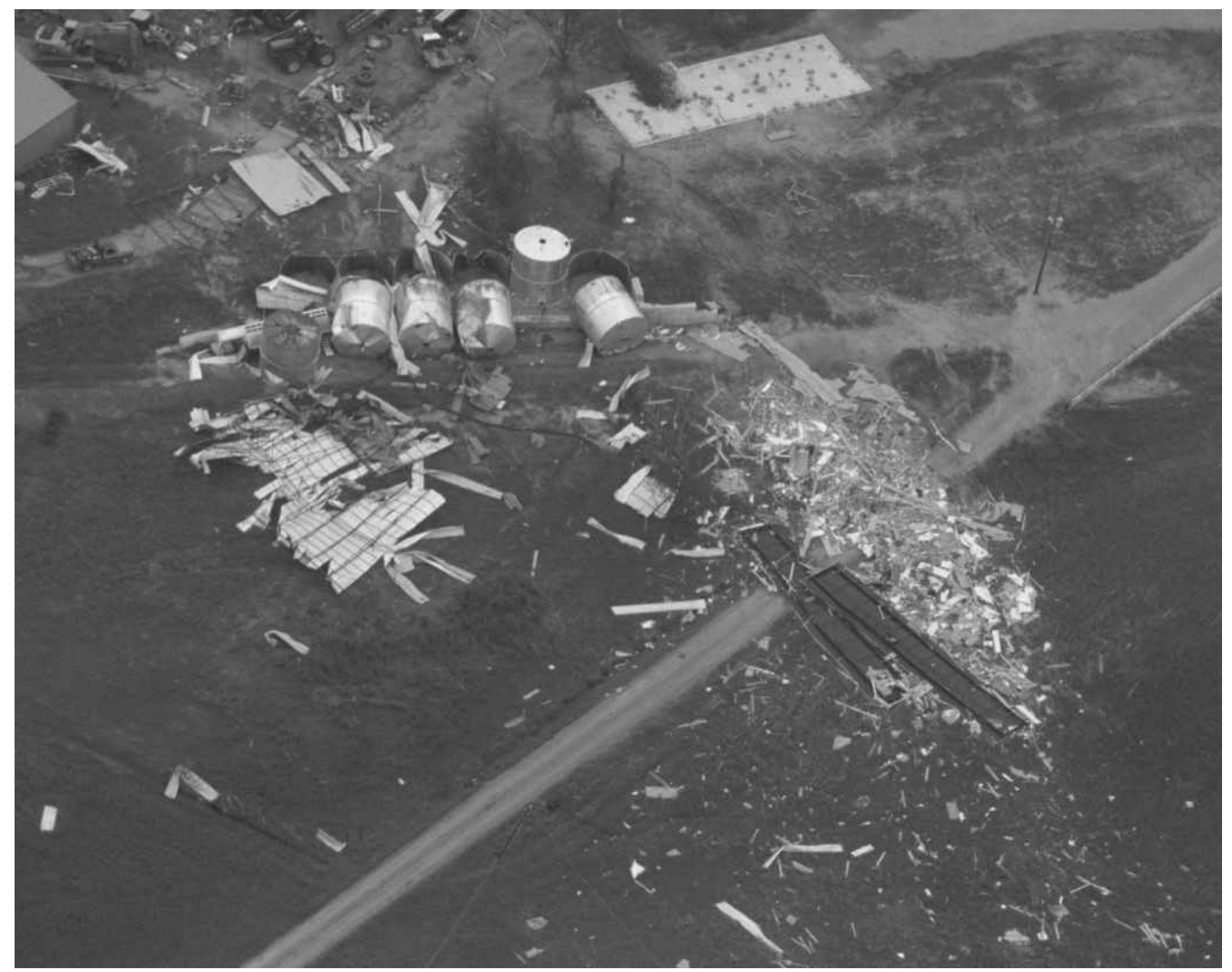

Figure 5-7: D amage to Farm buildings and Silos near Crescent, Oklahoma. 
This page intentionally left blank. 


\section{CONCLUSIONS AND RECOMMENDATIONS}

The destruction and losses caused by the 3 May 1999 tornadoes were the result of an unusually large and powerful storm. The tornado that passed through Oklahoma City certainly was extremely strong. The F5 rating that was given to this tornado by the NWS appears to be reasonable when the destruction caused by this tornado is compared to that of other large tornados. However, the vast majority of the damage could have been caused by wind loads associated with much smaller tornados, and only a few of the strongest buildings would have required F4 or larger wind speeds to be damaged as they were. It is entirely possible that the most destructive wind speeds that occurred in the May 3 tornadoes corresponded to the F4 tornado scale rating, rather than to an F5 scale.

The primary reason for most of the building losses caused by these tornadoes is simply that the buildings - like most ordinary buildings - were not designed to withstand the wind loads associated with even weak tornadoes. The basic design wind speed for the Oklahoma City area specified in "Minimum Design Loads for Buildings and Other Structures" [ANSI/ ASCE-7/ 95, 1996], the current standard at the time of the tornados, is $40 \mathrm{~m} / \mathrm{s}$ (90 mph). This wind speed corresponds to just an F1 tornado. In fact, a building design to resist the code wind loads with a safety factor of 2.0 will have reached its design limit in winds of just $57 \mathrm{~m} / \mathrm{s}$ (127 mph), which corresponds to a weak F2 tornado. There are strong reasons to believe that the wind speeds typically ascribed to tornadoes are significantly larger than the actual speeds [Phan and Simiu, 1998a; 1998b]. On the other hand, there is little doubt that the wind loads that occurred during the Oklahoma City tornado were much greater than the loads the buildings were designed for. Still, in many cases weaknesses in the design and construction of the buildings had a significant contribution to building failures.

The large amount of debris that was created by the tornadoes likely played a major role in damaging other buildings and structures. It certainly contributed to breaching the envelope of many buildings, and may have been the primary cause of broken windows and other cladding damage. It appears that, for some buildings in Tinker Industrial Park, and the building attached to the Regency Park Baptist Church, the debris, rather than the wind itself, was the major cause of damage.

Breaching of a building's envelope, including breaking windows, failing doors, or destruction of the roof covering, can lead to significantly increased pressures inside the buildings. This increased pressure can cause the loads on the roof and leeward walls to increase significantly, thereby causing the failure of structures that might otherwise have survived the tornado.

Three weaknesses that were commonly observed were un-reinforced or lightly reinforced masonry walls, poor connection details, and low strength glazing.

Since buildings in the Oklahoma City area are primarily designed for gravity loads, typical masonry walls are either unreinforced or have a minimal amount of lateral reinforcement. This level of reinforcement is more than sufficient for most loading cases; however, the extreme lateral loads caused by the tornado winds far $\propto$ ceeded the resistance that such walls can provide. The collapsed masonry walls at Kelley Elementary School (Figure 2-9) provide the best example of masonry that provided little lateral resistance to the wind 
loads. However, the relatively well reinforced concrete block wall that collapsed at the south building in Tinker Industrial Park shows that even strongly constructed masonry can fail in these extreme winds, particularly when there are other weaknesses in the structure.

One case of a poor detail that may have contributed to structural failure was the nailed wooden soffit on the over-hanging cornice at Kelley Elementary School (Figure 2-10). At first glance, the soffit was only architectural, not structural in nature, and should not have contributed to the strength of the building. However, the cornice and soffit may have contributed to the building failure in two ways. By extending the roof a few feet beyond the walls of the building, this overhang increased the roof area and, therefore, the total load on the roof and its support structures. The soffit itself had simple nailed connections, and although there is no way to determine if the soffit or the roof first failed, it is quite likely that the relatively lightly constructed soffit failed at low wind speeds. Once the soffit failed, the wind loads would have increased significantly on the overhanging portion of the roof. The increased wind load could have caused the covering to fail near the roof edges and peel from the entire roof.

Many of the buildings that were investigated had lost many or all of their windows. In most cases the glazing was simply a single layer of annealed glass, which has two properties that make it dangerous during large tornadoes. It has relatively low strength, which increases the probability that it will be broken by the wind pressure, flying debris, or a combination of the two. When it breaks, it tends to shatter and the shards become dangerous missiles that can cause serious harm. Tempered and laminated glass both provide better strength, reducing the chance of the building enve- lope being breached, especially by wind. Laminated glass will not fragment when broken, thereby reducing the risk of injury to building occupants.

The extent of the damage in Oklahoma City to homes, schools, commercial, and industrial buildings highlights the need for protected safe spaces. In homes, small underground or in-home shelters can provide the necessary safe haven. Schools and other public buildings need large shelters or other heavily reinforced areas that will remain intact even in the event of a powerful tornado. While underground shelters will provide the highest level of safety, adequate safety can be provided in well-reinforced corridors, which do not have windows, have reinforced roofs, and have doors capable of withstanding the wind pressures and debris loads.

Even with readily accessible shelters, adequate warning of approaching tornado is essential. In the case of the Oklahoma City tornadoes, NOAA, with the help of local TV stations, was able to provide warnings well in advance.

The destruction that occurred in Oklahoma City shows that changes and improvements to building codes are necessary to minimize the loss of life and property. Increasing the wind resistance of buildings can be achieved through a variety of methods. Improved anchorage between the roof and the rest of the building, and between the building and its foundation will provide a better load path. Reinforced masonry walls and cladding, reinforced doors, and laminated or other high strength glazing will all help to keep the building envelope intact during strong winds. Better attention to connection details can maximize the structural strength of a building for little additional cost. 
Unfortunately, much is unknown about the nature of large tornadoes and the loads that they generate on structures. A better understanding of the tornadoes, the wind speeds, and the wind loads they generate is necessary for engineers to be able to design safer and more risk-consistent structures. It will also help to speed the acceptance of better building codes, and will allow better estimation of the true risk of losses due to large tornadoes. Achieving this understanding will require considerably more data, as well as better methods of classifying tornadoes. 
This page intentionally left blank. 


\section{REFERENCES}

"Minimum Design Loads for Buildings and Other Structures," (1996) ANSI/ ASCE7/ 95, Revision of ANSI/ ASCE 7-93, ASCE, New York.

Phan, L., and Simiu, E. (1998a). "Tornado Aftermath: Questioning the Tools," Civil Engineering, ASCE, December 1998.

Phan, L., and Simiu, E. (1998b). “The Fujita Tornado Intensity Scale: A Critique Based on Observations of the Jarrell Tornado of May 27, 1997," NIST Technical Note (TN 1426), July 01, 1998. 